UNIVERSIDAD AUTÓNOMA METROPOLITANA - IZTAPALAPA DIVISIÓN DE CIENCIAS BÁSICAS E INGENIERIA

\title{
DETERMINACIÓN DEL CONTENIDO FENÓLICO EN EXTRACTOS NATURALES MEDIANTE SENSORES ENZIMÁTICOS
}

Tesis que presenta Pedro Ibarra Escutia Para obtener el grado de Doctor en Ciencias

Asesor: Dra. Ma. Teresa Ramírez Silva (UAM-Iztapalapa, México) Dr. Jean Louis Marty (Université de Perpignan, France)
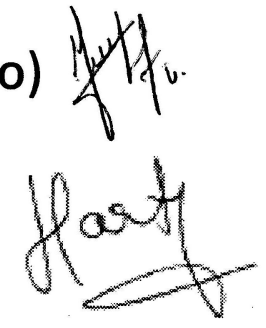

Jurado Calificador:

Presidente: Dra. Laura Galicia Luis

Secretario: Dra. María Teresa Ramírez Silva

Vocal: Dra. Sandra Olimpia Mendoza Díaz

Vocal: $\quad$ Dr. Carlos Andrés Galán Vidal

Vocal: Dr. Pablo Rogelio Hernández Rodríguez

México, D.F. Agosto 2010 
Agradecimientos.................................................................................. vii

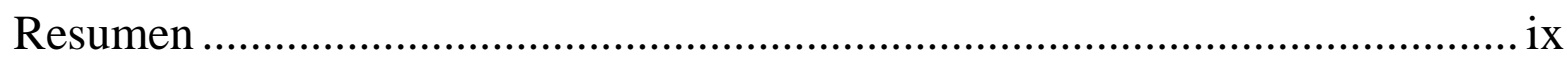

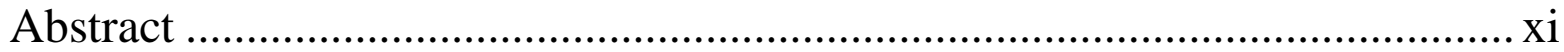

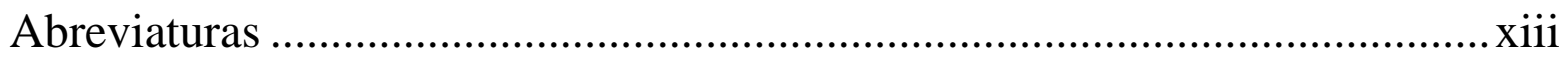

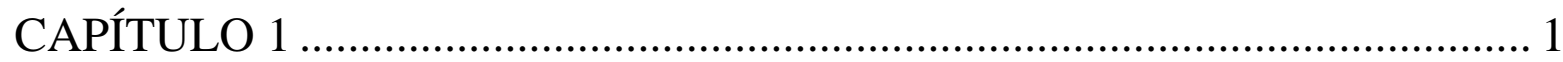

1Antecedentes y Objetivos....................................................................... 1

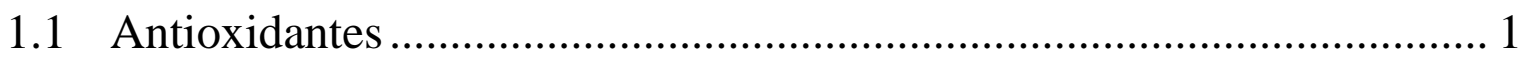

1.1.1 Estructura y Clasificación de los Antioxidantes …………………….. 2

1.1.2 Determinación de la Actividad Antioxidante...................................... 5

1.1.3 Determinación de Contenido Fenólico Equivalente (CFE) ……….... 8

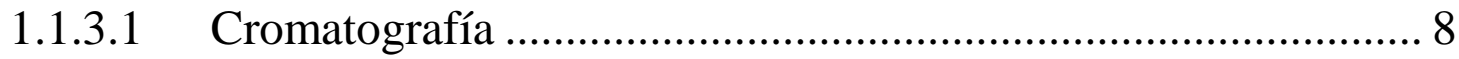

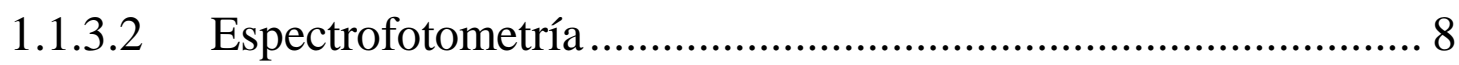

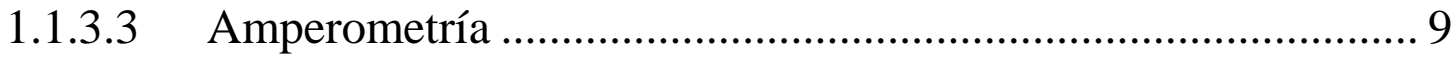

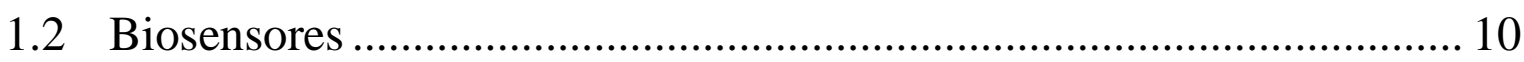

1.2.1 Características de los Biosensores ……………………………........ 10

1.2.2 Clasificación de Biosensores.......................................................... 12

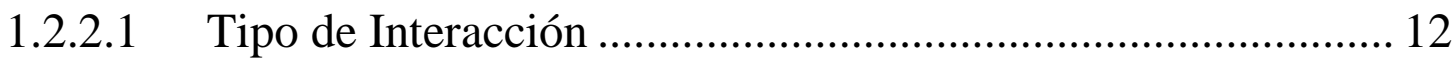

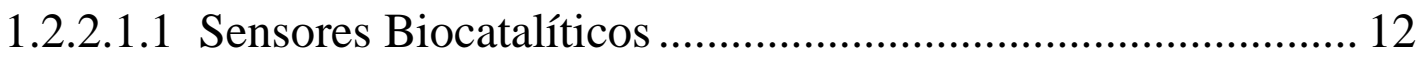

1.2.2.1.2 Sensores de Bioafinidad ...................................................... 14

1.2.2.2 Tecnología "Thick Film" ........................................................ 14

1.2.3 Técnicas de Inmovilización.............................................................. 15

1.2.4 Sistema de Transducción................................................................... 17

1.2.4.1 Transductor Electroquímico....................................................... 17

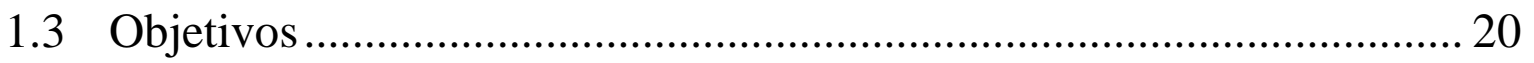


1.3.1 Objetivos específicos.

CAPÍTULO 2 21

2El uso del radical DPPH. para estimar la capacidad antioxidante. 21

2.1 Introducción 21

2.2 Experimental 25

2.2.1 Determinación de la CAox por el método espectrofotométrico del DPPH.

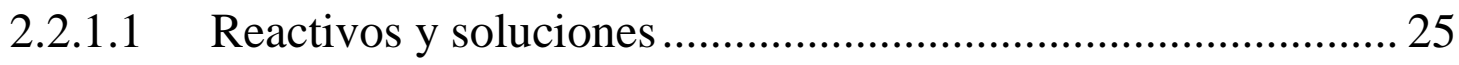

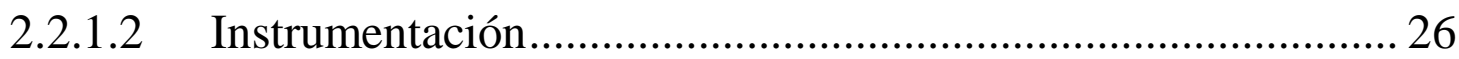

2.2.1.3 Procedimiento Experimental............................................. 26

2.2.2 Determinación de la CAox por el método electroquímico del DPPH.

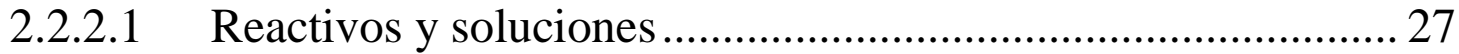

2.2.2.2 Instrumentación y electrodos ................................................. 27

2.2.2.3 Procedimiento experimental ................................................. 27

2.2.3 Contenido de fenoles totales: Método Folin-Ciocalteu ..................... 28

2.2.3.1 Reactivos y soluciones …........................................................ 28

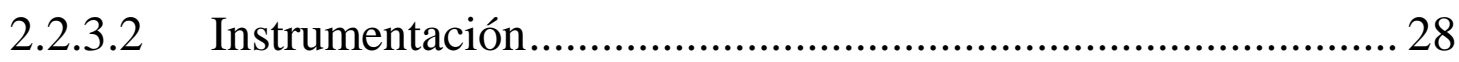

2.2.3.3 Procedimiento experimental ............................................... 29

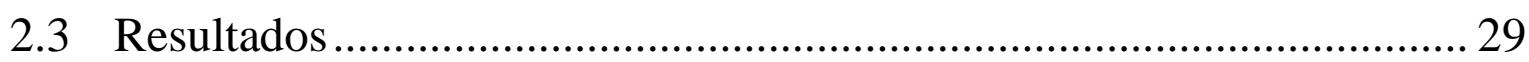

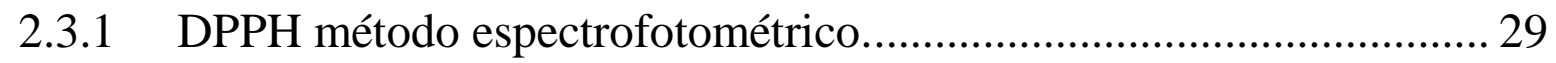

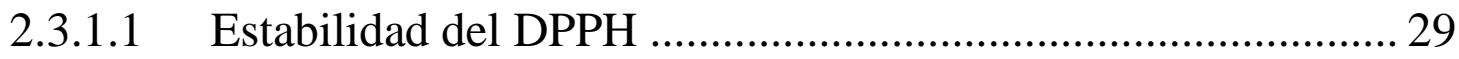

2.3.1.2 Efecto del solvente sobre el DPPH..................................... 32

2.3.1.3 Capacidad Antioxidante de compuestos orgánicos ................. 33

2.3.1.4 Determinación de $\mathrm{EC}_{50}$ en compuestos estándar ...................... 36

2.3.2 DPPH método electroquímico.......................................................... 40

2.3.3 Análisis de CAox de muestras reales ................................................ 44

2.3.4 Análisis por el método Folin-Ciocalteu (FCR) ................................. 45 
CAPÍTULO 3

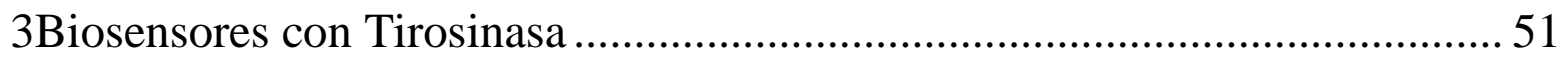

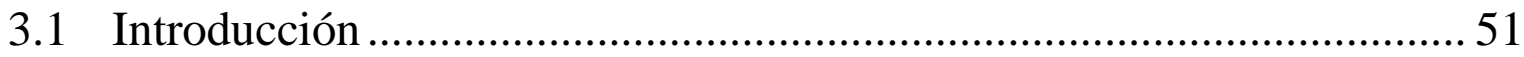

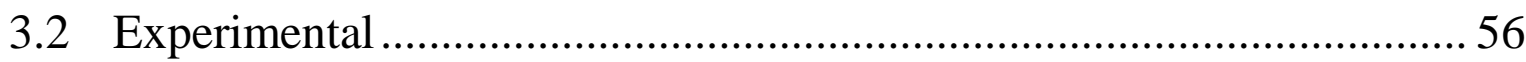

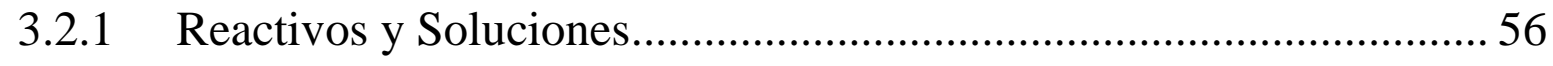

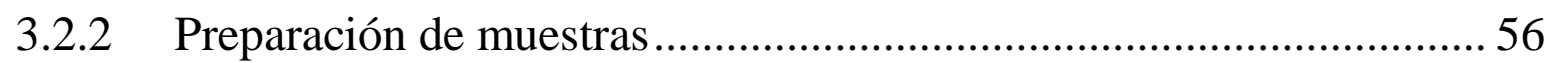

3.2.3 Manufactura de electrodos y preparación de biosensores.................. 56

3.2.3.1 Inmovilización por reticulado ................................................. 57

3.2.3.2 Inmovilización por atrapamiento …….................................... 58

3.2.4 Instrumentación y procedimiento experimental.................................58

3.2.4.1 Voltamperometría cíclica........................................................ 58

3.2.4.2 Mediciones Amperométricas ...................................................... 59

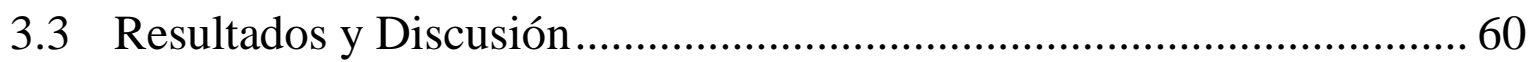

3.3.1 Determinación del potencial de trabajo.............................................. 60

3.3.2 Respuesta Amperométrica del biosensor TM-SPE ........................... 61

3.3.2.1 Cross-linking con glutaraldehído (GLU) ................................. 61

3.3.2.1.1 Composición de la matriz de soporte .................................... 62

3.3.2.2 Atrapamiento en PVA-AWP..................................................... 63

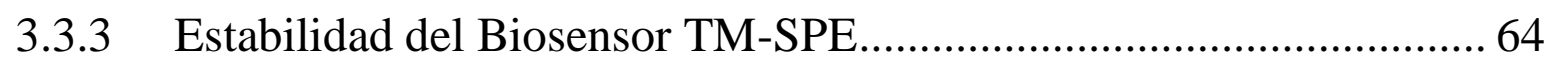

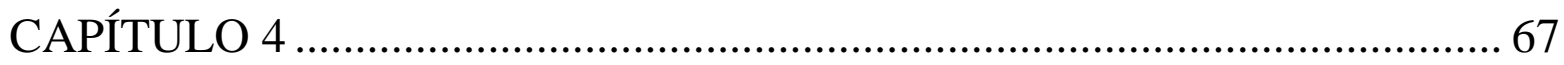

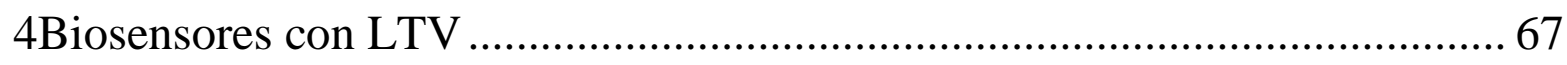

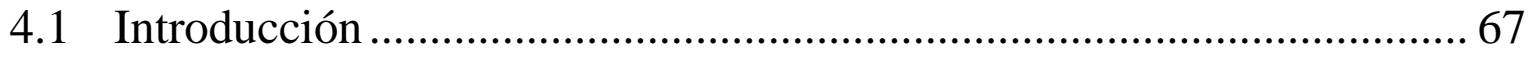

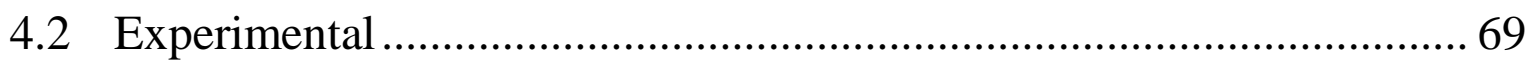

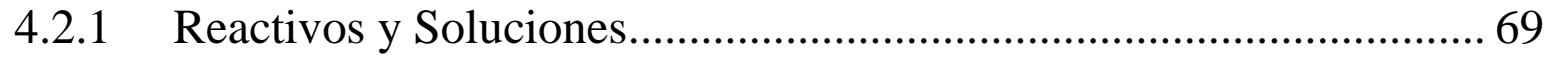

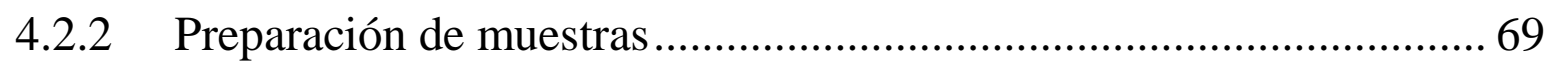


4.2.3 Manufactura de Electrodos y preparación de Biosensores ................ 70

4.2.4 Instrumentación y procedimiento experimental................................. 70

4.2.4.1 Voltamperometría cíclica......................................................... 70

4.2.4.2 Mediciones Amperométricas .................................................... 71

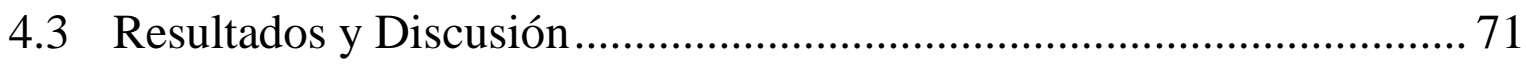

4.3.1 Determinación del potencial de reducción ........................................ 71

4.3.2 Tiempo de respuesta del sensor........................................................ 73

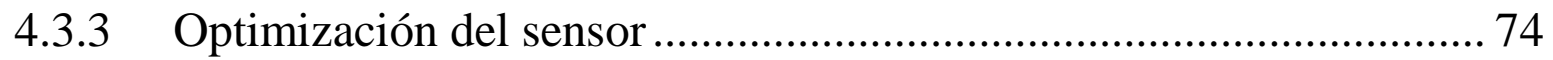

4.3.4 Respuesta del LTV-SPE ante diferentes polifenoles. ....................... 77

4.3.5 Aplicación del LTV-SPE en análisis de muestras reales ................... 79

4.3.6 Estabilidad del Biosensor LTV-SPE ............................................. 82

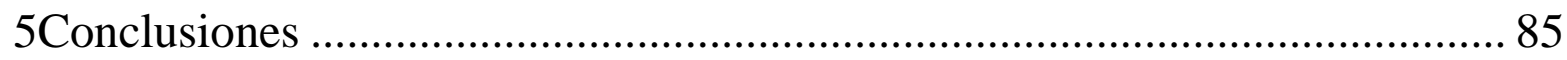

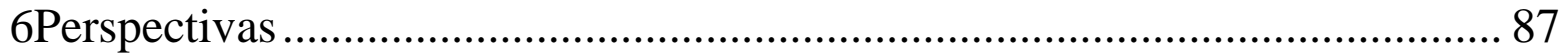

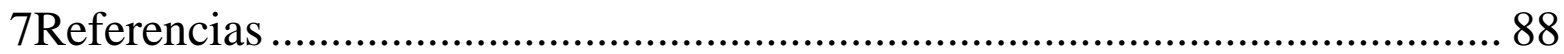


A mis padres, orgulto e inspiración de mi vida.

A Cecitia, mi esposa, por su incansable paciencia. Espero que este trabajo en algo justifique mi constante ausencia.

A mis hüjos Jesís y Yoliztli, mi sonrisa de cada mañana.

A mis hermanos, porque desde que nacimos hemos estado juntos en todo.

A Díos, por la maravillosa famitia que me regató y por toda una vida llena de sueños cumplidos. 


\section{Agradecimientos}

Al CONACyT por el apoyo financiero al proyecto 82932 para el desarrollo de esta investigación y por la beca otorgada para la realización de mis estudios de posgrado.

A la UAM iztapalapa, mi "casa abierta al tiempo" por recibirme y dejarme crecer como persona.

A la Universidad de Perpignan (Francia) por su importante aportación en el desarrollo de esta investigación.

A la Red ALFA II BioSenIntg Clave: II-0486-FCFA-FCD-FI (Métodos de procesamiento avanzado $\mathrm{e}$ inteligencia artificial en sistemas sensores $\mathrm{y}$ biosensores) por el apoyo otorgado.

A la Dra. María Teresa Ramírez Silva por darme la oportunidad de trabajar bajo su dirección. Su interminable ayuda ha sido determinante en la realización de este trabajo.

Al Dr. Jean Louis Marty por brindarme todas las facilidades para trabajar en su país y por sus sabios y oportunos consejos.

A Dr. Mario A. Romero Romo y Dr. Manuel Palomar Pardavé por su invaluable apoyo en la revisión del primer artículo publicado. 
A la Dra. Laura Galicia Luis, Dra. Sandra Olimpia Mendoza Díaz, Dr. Pablo R. Hernández Rodríguez y Dr. Carlos A. Galán Vidal, por el tiempo dedicado a la revisión del manuscrito y por sus sugerencias que contribuyen enormemente a mejorar este trabajo.

A todos y cada uno de los docentes del posgrado en Química de la UAMIztapalapa por colaborar en mi formación profesional y humana. En especial a todos los miembros del área de Química Analítica.

A Karla, Ariana y Manolo mis entrañables amigos desde el inicio de esta odisea.

A mi "familia" europea. Sandra Eremia, Gabriela, Montse, Xavi, Bea, Monica Campas, Antonio Radoi, Martina Targa, Marilena Parvulescu, Georges, Angelika Galowska, Thierry Noguer, Carole Blanchard y Reguis Rouillon. $12,000 \mathrm{~km}$ no son nada.

A todas las personas que directa o indirectamente han contribuido a la realización de este trabajo. 


\section{Resumen}

En este trabajo se describe el desarrollo y optimización de biosensores amperométricos basados en Lacasa de Trametes versicolor (LTV) o Tirosinasa de hongos (TM); así como su aplicación para determinar el contenido de compuestos fenólicos en tés y extractos de uvas.

Los estudios electroquímicos realizados incluyen diferentes técnicas como voltamperometría cíclica (VC), voltamperometría de pulso diferencial (VPD) y amperometría, empleando SPE's modificados con LTV o TM, ambas enzimas del grupo de las polifenoloxidasas (PPO) Con el propósito de comparar el desempeño de biosensores construidos usando dos métodos diferentes, TM fue inmovilizada primero por reticulado con glutaraldehído y posteriormente por atrapamiento usando alcohol polivinilico PVA-AWP (Azide-unit pendant watersoluble). En ambos métodos se utilizaron electrodos impresos de grafito (SPE) y se evaluaron diferentes cantidades de enzima sobre la superficie del electrodo de trabajo. Adicionalmente se analizaron y optimizaron otras condiciones experimentales en base al esquema del diseño factorial para 3 factores (temperatura, $\mathrm{pH}$ y potencial aplicado) y una vez determinadas las condiciones experimentales óptimas se realizó el análisis de extractos de uvas y distintas infusiones herbales

Los resultados muestran que el biosensor modificado con tirosinasa (TM-SPE) inmovilizada en PVA-AWP, supera al biosensor construido por reticulado. La enzima LTV también es estudiada utilizando los mismos métodos de inmovilización. Se realizó también la optimización de los biosensores en términos de $\mathrm{pH}$, temperatura y potencial aplicado. Se determinó el intervalo de linealidad, límite de detección, estabilidad operacional y estabilidad al almacenamiento. El biosensor modificado con lacasa (LTV-SPE) fue calibrado 
usando o-, m-, p-difenol y ácido caféico. La respuesta más alta se encontró utilizando amortiguador de acetatos $0.1 \mathrm{M}$ de $\mathrm{pH} 4.7$ y $30^{\circ} \mathrm{C}$. El tiempo de vida del biosensor se estima en más de seis meses. Por otra parte el biosensor modificado con tirosinasa fue calibrado únicamente para catecol y para ácido caféico, ambos en amortiguador $0.1 \mathrm{M}$ de fosfatos $\mathrm{pH}$ 7.0. LTV-SPE fue utilizado para la determinación del contenido fenólico equivalente (CFE) en infusiones de tés mientras que el biosensor TM-SPE fue utilizado para determinar el CFE en extractos de uvas.

El biosensor modificado con LTV muestra mayor sensibilidad y estabilidad en comparación con otros sensores enzimáticos reportados en la literatura. La principal ventaja de los dispositivos propuestos, radica en la facilidad del método de fabricación y de análisis pues las mediciones se realizan mediante la adición directa a la celda electroquímica de pequeños volúmenes de las muestras reales. En conclusión se considera que la inmovilización de las enzimas LTV y TM sobre SPE's permite la construcción de biosensores que muestran buen desempeño analítico que pueden usarse como un método rápido y confiable para determinar el contenido fenólico, el cual puede vincularse a la capacidad antioxidante de los extractos naturales. 


\section{Abstract}

Amperometric biosensors based on Laccase from Trametes versicolor (LTV) or Tyrosinase from mushrooms (TM) were developed and optimized for monitoring the phenolic compounds content in tea infusions and grapes extracts. With the aim of comparing the performances of the biosensors developed using two different methods, TM was immobilized firstly by cross-linking with glutaraldehyde and afterward by entrapment in a polymeric film using polyvinyl alcohol photopolymer PVA-AWP (Azide-unit pendant water-soluble) both of them onto disposable graphite screen-printed electrodes (SPE), evaluating at the same time, different amount of enzyme fixed on the working electrode surface. Since the obtained results show that the performance of the TM-SPE manufactured by entrapment within PVA-AWP is better than cross-linking, a different enzyme is evaluated also entrapped in the same polymeric film. LTV was immobilized onto disposable graphite screen-printed electrodes (SPE) to construct a second type of biosensor. Sensitivity optimization in terms of $\mathrm{pH}$, temperature and applied potential was carried out. The linear range, detection limit, operational and storage stabilities were also determined.

The laccase biosensor (LTV-SPE) was calibrated for o-, m- and p-diphenol as well as caffeic acid. The highest response was found at $0.1 \mathrm{M}$ acetate buffer $\mathrm{pH}$ 4.7, though it must be added the good reproducibility and operational stability were also obtained. The useful lifetime of the biosensor is estimated to be greater than 6 months. Whereas the tyrosinase biosensor (TM-SPE) was calibrated only for its natural substrate $o$-diphenol (catechol) and caffeic acid at $0.1 \mathrm{M}$ phosphate buffer $\mathrm{pH}$ 7.0.

LTV-SPE was used for the determination of the equivalent phenol content in tea infusions whereas TM-SPE was used to determine the equivalent phenol content 
in grapes extracts, both of them by the direct addition of small sample into the electrochemical cell; the results were compared with those from the FolinCiocalteu spectrophotometric method.

The amperometric detection exhibits some interesting advantages such as high simplicity, minimal sample preparation and shorter response time. A stable and sensitive amperometric response was obtained toward standard diphenolic compounds, grapes extracts and herbal infusions. In conclusion both types of biosensors are useful for easy and fast monitoring of equivalent phenol content that can be related to the antioxidant capacity of natural extracts. 


\section{Abreviaturas}

$\mathrm{AOx}$

Compuesto Antioxidante

$\mathrm{A}_{\max }$

Absorbancia máxima

ABTS

2,2'-azino-bis(3-ethylbenzthiazoline)-6-sulfonic acid cation radical

BSA Bovine Serum Albumine

CAox

Capacidad Antioxidante

CFE Contenido Fenólico Equivalente

DPPH

Radical 1,1-diphenyl-2-picrylhydrazil

$\Delta \mathrm{I}_{\mathrm{p}}$

Diferencia de intensidad de corriente de pico

EA

Electrodo Auxiliar

EAox

Eficiencia Antioxidante

$\mathrm{EC}_{50}$

Concentración efectiva media

EPC

Electrodo de pasta de carbono

ER

Electrodo de Referencia

ESR

Electron Spin Resonance

ET

Electrodo de trabajo

FCR

Reactivo de Folin-Ciocalteu

FRAP

Ferric reducing antioxidant power

GC

Gas Chromatography

GLU

Glutaraldehído

HAT

Hydrogen Atom Transfer

HPLC

High Performance Liquid Chromatography

LC

Liquid Chromatography 
LTV Laccase from Trametes Versicolor

LTV-SPE Biosensor con lacasa LTV

M Concentración molar en mol L ${ }^{-1}$

nm nanómetros

ORAC Oxigen Radical Absorbance Capacity

PC Computadora personal

PPO Polifenoloxidasa

PVP Polivinilpirrolidona

ROS Especies Reactivas de Oxígeno

SET Single Electron Transfer

SPE Electrodos Impresos por serigrafía (Screen-Printed Electrodes)

TEAC Capacidad antioxidante en equivalentes de trolox

$\mathrm{TEC}_{50} \quad$ Tiempo de reacción en la concentración $\mathrm{EC}_{50}$

TM Tirosinasa (Tyrosinase from Mushrooms)

TM-SPE Biosensor con tirosinasa

TM-SPE-GLU Biosensor con tirosinasa y glutaraldehído

Trolox Ácido (S)-(-)-6-hidroxi-2,5,7,8-tetrametilcroman-2carboxílico

VC Voltamperometría Cíclica

VPD Voltamperometría de pulso diferencial 


\section{CAPÍTULO 1}

\section{Antecedentes y Objetivos}

\subsection{Antioxidantes}

El término antioxidante originalmente se refiere en específico a la especie química que previene el consumo de oxígeno molecular. Recientes estudios en nutrición enfocan el uso de antioxidantes para prevenir la oxidación de grasas insaturadas. La actividad antioxidante puede medirse colocando la grasa en un recipiente cerrado que contiene oxígeno y observar el porcentaje de consumo del mismo. Sin embargo, fue la identificación de las vitaminas A, C y E como antioxidantes lo que revolucionó este campo y llevó a la realización de numerosas trabajos que confirmaron la importancia de estos compuestos en la biología y la bioquímica [1].

El posible mecanismo de acción fue estudiado por Moreau y Dufraisse en 1926 quienes reconocieron que una sustancia con actividad antioxidante es como si la sustancia por si misma fuera el objetivo de la oxidación. El mecanismo de como la vitamina E previene el proceso de peroxidación en lípidos conduce a la comprensión de los antioxidantes como agentes reductores que evitan la reacción oxidante atrapando las especies reactivas antes que causen daño a las células [1]. En este sentido se considera que los antioxidantes son necesarios para prevenir la formación de especies reactivas de oxígeno (ROS), algunas de las cuales son radicales libres.

Un radical libre es una especie que contiene uno o más electrones desapareados, es decir, electrones solitarios en un orbital atómico o molecular [2]. Las especies como el peróxido de hidrogeno $\mathrm{H}_{2} \mathrm{O}_{2}$ o radicales libres como el hidroxilo $\mathrm{OH} \cdot$ son moléculas inestables y altamente reactivas que pueden dañar las células por 
reacciones químicas en cadena tales como la formación de aductos de DNA que podrían causar cáncer o muerte celular. Todas las células contienen por lo tanto, antioxidantes que sirven para reducir o prevenir este daño. Los antioxidantes son especialmente importantes en la mitocondria de células eucarióticas pues el oxígeno como parte del proceso de generación de energía, produce especies reactivas oxigenadas $[3,4]$.

Muchos de los compuestos antioxidantes provienen de fuentes naturales como son los granos, frutas y algunos vegetales; mientras que algunos otros son sintetizados artificialmente como las vitaminas $\mathrm{C}, \mathrm{E}$, carotenos y ácidos fenólicos [5,6].

\subsubsection{Estructura y Clasificación de los Antioxidantes}

Existen diferentes tipos de antioxidantes. Las siguientes sustancias pueden tener efectos antioxidantes: Vitaminas A, C y E, Zinc, $\alpha$-caroteno, $\beta$-caroteno, manganeso (la especie +2 en la enzima superóxido dismutasa), flavonoides, ácidos fenólicos y sus ésteres [7].

Los flavonoides son moléculas polifenólicas que pueden ser vistos como dos anillos de benceno unidos por una pequeña cadena de tres carbonos. Uno de estos átomos de carbono está siempre conectado a uno de los anillos de benceno; ya sea directamente o por puente de hidrógeno, formando así un tercer anillo en el centro, el cual puede tener cinco o seis miembros (fig. 1.1). 


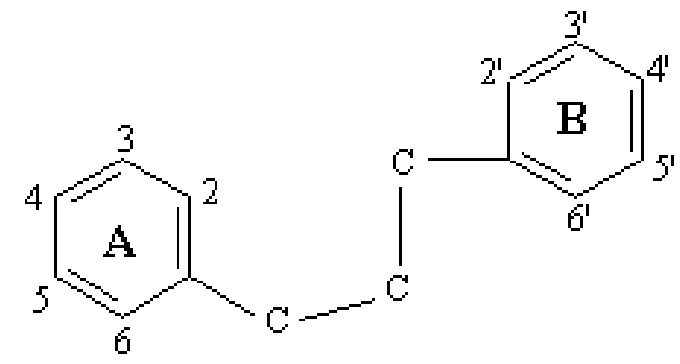

Fig. 1.1 Estructura de los flavonoides

La estructura química de los flavonoides se basa en un esqueleto donde el segundo anillo aromático B se une en la posición 2, 3 o 4 (fig. 1.2)

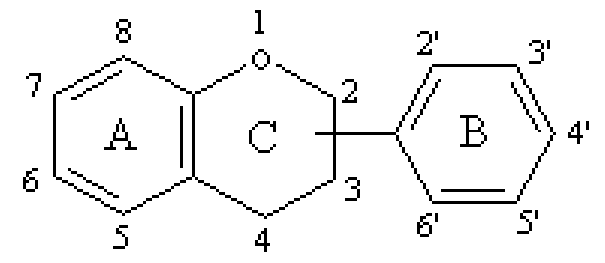

Fig. 1.2 Estructura de los flavonoides II

Se han caracterizado más de 5000 flavonoides que existen en la naturaleza provenientes de varias plantas; se clasifican en varios subgrupos de acuerdo a la posición del sustituyente sobre el anillo C. Tanto el estado de oxidación del anillo heterocíclico como la posición del anillo B, son importantes para la clasificación $[8,10]$. Los principales subgrupos de flavonoides son: chalconas, flavonas, flavonoles, flavanonas, antocianinas e isoflavonoides (Tabla 1.1) 
Tabla 1.1 Estructura de los principales grupos de flavonoides.

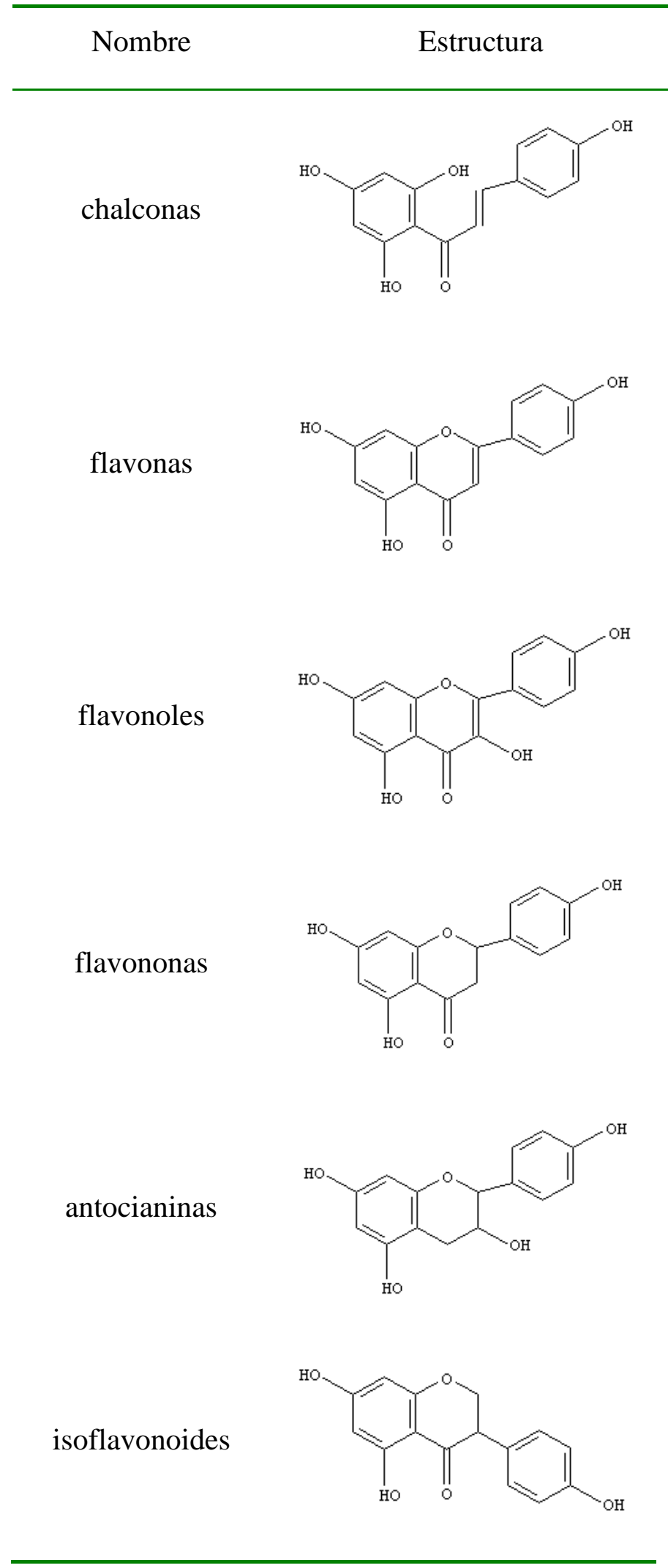


Las antocianinas son el más importante grupo de pigmentos en plantas, visibles para el ojo humano por ejemplo, las antocianidinas de la especie hidrangea dan coloración roja en medio ácido y azul en medio básico (fig. 1.3).

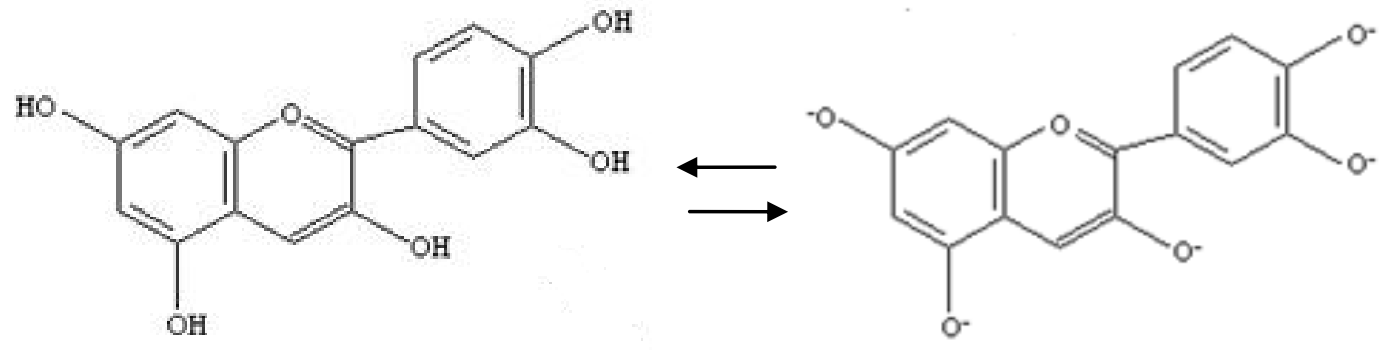

Fig. 1.3 Antocianidinas de la hidrangea

\subsubsection{Determinación de la Actividad Antioxidante}

En la actualidad existe un gran interés en determinar las propiedades antioxidantes de alimentos y bebidas de origen natural, en relación a los compuestos que contienen. Los métodos empleados para medir la actividad antioxidante dependen de la especificidad del radical libre usado como reactivo y están limitados a compuestos solubles en un solvente elegido. Los compuestos antioxidantes pueden tener distinta solubilidad dependiendo del solvente; por esta razón presentan distinta reactividad con los radicales libres reaccionando en diferente porcentaje y con cinética distinta. Dado este hecho, la eficiencia en la extracción de la especie donadora del hidrógeno es un factor importante en la evaluación de la actividad antioxidante [11-14].

Si representamos un radical como $\mathrm{R} \cdot \mathrm{y}$ el donador de hidrógeno como HA, la reacción que se lleva a cabo es

$$
\mathrm{R} \cdot+\mathrm{HA} \rightarrow \mathrm{R}-\mathrm{H}+\mathrm{A} \cdot
$$


Donde $\mathrm{R}-\mathrm{H}$ es la forma reducida de $\mathrm{R} \cdot \mathrm{y}$ A es un nuevo radical libre menos reactivo generado en este primer paso. En la reacción anterior se aprecia la reducción de un radical $\mathrm{R}$ · por una molécula de HA, es decir la estequiometría es 1:1. Además el radical $A^{\bullet}$ puede formar dímeros en una reacción regulada estequiométricamente por el número de moléculas de $\mathrm{R} \cdot$ reducidas

$$
\mathrm{A} \cdot+\mathrm{A} \cdot \rightarrow \mathrm{A}-\mathrm{A}
$$

En otros casos la especie donadora de hidrógeno cuenta con varios sitios de abstracción. Una molécula de ácido ascórbico puede reaccionar con dos radicales $\mathrm{R} \cdot$ es decir una estequiometría 2:1 [15].

Uno de los métodos más usados para determinar la capacidad antioxidante in vitro es el método ABTS el cual monitorea la desaparición del radical cromóforo ABTS $^{+}$(azul/verde) por la reacción con un compuesto antioxidante. Inicialmente el radical catión se produce por medio de enzimas (peroxidasa, mioglobina) o químicamente (dióxido de manganeso, persulfato de potasio) [16]. Este ensayo es sensible a antioxidantes simples ó complejos.

Otro de los métodos más comunes se basa en las propiedades cromáticas del radical 1,1-difenil-2-picrilhidrazil conocido como DPPH; esta molécula es un radical libre químicamente estable que no forma dímeros como sucede con otros radicales libres. Una solución de $\mathrm{DPPH} \cdot$ es color morado y da máximos de absorción en 328 y $514 \mathrm{~nm}$; cuando se mezcla con una sustancia que puede donar uno o varios átomos de hidrógeno, la concentración del radical $\mathrm{DPPH} \cdot$ disminuye mientras aparece la forma reducida DPPH-H provocando un cambio en el color de morado a amarillo y la absorbancia de la solución decrece. La decoloración resultante esta directamente ligada a la estequiometria de la reacción (fig. 1.4). 


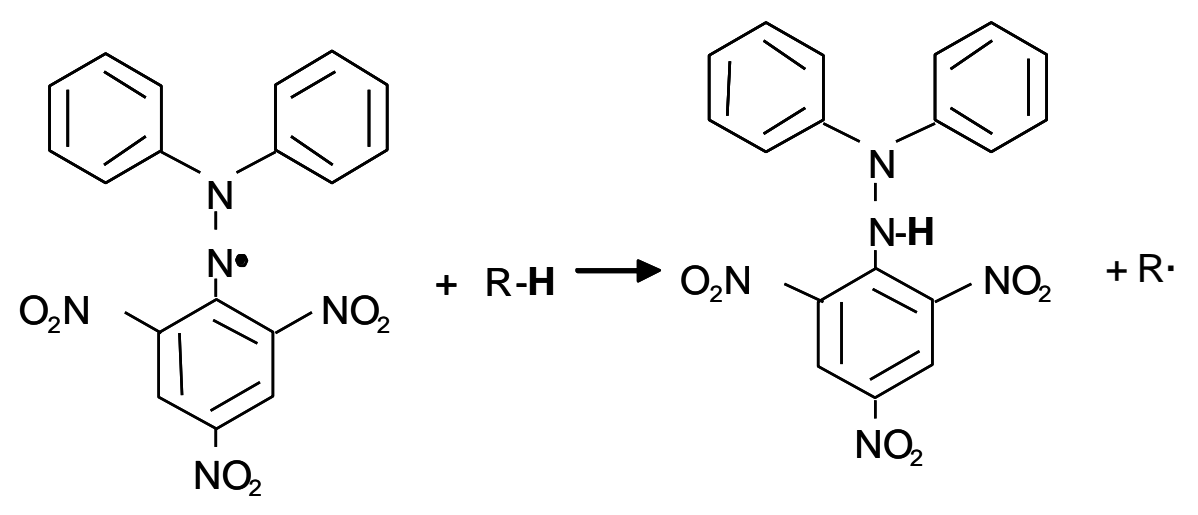

Fig. 1.4 Abstracción de un átomo de hidrogeno por el radical DPPH.

Este método no es específico a ningún tipo de antioxidante en particular, por lo tanto aplica para evaluar una capacidad antioxidante total. Es importante mencionar que los resultados obtenidos presentan tendencias similares al reportado usando otros métodos $[11,17,18]$.

En otros métodos la sensibilidad y selectividad aumentan. Por ejemplo la fluorescencia es empleada conjuntamente con HPLC y detección UV. Los barridos a flujo estático han sido usados para obtener los espectros de emisión y excitación de las especies eluidas. Este método se ha usado para determinar las intensidades de fluorescencia de algunas flavonas polimetoxiladas encontradas en jugos de frutas.

A diferencia de los métodos que estudian la habilidad para atrapar radicales libres, el método ORAC (Oxigen Radical Absorbance Capacity) mide la pérdida de fluorescencia cuando la proteína $\beta$-ficoeritrina es oxidada $[11,12,19]$.

Una manera sencilla de reportar la actividad antioxidante de compuestos o de alimentos que los contienen es mediante el empleo de un material de referencia. 
Un estándar común es el ácido (S)-(-)-6-hidroxi-2,5,7,8-tetrametilcroman-2carboxílico conocido como trolox.

\subsubsection{Determinación de Contenido Fenólico Equivalente (CFE)}

Los compuestos fenólicos y polifenólicos constituyen la principal clase de antioxidantes naturales presentes en plantas, comidas y bebidas y son cuantificados usando distintos métodos. Los detectores más utilizados para la determinación de flavonoides en general son: UV, electroquímico, fluorescencia y quimioluminiscencia. Los métodos espectroscópicos ( $\mathrm{RMN} \mathrm{H}^{+}, \mathrm{C}^{13}$, ESR y MS) son usados como técnicas adicionales para poder corroborar los mecanismos de reacción que pueden seguir los flavonoides.

\subsubsection{Cromatografía}

Entre los métodos que han resultado ser muy útiles están los cromatográficos teniendo más importancia la cromatografía de líquidos de alta resolución HPLC, acoplada a diferentes detectores según las necesidades y condiciones de trabajo.

La HPLC acoplada a un detector UV ha sido ampliamente utilizada para la determinación cuantitativa de diferentes flavonoides y polifenoles. Además de la cromatografía de líquidos (LC) también se emplean la cromatografía de capa fina (CCF) y la cromatografía de gases (GC) acoplada con espectrometría de masas [20-25].

\subsubsection{Espectrofotometría}

En este método se emplea el llamado reactivo de Folin-Ciocalteu (FCR) el cual consiste en una solución que contiene iones poliméricos complejos de los ácidos fosfomolíbdico y hateropoli fosfotúngstico. Este compuesto oxida fenoles produciendo un complejo molibdeno-tungsteno (azul). En la práctica la muestra 
se hace reaccionar con una disolución del FCR y después se agrega una solución de $\mathrm{Na}_{2} \mathrm{CO}_{3}, \mathrm{HCl}$ y $\mathrm{Li}_{2} \mathrm{SO}_{4}$ (Estos compuestos previenen la formación de especies interferentes). El color azul que se produce es medido espectrofotométricamente. La concentración de fenoles totales se determina por comparación con los valores de absorbancia de diferentes concentraciones de un compuesto estándar. Los resultados se expresan en términos de equivalentes del estándar seleccionado (comúnmente de ácido gálico) [26].

\subsubsection{Amperometría}

En la actualidad se emplean sensores sólidos modificados con enzimas para la determinación amperométrica de fenoles simples. La tirosinasa es la enzima de uso más frecuente en la determinación de fenol pues lo oxida en dos etapas: primeramente el fenol se oxida a catecol (o-benzenodiol) y éste a su vez se oxida a o-quinona (fig. 1.5) [27].

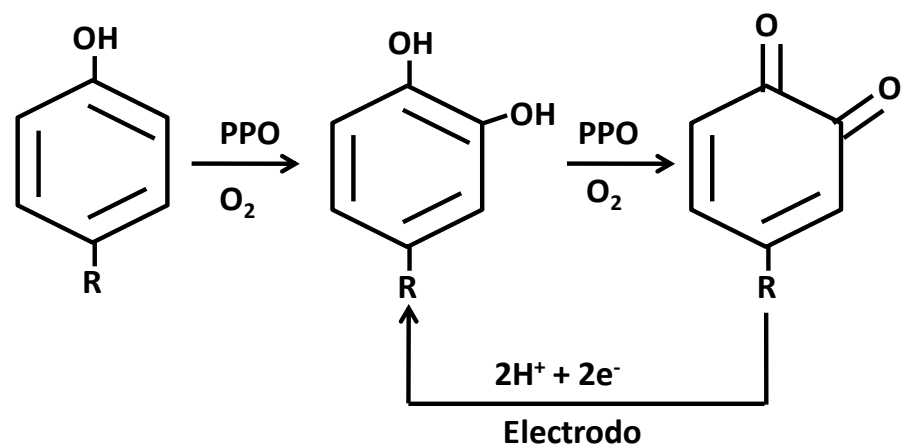

Fig. 1.5 Oxidación enzimática de fenol y catecol en presencia de oxígeno. La reducción electroquímica del producto se utiliza como método de cuantificación.

La principal desventaja al emplear la tirosinasa es que no muestra actividad para la oxidación de $p$ - y $m$-benzenodiol [28] mientras que la enzima lacasa cataliza la oxidación de los tres isómeros $o$-, $m$-, y $p$-bencenodiol a las correspondientes $o$-, $m$-, y $p$-quinonas y puede por lo tanto ser empleada para la detección de estos 
bencenodioles con un considerable aumento en la intensidad de la respuesta amperométrica.

\subsection{Biosensores}

Un biosensor se define como un dispositivo compacto de análisis que incorpora un elemento de reconocimiento biológico (ácido nucléico, enzima, anticuerpo, tejido, célula) o biomimético (polímeros de impresión molecular o PIMs, aptámeros) asociado a un sistema de transducción que permite procesar la señal producida por la interacción entre el elemento de reconocimiento y el analito.

El principio de detección de un biosensor se basa en la interacción específica entre el compuesto de interés y el elemento de reconocimiento. Como resultado de esta unión se produce la variación de una o más propiedades fisicoquímicas ( $\mathrm{pH}$, transferencia de electrones, de calor, diferencia de potencial, de masa, variación de las propiedades ópticas, etc.) que detecta el transductor. Este sistema transforma la respuesta del elemento de reconocimiento en una señal electrónica indicativa de la presencia del analito o proporcional a su concentración en la muestra [29].

El primer biosensor (que se denominó "enzyme electrode") consistía en una enzima glucosa oxidasa acoplada a un electrodo para oxígeno. La enzima oxida la glucosa y como consecuencia se produce un descenso proporcional de la concentración de oxígeno en la muestra, que es detectado e interpretado por el transductor.

\subsubsection{Características de los Biosensores}

En las múltiples aplicaciones de los biosensores es deseable que cuenten con las siguientes características: 
Alta especificidad. Permite el análisis de compuestos en concentraciones de partes por billón ( $\left.\mathrm{mg} \mathrm{l}^{-1}\right)$ [29].

Alta selectividad El elemento de reconocimiento debe interaccionar exclusivamente con el analito y no con otros componentes de propiedades similares.

Bajo costo. En general estos sistemas pueden fabricarse a escala industrial lo cual reduce considerablemente su costo. Sin embargo, existen fases críticas en su construcción que dificultan el proceso (por ejemplo procesos de inmovilización).

Tiempo de respuesta. Muchos biosensores emplean algunos minutos en cuantificar el compuesto de interés. El análisis se realiza en tiempo real.

Manejo sencillo. Esta tecnología no requiere personal calificado. Sus diseños portátiles permiten su aplicación in situ. Prescindir del control manual facilita su integración dentro de los sistemas automatizados.

Tamaño. Los desarrollos en microelectrónica y nanotecnología han permitido reducir las dimensiones de estos dispositivos. Así pueden ensamblarse varios de ellos en un mismo sistema que realiza varias tareas a la vez y son aplicables a ensayos donde el tamaño físico del dispositivo o el volumen de la muestra son factores limitantes.

Multi-análisis. Ciertos biosensores llevan a cabo la determinación de diferentes analitos de forma simultánea. La combinación de varios de ellos podría darles ventaja frente a las técnicas de análisis convencionales (cromatografía, espectrometría, etc.) [30-31]. 


\subsubsection{Clasificación de Biosensores}

Estos dispositivos pueden clasificarse en función a:

- El tipo de interacción que se establece entre el elemento de reconocimiento y el analito.

- La naturaleza del elemento de reconocimiento

- El sistema de transducción seleccionado

Existen múltiples elementos de reconocimiento y sistemas de transducción, teóricamente estos componentes admiten diversas combinaciones. En la práctica, la elección del material biológico depende de las características del compuesto a analizar. La elección del transductor está condicionada por el tipo de elemento de reconocimiento elegido, ya que éste determina cuál será la variación en las propiedades fisicoquímicas que ocurra como consecuencia de la interacción. Por ejemplo, cuando el elemento de reconocimiento usado es una enzima se utiliza un transductor electroquímico que "lee" un proceso redox.

\subsubsection{Tipo de Interacción}

\subsection{Sensores Biocatalíticos}

Son los biosensores mejor conocidos y los más aplicados. Se basan en la utilización de biocatalizadores que son elementos que favorecen una reacción (sin consumo del biocatalizador que se regenera). Estos biocatalizadores pueden ser sistemas que contienen enzimas, organelos celulares, células completas o tejidos animales o vegetales en los que estos sistemas se encuentran en su medio natural [31]. Existen sustancias que inhiben la actividad de determinados sistemas enzimáticos de manera selectiva, de modo que estos sistemas se utilizan para detectar su presencia. 
El principal elemento de reconocimiento de tipo biocatalítico que puede acoplarse a distintos tipos de transductores son las enzimas. Estos compuestos son proteínas que catalizan reacciones químicas en los seres vivos. En una reacción catalizada por una enzima se produce la unión del sustrato en una región concreta de la enzima denominada centro activo, que comprende un sitio de unión y un sitio catalítico. Una vez formados los productos la enzima se recupera iniciando un nuevo ciclo de reacción aunque en ocasiones es necesaria la presencia de cofactores para que la enzima pueda regenerarse.

La actividad enzimática está controlada normalmente por el $\mathrm{pH}$, la fuerza iónica, la temperatura y la presencia de cofactores. La estabilidad de las enzimas es un factor limitante para el tiempo de vida de un biosensor enzimático y se utilizan distintas técnicas para aumentarla, como estabilización química y/o inmovilización.

En algunas ocasiones se utilizan cascadas multienzimáticas, en las que la enzima que actúa como elemento de reconocimiento no actúa directamente sobre el analito, sino sobre algún producto derivado del mismo. Entre las enzimas disponibles comercialmente las más utilizadas suelen ser las óxido-reductasas. Son enzimas muy estables que catalizan fenómenos de oxidación o reducción utilizando oxígeno o cofactores. Las enzimas pueden acoplarse a transductores de los tipos potenciométrico, amperométrico, optoeléctrico, calorimétrico o piezoeléctrico, y básicamente todas funcionan por inmovilización de la enzima en el propio transductor [31].

Existen enzimas que no se pueden utilizar aisladas debido a que no son suficientemente estables o su purificación es difícil y costosa. En estas circunstancias pueden utilizarse organelos celulares, células completas o tejidos que contienen las enzimas en una forma natural en un medio más estable. Entre 
las ventajas que presentan las enzimas para su utilización en biosensores se puede mencionar su elevada selectividad, rápida respuesta además de ser autoregenerables [32].

\subsection{Sensores de Bioafinidad}

Estos sensores se basan en la interacción del analito y el elemento de reconocimiento, sin que exista una transformación catalítica sino que se produce una reacción de equilibrio en la que se forma un complejo analito-receptor [31]. Algunos elementos de reconocimiento usados para este tipo de biosensores son los anticuerpos, células completas, lectinas (proteínas que se unen de manera selectiva y reversible a distintos sacáridos), polímeros de impresión molecular y aptámeros (secuencia de oligonucleóticos ADN o ARN de cadena sencilla sintetizada artificialmente).

\subsubsection{Tecnología "Thick Film"}

Con el paso del tiempo, se ha incrementado el interés en el desarrollo de biosensores más simples, rápidos y económicos útiles en aplicaciones clínicas, ambientales o industriales. Entre los dispositivos con mayor desarrollo se encuentran los construidos con la llamada tecnología "thick film". Estos biosensores se forman con capas de pasta o tintas depositadas secuencialmente sobre un soporte o sustrato. Un factor clave que distingue esta tecnología es el método con el cual se deposita la película (screen printing). Convencionalmente, los electrodos "thick film" se secan a temperaturas elevadas para eliminar los solventes de la pasta. Este paso es determinante en la construcción del biosensor

pues podría dañar el elemento de reconocimiento, (algunas enzimas son altamente inestables a la alta temperatura). Una solución alternativa es el uso de pastas termocurables o el proceso de fotocurado utilizando luz ultravioleta. 
Estos biosensores han sido muy usados en aplicaciones clínicas y ambientales con gran éxito. La aplicación más conocida es quizás el uso de biosensores enzimáticos en la determinación de los niveles de glucosa en personas con diabetes.

\subsubsection{Técnicas de Inmovilización}

Una etapa clave en la construcción de un biosensor es la inmovilización del elemento de reconocimiento sobre una membrana o matriz, que a su vez se fija a la superficie del transductor. Este material de base puede actuar únicamente como soporte del componente biológico o participar además en la transmisión de la señal al sistema de transducción. La elección de uno u otro procedimiento depende de la naturaleza del elemento biológico, el tipo de transductor, las propiedades fisicoquímicas del analito y las condiciones de trabajo del biosensor.

Entre las técnicas empleadas las más comunes son la adsorción física, el atrapamiento, el entrecruzamiento o reticulado (cross-linking) y la formación de

enlaces covalentes. La tabla 1.2 resume las principales características de los métodos de inmovilización [31]. 
Tabla 1.2 Técnicas de inmovilización más comunes en la construcción de biosensores [34]

\begin{tabular}{|c|c|c|c|c|}
\hline $\begin{array}{l}\text { Técnica de } \\
\text { inmovilización }\end{array}$ & Descripción & Matriz & Ventajas & Inconvenientes \\
\hline Adsorción física & $\begin{array}{l}\text { Unión del ER* a } \\
\text { la matriz } \\
\text { mediante } \\
\text { interacciones } \\
\text { iónicas, puentes } \\
\text { de hidrógeno, } \\
\text { fuerzas de Van } \\
\text { der Waals. }\end{array}$ & $\begin{array}{l}\text { Celulosa. Gel de sílice. } \\
\text { Colágeno. Hidroxiapatita. } \\
\text { Acetato. }\end{array}$ & $\begin{array}{l}\text { Sencilla, Bajo } \\
\text { costo, Matriz } \\
\text { regenerable, Sin } \\
\text { modificaciones } \\
\text { en ER. }\end{array}$ & $\begin{array}{l}\text { Unión débil: } \\
\text { pérdida de ER } \\
\text { por condiciones } \\
\text { externas. } \\
\text { Control estricto } \\
\text { del proceso. }\end{array}$ \\
\hline Atrapamiento & $\begin{array}{l}\text { Retención física } \\
\text { del ER en las } \\
\text { cavidades } \\
\text { interiores de la } \\
\text { matriz }\end{array}$ & $\begin{array}{l}\text { Geles: agar, nylon, } \\
\text { almidón, poliacrilamida. } \\
\text { Matrices electródicas } \\
\text { compositas rígidas: } \\
\text { grafito-teflón ó grafito- } \\
\text { resina epoxi }\end{array}$ & $\begin{array}{l}\text { Sencilla. Bajo } \\
\text { costo. Se } \\
\text { necesita poca } \\
\text { cantidad de ER. } \\
\text { Sin } \\
\text { modificaciones } \\
\text { de ER. } \\
\text { Proximidad } \\
\text { entre ER y el } \\
\text { transductor. }\end{array}$ & $\begin{array}{l}\text { Unión débil. } \\
\text { Control estricto } \\
\text { de la } \\
\text { polimerización } \\
\text { de la matriz. No } \\
\text { regenerable. }\end{array}$ \\
\hline Entrecruzamiento & $\begin{array}{l}\text { Uniones } \\
\text { irreversibles de } \\
\text { los ER entre sí } \\
\text { mediante } \\
\text { reactivos } \\
\text { funcionales. }\end{array}$ & $\begin{array}{l}\text { Reactivos: Glutaraldehído } \\
\text { Hexametilen-di- } \\
\text { isocianato, 2,4-dinitro- } \\
\text { benceno. }\end{array}$ & $\begin{array}{l}\text { Costo } \\
\text { moderado. } \\
\text { Estable en } \\
\text { condiciones } \\
\text { extremas. } \\
\text { Mínima pérdida } \\
\text { de ER }\end{array}$ & $\begin{array}{l}\text { Tratamiento con } \\
\text { sustancias } \\
\text { químicas tóxicas. } \\
\text { No regenerable. }\end{array}$ \\
\hline $\begin{array}{l}\text { Enlaces } \\
\text { covalentes }\end{array}$ & $\begin{array}{l}\text { Uniones } \\
\text { covalentes del } \\
\text { ER con grupos } \\
\text { químicos } \\
\text { activados de la } \\
\text { matriz o } \\
\text { directamente del } \\
\text { transductor }\end{array}$ & $\begin{array}{l}\text { Diciclohexilcarbodiimida, } \\
\text { chitosa, agarose, } \\
\text { microelectrodos de fibras } \\
\text { de carbono, celulosa, } \\
\text { sefarosa CL-6B }\end{array}$ & $\begin{array}{l}\text { Manipulación } \\
\text { sencilla. Estable } \\
\text { en condiciones } \\
\text { extremas }\end{array}$ & $\begin{array}{l}\text { Alteración del } \\
\text { ER (centro activo } \\
\text { en enzimas). } \\
\text { Inadecuado para } \\
\text { ERs muy } \\
\text { sensibles (pH, } \\
\text { temperatura) No } \\
\text { regenerable. } \\
\text { Tratamiento con } \\
\text { sustancias } \\
\text { químicas tóxicas. } \\
\text { Costo elevado. }\end{array}$ \\
\hline
\end{tabular}

*ER: elemento de reconocimiento 


\subsubsection{Sistema de Transducción}

El sistema de transducción o transductor es el elemento que convierte las variaciones de las propiedades físicas o químicas que se producen por la interacción entre el elemento de reconocimiento y el analito en una señal que puede ser amplificada, almacenada y registrada. La señal generada por el transductor en algunos casos no puede ser interpretada directamente y es necesaria la utilización de un software para su procesamiento.

Existen varios tipos de transductores: electroquímicos, ópticos, piezoeléctricos (másicos, gravimétricos), termométricos y nanomecánicos. Dependiendo de la naturaleza de la interacción entre el elemento de reconocimiento y el analito se puede utilizar un tipo de transductor u otro [35].

\subsubsection{Transductor Electroquímico}

Los transductores electroquímicos transforman la señal que se produce por la interacción entre el sistema de reconocimiento y el analito en una señal eléctrica. Proporcionan información analítica cuantitativa o semicuantitativa específica. El elemento de reconocimiento biológico y el elemento de transducción deben estar en contacto.

Se diferencian cuatro tipos de biosensores electroquímicos que son conductimétricos, potenciométricos, amperométricos e impedimétricos en función de si detectan cambios en la conductividad, en el potencial, en una corriente generada o en la impedancia respectivamente. Por ejemplo, en un sensor electroquímico amperométrico, la interacción entre el elemento de reconocimiento y el analito provoca la conversión electroquímica de una especie redox que genera una corriente eléctrica. En general se utilizan junto con elementos de reconocimiento biocatalíticos ya que las reacciones enzimáticas 
generan aparición de sustancias electroactivas, cambios en el $\mathrm{pH}$ o en el potencial, etc.

Tabla 1.3. Tipos de transductores electroquímicos [34].

\begin{tabular}{|c|c|c|c|}
\hline $\begin{array}{l}\text { Transductor } \\
\text { electroquímico }\end{array}$ & Tipo de medida & Ventajas & Desventajas \\
\hline Conductimétrico & $\begin{array}{l}\text { Variación de } \\
\text { conductividad del } \\
\text { medio }\end{array}$ & & \\
\hline Potenciométrico & $\begin{array}{l}\text { Diferencia depotencial } \\
\text { eléctrico }\end{array}$ & $\begin{array}{l}\text { Simplicidad de } \\
\text { operación.Tamaño } \\
\text { pequeño }\end{array}$ & $\begin{array}{l}\text { Menor sensibilidad que } \\
\text { amperométricos. Unión } \\
\text { a otros iones presentes } \\
\text { en la muestra. Para } \\
\text { muestras con gran } \\
\text { cantidad de analito }\end{array}$ \\
\hline Amperométrico & $\begin{array}{l}\text { Corriente generada por } \\
\text { la reducción u } \\
\text { oxidación de especies } \\
\text { electroactivas }\end{array}$ & $\begin{array}{l}\text { Pequeños y robustos. } \\
\text { Sensibles. Rápidos. } \\
\text { Económicos. Fácil para } \\
\text { ensayos de campo. }\end{array}$ & $\begin{array}{l}\text { Pueden tener baja } \\
\text { selectividad }\end{array}$ \\
\hline Impedimétrico & $\begin{array}{l}\text { Incremento de } \\
\text { conductancia }\end{array}$ & & \\
\hline
\end{tabular}

Los biosensores amperométricos se basan en la medida de las corrientes resultantes del intercambio de electrones que se produce entre el elemento de reconocimiento (enzimas) y un electrodo mantenido a un potencial apropiado. $\mathrm{La}$ posibilidad de poder incorporar en el electrodo otros componentes (biomoléculas), confiere a este tipo de biosensores una gran diversidad de uso. La mayor parte de los biosensores amperométricos utilizan enzimas del grupo oxido-reductasas, pues los productos consumidos o producidos durante el 
proceso de óxido-reducción, suelen ser fácilmente leídos por el transductor amperométrico.

Basados en medidas potenciométricas, los electrodos selectivos a iones (Ion Selective Electrode o ISE), determinan la variación en la concentración de un ión, inducida mediante una interacción. Las variaciones en la medida del potencial vienen determinadas por la ecuación de Nernst. Una de las configuraciones más empleadas en este tipo de biosensores utiliza el electrodo de vidrio como referencia. Los ISE's responden a la diferencia de potencial que se genera a ambos lados de una membrana con propiedades selectivas para un determinado ión.

Considerando lo anterior es importante generar un sensor que mantenga inmovilizada la enzima adecuadamente, y que sea sencillo de construir, portatil y con respuestas analíticas de calidad es por ello que en este trabajo se pretende alcanzar los objetivos que se presentan a continuación. 


\subsection{Objetivos}

Desarrollar sensores enzimáticos y aplicarlos en la determinación del contenido fenolico total en extractos naturales.

\subsubsection{Objetivos específicos}

- Determinación de la capacidad antioxidante en extractos de uvas e infusiones herbales mediante el método espectrofotométrico DPPH.

- Construir sensores modificados con una de las enzimas seleccionadas empleando electrodos impresos por serigrafía (SPE) mediante distintos métodos de inmovilización.

- Caracterizar y optimizar las condiciones de operación de los biosensores LTV-SPE y TM-SPE.

- Determinación del contenido fenólico equivalente (CFE) en extractos de uvas e infusiones herbales empleando los biosensores LTV-SPE y TMSPE

- Determinación del contenido fenólico equivalente en extractos de uvas e infusiones herbales mediante el método espectrofotométrico FolinCiocalteu (FCR), esto con el fin de realizar una comparación entre los resultados obtenidos por ambos métodos. 


\section{CAPÍTULO 2}

\section{El uso del radical DPPH• para estimar la capacidad antioxidante}

\subsection{Introducción}

En la actualidad es bien conocido que los compuestos fenólicos son los principales responsables de los beneficios derivados del consumo de alimentos de origen natural. Estos alimentos juegan un papel clave como antioxidantes debido a la presencia de grupos $\mathrm{OH}$ y a su estructura aromática, lo cual les confiere la capacidad de atrapar radicales libres. Los radicales libres y las especies reactivas de oxígeno (ROS) están presentes en sistemas biológicos de una gran variedad de fuentes. Especies como el peróxido de hidrogeno $\left(\mathrm{H}_{2} \mathrm{O}_{2}\right)$ o el radical hidroxilo $(\mathrm{OH} \cdot)$ son moléculas inestables que pueden dañar a las células por reacciones químicas en cadena. Compuestos como ácidos fenólicos, polifenoles y flavonoides actúan como agentes reductores que evitan la reacción oxidante atrapando las ROS antes de que causen daño. La mayoría de los compuestos antioxidantes provienen de fuentes naturales como son los granos, frutas y vegetales; mientras que algunos también son sintetizados artificialmente como las vitaminas $\mathrm{C}, \mathrm{E}$ y carotenos.

Los compuestos antioxidantes (AOx) pueden ser solubles en agua, en lípidos, pueden también ser insolubles o estar unidos a las paredes celulares, por lo tanto no necesariamente disponibles para reaccionar. Por estas razones se espera que la reacción con los radicales libres se realice con mecanismos diferentes y con cinética distinta. Dado este hecho, la eficiencia en la extracción de la especie donadora del átomo de hidrógeno es un factor importante en la evaluación de la capacidad antioxidante (CAox) [11]. 
Se ha desarrollado una amplia variedad de métodos para evaluar la CAox de los compuestos y los alimentos que los contienen, estos métodos dependen de la especificidad del radical libre usado como reactivo y están limitados por la solubilidad de los compuestos en el solvente elegido. En años recientes ensayos como el ORAC y quimioluminiscencia han sido muy usados para establecer la CAox en frutos, vegetales y fluidos biológicos. El método ORAC (Oxigen Radical Absorbance Capacity) mide la pérdida de fluorescencia cuando la proteína $\beta$-ficoeritrina es oxidada [12].

La CAox de los compuestos fenólicos también puede ser estimada monitoreando la absorbancia de radicales cromógenos usando un espectrofotómetro. Se han empleado diferentes compuestos sintéticos tales como el ABTS y el DPPH, los cuales pueden reaccionar directamente con AOx. Las condiciones experimentales varían de un método a otro $(\mathrm{pH}$, solventes, longitud de onda) lo que ha conducido a diversos resultados. Estos radicales sintéticos son muy útiles para evaluar y comparar la habilidad de los compuestos fenólicos como donadores de átomos de hidrógeno y captores de radicales libres.

FRAP (Ferric reducing antioxidant power), ABTS, DPPH y ORAC son los métodos más comunes para determinar la capacidad antioxidante in vitro. Cada uno de estos métodos presenta ventajas y desventajas. En el ensayo FRAP se mide la capacidad de una muestra para reducir metales mientras que en los métodos ABTS, DPPH y ORAC se mide la capacidad de los compuestos antioxidantes para capturar radicales libres.

En cuanto a los mecanismos de reacción, también existen diferencias entre los métodos de análisis. En los métodos FRAP, ABTS y DPPH ocurre una reacción con transferencia electronica denominada SET (single electron transfer) mientras que el método ORAC implican una reacción denominada HAT (Hydrogen Atom 
Tranfer). Anteriormente se creía que en el método del DPPH se combinaban ambos mecanismos [17-19, 36].

El método usado en el desarrollo de esta investigación se basa en las propiedades cromáticas del DPPH; esta molécula es un radical libre estable el cual no forma dímeros como sucede con otros radicales libres. El electrón desapareado da un máximo de absorción a $514 \mathrm{~nm}$ y es color morado. Cuando una solución de $\mathrm{DPPH} \cdot$ se mezcla con una sustancia que puede donar un átomo de hidrógeno, entonces aparece la forma reducida DPPH-H provocando un cambio en el color de morado a amarillo. La decoloración resultante es estequiométrica con respecto al número de electrones capturados. Este método no es específico a un antioxidante en particular por lo tanto aplica para evaluar una capacidad antioxidante total. Es importante mencionar que los resultados obtenidos presentan tendencias similares al reportado usando ORAC u otros métodos [37$38]$.

$$
\mathrm{DPPH} \bullet+\mathrm{A}-\mathrm{H} \rightarrow \mathrm{DPPH}-\mathrm{H}+\mathrm{A} \bullet
$$

La especie A- es un nuevo radical libre menos reactivo generado en este primer paso. En la reacción anterior se aprecia la reducción de una molécula de DPPH• por una molécula del antioxidante $\mathrm{A}-\mathrm{H}$, es decir una estequiometría 1:1. El radical A puede formar dímeros en una reacción regulada estequiométricamente por el número de moléculas de DPPH• reducidas.

$$
\mathrm{A}^{\cdot}+\mathrm{A} \cdot \rightarrow \mathrm{A}-\mathrm{A}
$$

En otros casos la especie donadora de hidrógeno cuenta con varios sitios de abstracción. Una molécula de ácido ascórbico puede reaccionar con dos radicales 
$\mathrm{R} \cdot$ dando una estequiometría $2: 1$. El DPPH• puede también combinarse con otros radicales $R \cdot$ de acuerdo a la siguiente reacción [35].

$$
\mathrm{DPPH} \cdot+\mathrm{R} \cdot \rightarrow \mathrm{DPPH}-\mathrm{R}
$$

Los métodos electroquímicos también han sido empleados para determinar la CAox y se basan en la ecuación 1, sin embargo, la detección de la concentración residual del radical se realiza amperométricamente [37].

Aunque existen varias formas de expresar los resultados, una de las más comunes es el índice TEAC (capacidad antioxidante en equivalentes de trolox) en el cual la CAox de una sustancia dada es comparada a la del compuesto estándar trolox (un análogo hidrosoluble de la vitamina E).

Cuando se utiliza espectrofomometría UV-Vis el TEAC se obtiene a partir de la absorbancia

$$
T E A C=\frac{\left(A_{o}-A_{\text {muestra }}\right)}{\left(A_{o}-A_{\text {trolox }}\right)}
$$

En la ecuación (4) $A_{o}$ representa la absorbancia inicial del DPPH en solución; $\mathrm{A}_{\text {muestra }}$ es la absorbancia del DPPH después de la reacción con el antioxidante de prueba y $\mathrm{A}_{\text {trolox }}$ es la absorbancia del DPPH después de la reacción con el trolox.

Otra forma de expresar la capacidad de los compuestos para donar átomos $\mathrm{H}$, es mediante el parámetro conocido como "concentración efectiva media" $\mathrm{EC}_{50}$ definido como la concentración del antioxidante necesaria para reducir el 50\% de la concentración inicial de $\mathrm{DPPH} \cdot$. El tiempo necesario para completar la reacción en la concentración $\mathrm{EC}_{50}$ se denomina $\mathrm{TEC}_{50}$ el cual depende de la 
velocidad de la reacción frente al radical libre. La eficiencia antioxidante (EAox) es un parámetro que combina ambos factores [4-5].

$$
E A o x=\frac{E C_{50}}{T E C_{50}}
$$

En esta investigación se aplican los métodos espectrofotométrico y amperométrico del DPPH para evaluar la CAox de extractos de uvas y de algunos compuestos fenólicos comúnmente presentes en vegetales. Los métodos son fáciles de desarrollar y altamente reproducibles además tiene la ventaja de emplear un radical libre estable y comercialmente disponible [39].

\subsection{Experimental}

\subsubsection{Determinación de la CAox por el método espectrofotométrico del DPPH.}

\subsubsection{Reactivos y soluciones}

DPPH (394.32 $\mathrm{g} \mathrm{mol}^{-1}$ ), Ácido (S)-(-)-6-hidroxi-2,5,7,8-tetrametilcroman-2carboxílico o trolox $97 \%$ (250.32 $\left.\mathrm{g} \mathrm{mol}^{-1}\right)$ y mangiferina fueron obtenidos de sigma-aldrich. Quercetina, curcumina, catequina, ácido tánico y xantona fueron obtenidos de Merck. Etanol y metanol fueron obtenidos de JT Baker.

DPPH $10^{-3} \mathrm{M}$ en metanol, DPPH $10^{-3} \mathrm{M}$ en etanol, trolox $10^{-3}, 10^{-4}$ y $10^{-5} \mathrm{M}$ en metanol. Quercetina, curcumina, catequina, ácido tánico y xantona $10^{-3} \mathrm{M}$ en metanol. Para disminuir la oxidación de los compuestos fenolicos en condiciones de temperatura ambiente e iluminación, todas las soluciones fueron protegidas de la luz y preparadas el mismo día de su uso manteniéndolas en hielo durante las mediciones. 


\subsubsection{Instrumentación}

Las mediciones se realizan utilizando un espectrofotómetro UV-vis Lambda 950 de Perkin-Elmer y celdas desechables de $1.5 \mathrm{ml}$.

\subsubsection{Procedimiento Experimental}

La habilidad para donar electrones o átomos de hidrógeno de los compuestos fenólicos sobre el DPPH en solución es estimada por reacción directa. La curva de calibración se obtiene graficando distintas concentraciones de trolox en función de la absorbancia del DPPH residual usando metanol como blanco. Todas las celdas contienen $100 \mu \mathrm{L}$ de DPPH $10^{-3} \mathrm{M}$ en las cuales se agregan distintos volúmenes de la solución $10^{-4}$ ó $10^{-5} \mathrm{M}$ de trolox ajustando con metanol a un volumen final de $1.0 \mathrm{~mL}$ de tal forma que la concentración final del trolox se incrementa desde 1.0 hasta $50 \mu \mathrm{M}$ (Ver tabla 2.1). La absorbancia de la mezcla trolox-DPPH se registra en $514 \mathrm{~nm}$ a 120 segundos de iniciada la reacción. Cada una de las celdas de reacción se realiza por duplicado.

Tabla 2.1. Volúmenes de reacción para el sistema trolox-DPPH en metanol.

\begin{tabular}{ccccccc}
\hline Celda & $\mathrm{V}_{\text {DPPH }}$ & $\mathrm{V}_{\text {CH3OH }}$ & $\mathrm{V}_{\text {trolox }}$ & $\mathrm{V}_{\text {trolox }}$ & [trolox $]_{\text {final }}$ & \\
& $10^{-3} \mathrm{M} / \mu \mathrm{L}$ & $/ \mu \mathrm{L}$ & $10^{-5} \mathrm{M} / \mu \mathrm{L}$ & $10^{-4} \mathrm{M} / \mu \mathrm{L}$ & $/ \mu \mathrm{M}$ & $\mathrm{A}^{514}$ \\
\hline 1 & 100 & 900 & 0 & 0 & 0 \\
2 & 100 & 800 & 100 & 0 & 1 \\
3 & 100 & 400 & 500 & 0 & 5 \\
4 & 100 & 800 & 0 & 100 & 10 \\
5 & 100 & 700 & 0 & 200 & 20 \\
6 & 100 & 500 & 0 & 400 & 40 \\
7 & 100 & 400 & 0 & 500 & 50 \\
\hline
\end{tabular}




\subsubsection{Determinación de la CAox por el método electroquímico del DPPH.}

\subsubsection{Reactivos y soluciones}

$\mathrm{DPPH}$, trolox y $\mathrm{KCl}$ fueron adquiridos de Sigma-Aldrich. Etanol y metanol fueron obtenidos de JT Baker. DPPH $10^{-3} \mathrm{M}$ en metanol, trolox $10^{-3} \mathrm{M}$ en metanol, $\mathrm{KCl} 0.03 \mathrm{M}$ en metanol. Todas las soluciones son preparadas el mismo día de su uso y protegidas del contacto con la luz.

\subsubsection{Instrumentación y electrodos}

La utilización de la voltamperometría de pulso diferencial (VPD) para la determinación de la actividad antioxidante se basa en la oxidación electroquímica del DPPH sobre el electrodo de pasta de carbono (EPC). La VPD se realiza utilizando un potenciostato BAS $100 \mathrm{~W}$ con una celda de tres electrodos. Se utiliza $\mathrm{Ag} / \mathrm{AgCl}$ como electrodo de referencia (ER) y un alambre de platino es el electrodo auxiliar (EA).

\subsubsection{Procedimiento experimental}

Inicialmente se agregan $4 \mathrm{~mL}$ del electrolito soporte en la celda y se obtiene un voltamperograma con el fin de revisar que no existe alguna respuesta; después se adiciona $1.0 \mathrm{~mL}$ de DPPH $10^{-3} \mathrm{M}$ y se obtiene un segundo voltamperograma. A continuación se realizan adiciones sucesivas de la solución patrón de $10^{-3} \mathrm{M}$ de trolox en intervalos de 2 minutos, obteniendo voltamperogramas en cada adición y se registra la diferencia $\Delta \mathrm{I}_{\mathrm{p}}$ en la intensidad del pico del DPPH antes y después de la adición del trolox; esta diferencia es asociada al efecto del antioxidante sobre la concentración inicial del radical libre. La curva de calibración se obtiene representando $\Delta \mathrm{I}_{\mathrm{p}}$ como función de la concentración del trolox en la celda. Para 
establecer la curva de calibración se realizaron adiciones sucesivas de $25 \mu \mathrm{L}$ de trolox $10^{-3} \mathrm{M}$ a la celda que inicialmente contenía $1.0 \mathrm{~mL}$ de DPPH $10^{-3} \mathrm{M}$ y 4 $\mathrm{mL}$ del electrolito soporte $\mathrm{KCl} 10^{-3} \mathrm{M}$ en metanol. En estas condiciones la concentración inicial del DPPH en la celda es $200 \mu \mathrm{M}$.

\subsubsection{Contenido de fenoles totales: Método Folin-Ciocalteu}

El método de Folin-Ciocalteu se basa en la transferencia de electrones en medio alcalino de compuestos fenólicos y otras especies reductoras al molibdeno formando complejos color azul que pueden detectarse espectrofotométricamente a 750-766 nm. Es importante remarcar que los complejos azules formados son independientes de la estructura de los compuestos fenólicos, además el reactivo de Folin-Ciocalteu (FCR) puede ser reducido por compuestos no fenólicos como la vitamina $\mathrm{C}$ o $\beta$-caroteno. La concentración de fenoles totales se establece por comparación con un compuesto estándar (comúnmente ácido caféico o ácido gálico) y los resultados se expresan como equivalentes del estándar utilizado.

\subsubsection{Reactivos y soluciones}

Reactivo de Folin-Ciocalteu 2N (sigma). FCR 1:10 en agua desionizada, $\mathrm{Na}_{2} \mathrm{CO}_{3}$ al $7.8 \%$ en agua desionizada, ácido caféico $1 \mathrm{mg} \mathrm{mL}^{-1}$ en etanol.

\subsubsection{Instrumentación}

Las mediciones se realizan por duplicado en un equipo Perkin Elmer Lambda 950 UV/Visible spectrophotometer. La absorbancia es medida en $766 \mathrm{~nm}$ usando como blanco una mezcla que contiene $500 \mu \mathrm{l}$ de la solución acuosa de FCR 1:10, $400 \mu \mathrm{lde} \mathrm{Na}_{2} \mathrm{CO}_{3}$ al $7.8 \%$ y $100 \mu \mathrm{l}$ de etanol. 


\subsubsection{Procedimiento experimental}

La curva de calibración se construye graficando diferentes concentraciones del estándar en función de su absorbancia correspondiente. Alícuotas de $100 \mu \mathrm{L}$ de ácido caféico 3.0, 5.0, 7.5 y $10 \mu \mathrm{M}$ se colocan en celdas de plástico de $1.5 \mathrm{~mL}$, se agregan $500 \mu \mathrm{L}$ de la solución acuosa de FCR 1:10 y transcurridos 7 minutos se agregan $400 \mu \mathrm{L}$ de la solución de $\mathrm{Na}_{2} \mathrm{CO}_{3}$ al $7.8 \%$. Después de agitar perfectamente las celdas se mantienen en la obscuridad durante una hora y se obtiene la absorbancia de cada tubo a $766 \mathrm{~nm}$.

El análisis de las muestras reales de extractos de uvas e infusiones herbales se realiza siguiendo el mismo procedimiento pero sustituyendo la alícuota del compuesto estándar (ácido caféico) por el mismo volumen de la muestra a analizar.

\subsection{Resultados}

\subsubsection{DPPH método espectrofotométrico.}

\subsubsection{Estabilidad del DPPH}

El DPPH es un radical libre químicamente estable disponible comercialmente como un polvo fino que es soluble en alcohol etílico o metílico. La figura 2.1 muestra el espectro UV-vis correspondiente a DPPH 0.01, 0.05 y $0.10 \mathrm{mM}$ en metanol. Como puede observarse en la figura el espectro de absorción muestra tres máximos de absorción en 206, 331 y 514 nm respectivamente y un hombro en $237 \mathrm{~nm}$. 


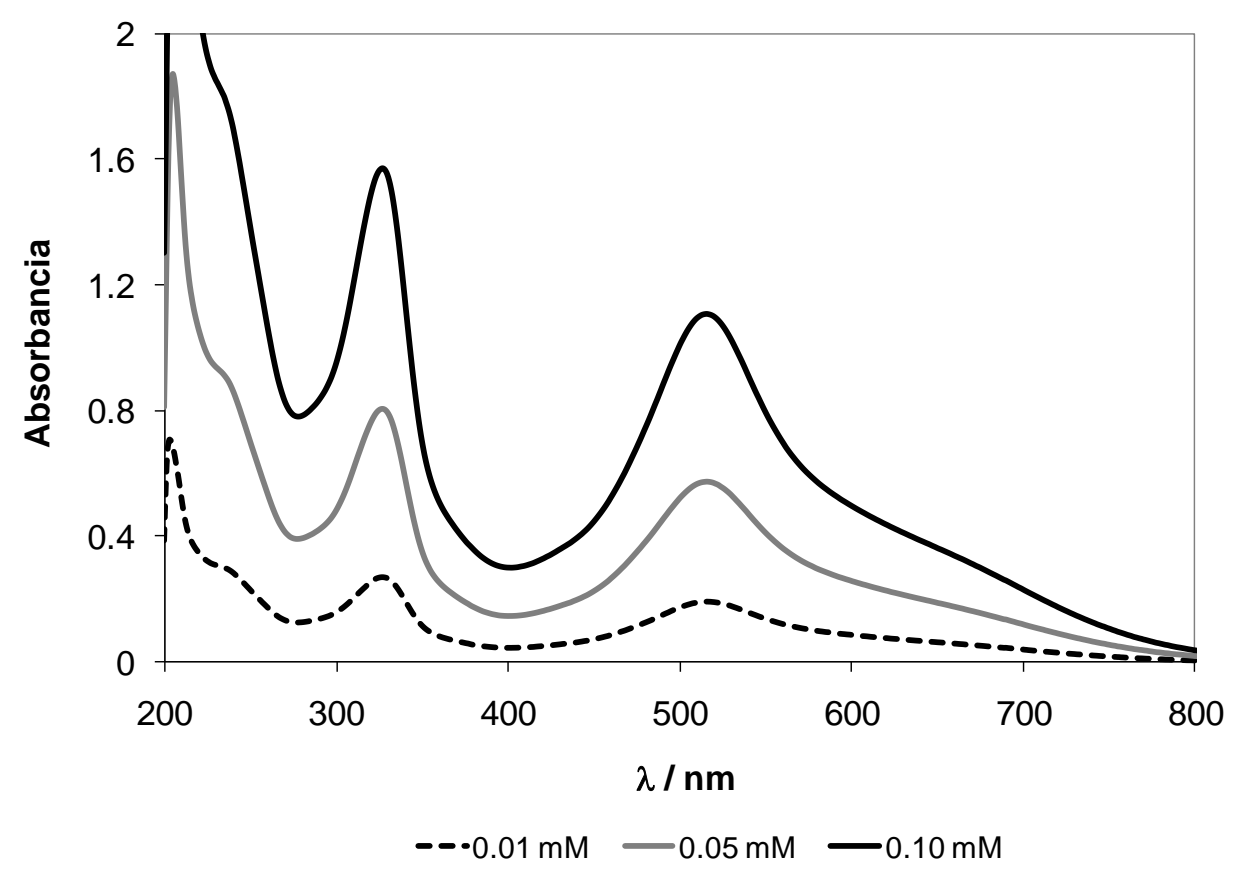

Fig. 2.1 Espectro UV-vis de DPPH en metanol. Los máximos de absorción se dan en 331 y $514 \mathrm{~nm}$.

A pesar de que el máximo de absorción de $331 \mathrm{~nm}$ sigue la ley de Lambert y Beer con un coeficiente de absortvidad molar de $14220 \mathrm{M}^{-1} \mathrm{~cm}^{-1}$ mayor que el que se obtiene en $514 \mathrm{~nm}$, la determinación de la actividad antioxidante se realiza midiendo el descenso en esta banda de absorción ya que es la característica del color morado.

La figura 2.2 muestra la dependencia de la concentración del DPPH en metanol y su absorbancia en $514 \mathrm{~nm}$. La regresión lineal obtenida es:

$$
\mathrm{A}_{514}=10,050 \mathrm{M}^{-1} \mathrm{~cm}^{-1} *[\mathrm{DPPH}]_{\mathrm{T}}+0.079 \text { con } \mathrm{R}^{2}=0.999
$$

Este resultado nos indica que la mayor concentración que se utiliza en el estudio cumple la ley de Lambert y Beer y que la disminución de la absorbancia por la reacción del DPPH con los antioxidantes puede ser monitoreada hasta el valor de 0.2 . 


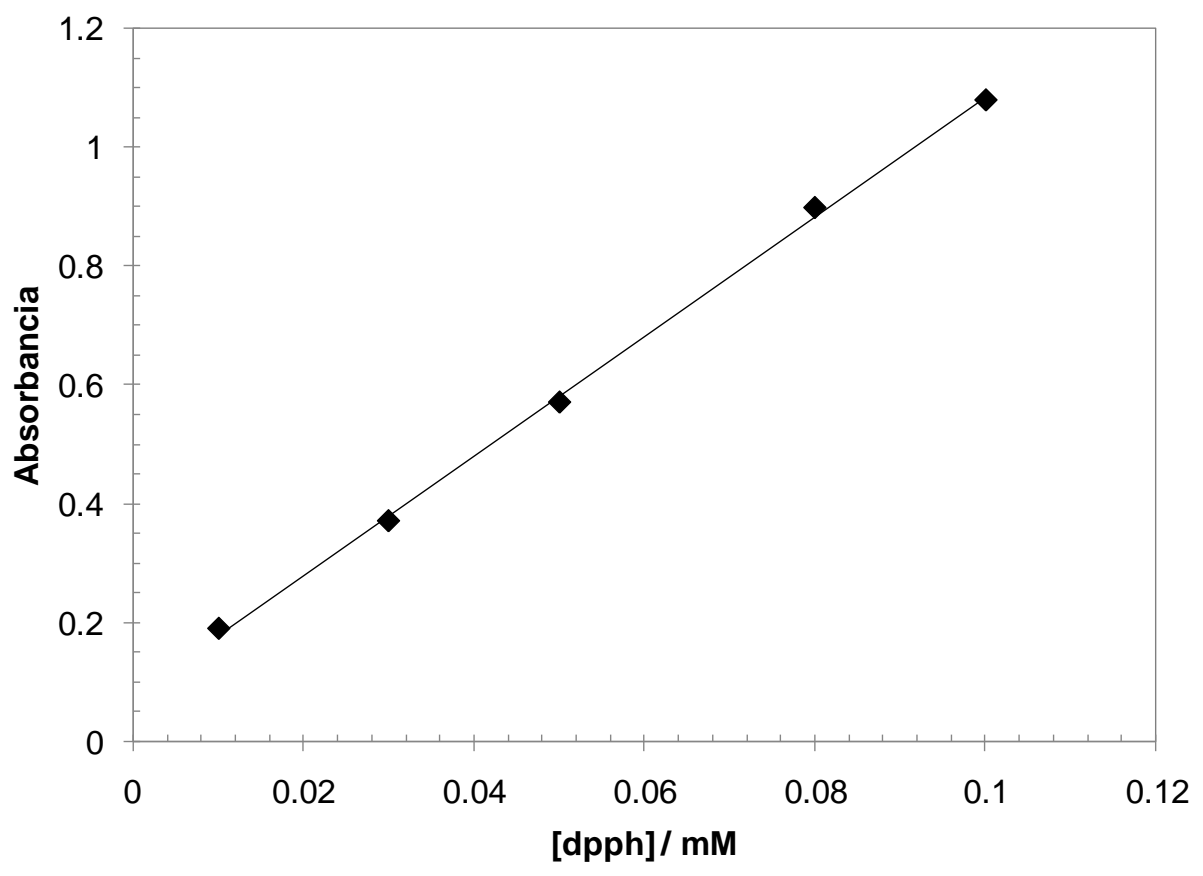

Fig. 2.2 Dependencia de la absorbancia con la concentración de DPPH en metanol en 514nm

La figura 2.3 muestra el descenso porcentual de la absorbancia de DPPH $100 \mu \mathrm{M}$ en metanol como una función del tiempo. Como se puede apreciar, en el transcurso de una hora la absorbancia del radical en solución disminuye alrededor del $1 \%$ sólo por la exposición a la luz. Considerando que al realizar las mediciones del sistema DPPH-antioxidante, los valores de absorbancia se obtienen a los dos minutos de iniciada la reacción (este tiempo es usado por la mayoría de los investigadores pues en el intervalo de concentraciones elegido, la gran mayoría de los compuestos ya ha completado la reacción), la disminución sería del $0.2 \%$, por lo se considera que no hay efecto significativo de la luz en la determinación. 


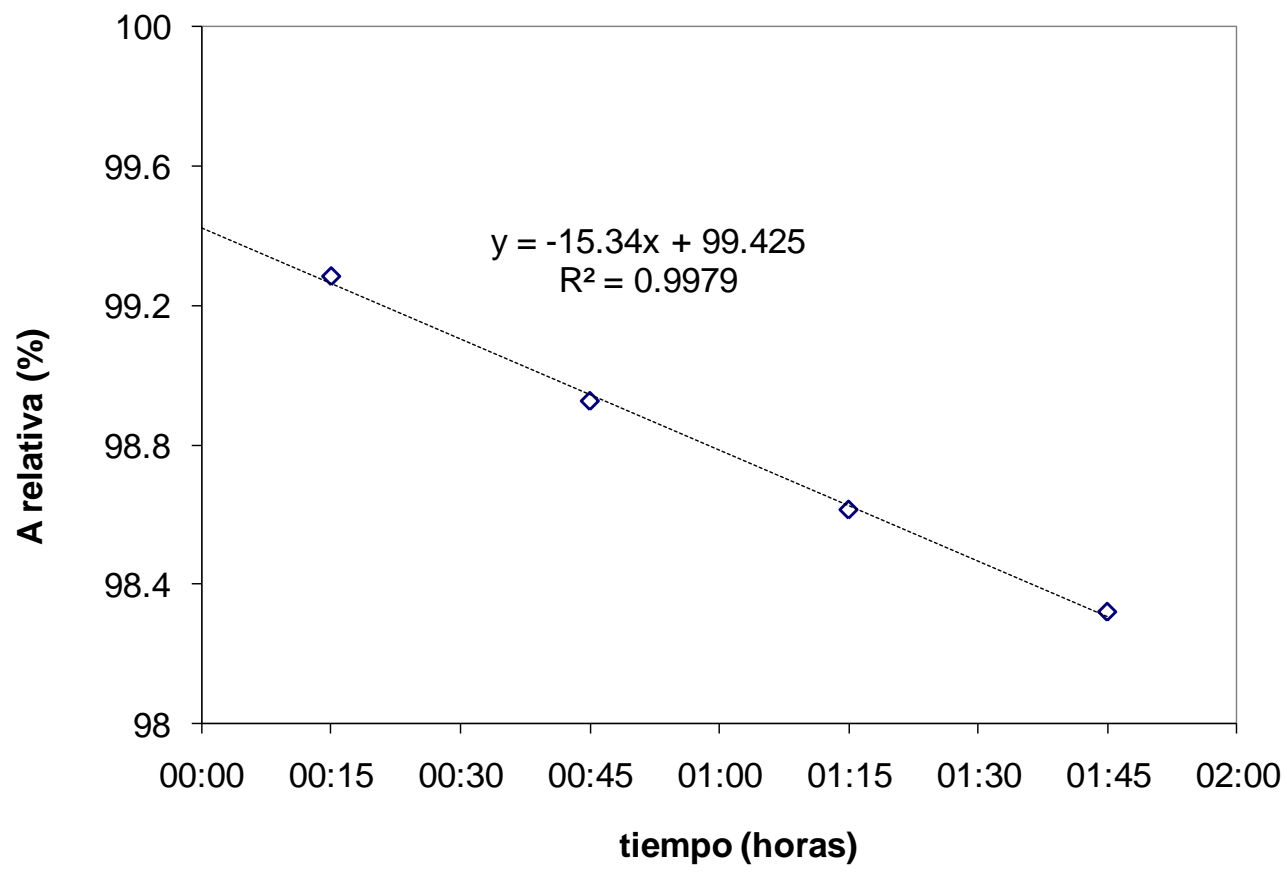

Fig. 2.3. Disminución de la absorbancia de DPPH $100 \mu \mathrm{M}$ en metanol por exposición a iluminación natural de laboratorio.

\subsubsection{Efecto del solvente sobre el DPPH.}

Considerando que en la literatura sólo se realiza la determinación utilizando DPPH en metanol, se analiza el efecto de cambio de solvente a etanol, ya que el metanol es más tóxico que el etanol.

La figura 2.4 muestra las curvas de calibración de los sistemas trolox-DPPHetanol y trolox-DPPH-metanol en un intervalo de concentración de 0 a $40 \mu \mathrm{M}$ de trolox. Las ecuaciones obtenidas en la regresión lineal son:

$$
\begin{aligned}
& \mathrm{A}^{514}=\left(-0.0190 \pm 2.0 \times 10^{-4}\right) \mu \mathrm{M}^{-1}[\text { trolox }]+\left(1.089 \pm 7 \times 10^{-3}\right) \text { para etanol } \\
& \mathrm{A}^{514}=\left(-0.0187 \pm 2.0 \times 10^{-4}\right) \mu \mathrm{M}^{-1}[\text { trolox }]+\left(1.107 \pm 6 \times 10^{-3}\right) \text { para metanol }
\end{aligned}
$$

con $\mathrm{R}^{2}=0.999$ en ambos casos. Considerando estos resultados se puede aseverar que las pendientes en ambos medios son estadísticamente iguales. 


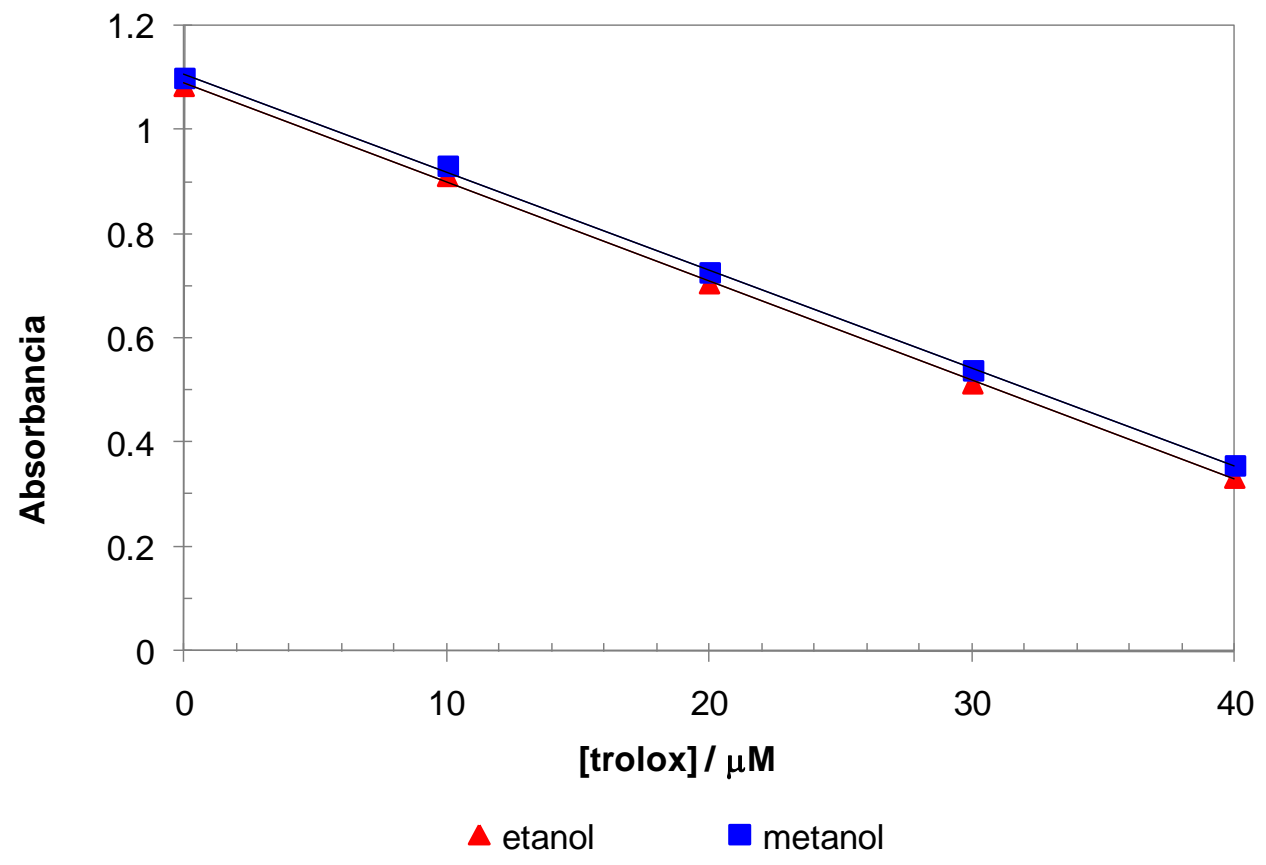

Fig. 2.4. Curvas de calibración para el sistema trolox- DPPH en metanol y en etanol utilizando una solución de DPPH $0.1 \mathrm{mM}$.

Con base en el resultado obtenido se considera que realizar las mediciones en este medio sería menos dañino para la salud y para el medio ambiente. Por lo que en los subsiguientes experimentos se utiliza etanol para las determinaciones.

\subsubsection{Capacidad Antioxidante de compuestos orgánicos}

La actividad antioxidante para seis compuestos orgánicos puros se determina con las mismas condiciones experimentales de la curva de calibración trolox-DPPH. La Tabla 2.2 muestra los resultados expresados en TEAC relativo obtenidos mediante la ecuación (4) de la sección (2.1). Como se puede apreciar, la xantona no registra actividad antioxidante ante el $\mathrm{DPPH} \cdot$ mientras que el ácido tánico resulta ser un excelente antioxidante lo cual puede atribuirse a la estructura de su molécula. Como se ha mencionado los antioxidantes fenólicos capturan e inactivan radicales libres. Esta propiedad depende principalmente de la 
estructura y propiedades de sus moléculas tales como la energía de disociación del enlace O-H, la deslocalización electrónica en sus estructuras resonantes y el impedimento estérico derivado de los grupos sustituyentes unidos al anillo aromático. 
Tabla 2.2 TEAC de algunos compuestos fenólicos y sus estructuras.

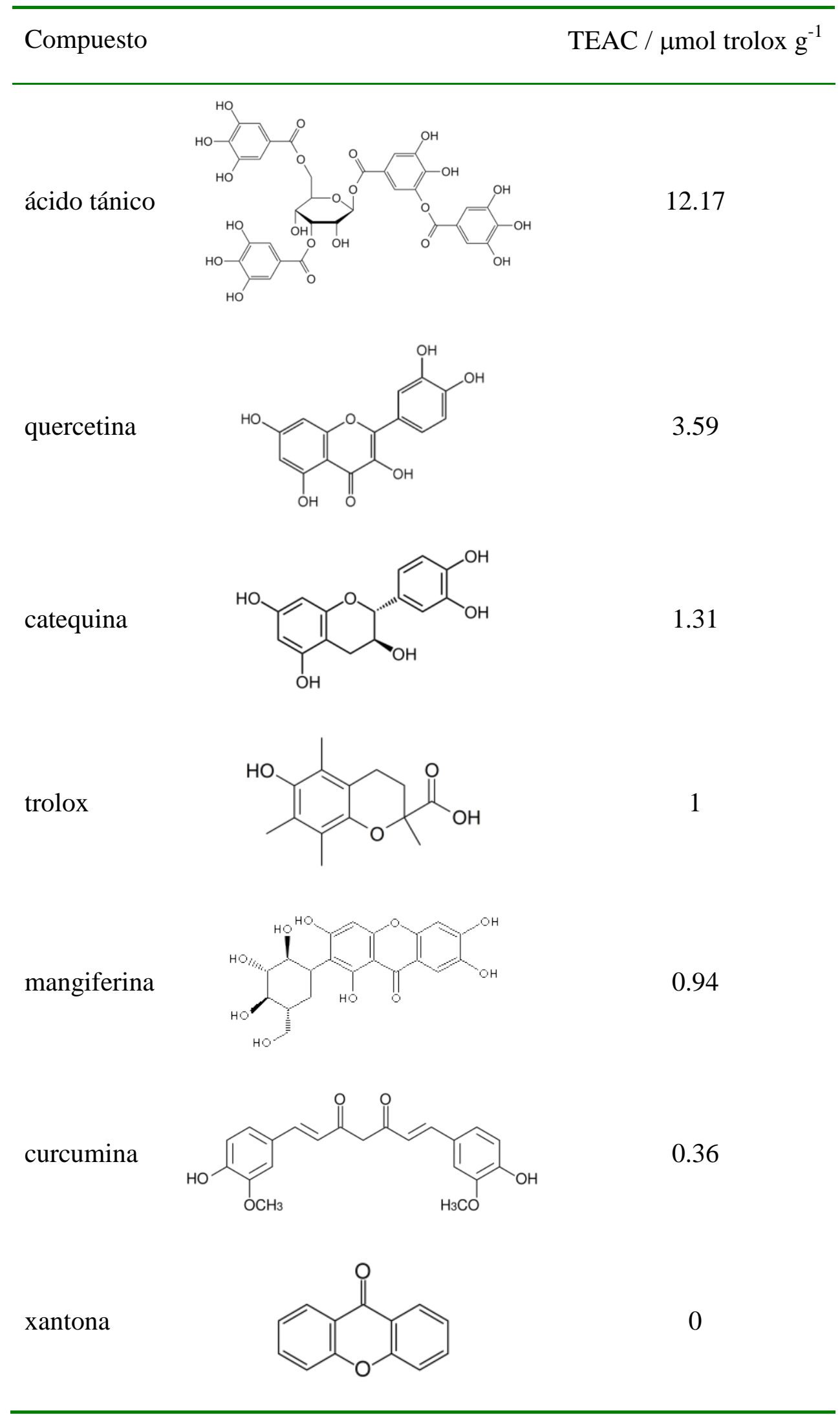


Analizando los resultados de la tabla 2.2, es un hecho que los compuestos estudiados presentan actividad antioxidante pues en su estructura existen grupos $\mathrm{OH}$ unidos a anillos aromáticos. Para aquellos con grupos $\mathrm{OH}$ unidos al anillo B, se observa una mayor CAox. La quercetina presenta también un oxígeno en el carbono 4 del anillo $\mathrm{C}$ y por los resultados obtenidos parece que este tipo de estructura lo favorece. Por otro lado la mangiferina presenta un valor menor de CAox en comparación con la catequina, lo cual puede atribuirse a que el grupo catecol está unido a dos carbonos del grupo C. En el caso de la curcumina, como sólo existe un $\mathrm{OH}$ fenólico presenta menor capacidad antioxidante. Por lo anterior, se puede inferir que la capacidad antioxidante se debe mayoritariamente a los hidróxidos fenólicos pero también a que se encuentren en una estructura menos rígida y con la posibilidad de formar puentes de hidrógeno.

\subsubsection{Determinación de $\mathrm{EC}_{50}$ en compuestos estándar}

Debido a que la "concentración efectiva media" $\mathrm{EC}_{50}$ es útil en la interpretación de los resultados del método del DPPH, pues muestra la reactividad ante el radical en solución, se determinó este parámetro para ácido caféico, hidroquinona, catecol, trolox y ácido gálico ya que todos estos compuestos son utilizados en las diferentes técnicas como referencia en las determinaciones de actividad antioxidante. $\mathrm{La} \mathrm{EC}_{50}$ se obtiene interpolando sobre la curva de calibración del estándar de prueba.

La figura 2.5 muestra la disminución de la absorbancia debido a la reacción del DPPH en presencia de hidroquinona. La línea (a) corresponde al cambio de la absorbancia en $\lambda=514 \mathrm{~nm}$ de una solución de DPPH $100 \mu \mathrm{M}$, esta concentración se usa en todas las celdas y se hace reaccionar con diferentes concentraciones de hidroquinona. Las curvas de calibración para otros compuestos se obtienen siguiendo la metodología establecida para el trolox en la sección 2.2.1.3. 
Como se puede observar en la figura 2.5, conforme aumenta la concentración adicionada de hidroquinona en el sistema, hay una pendiente mayor en la disminución de la absorbancia en los primeros minutos, en la mayoría de los casos al alcanzar los dos minutos se tiende a un estado estacionario, sin embargo para las concentraciones mayores a $15 \mu \mathrm{M}$, en dos minutos todavía el valor de la absorbancia no permanece constante, esto demuestra que para la determinación de TEAC a los dos minutos es importante considerar el trabajar con concentraciones bajas para hacer las determinaciones adecuadamente.

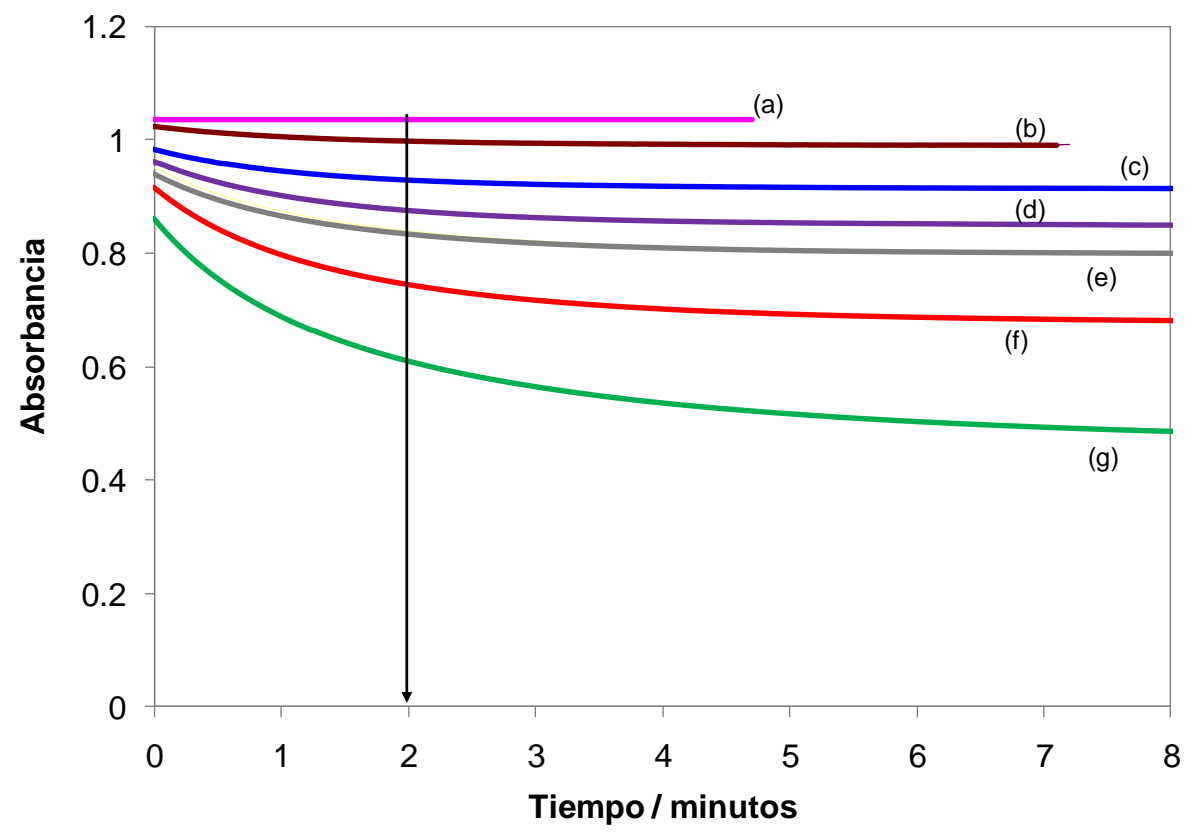

Fig. 2.5 Disminución de la absorbancia de (a) DPPH $100 \mu \mathrm{M}$ (b) ante hidroquinona $2.5 \mu \mathrm{M}$, (c) $5 \mu \mathrm{M}$, (d) $7.5 \mu \mathrm{M}$, (e) $10 \mu \mathrm{M}$, (f) $15 \mu \mathrm{M}$ y (g) $25 \mu \mathrm{M}$ en etanol

La concentración $\mathrm{EC}_{50}$ se calcula interpolando el $50 \%$ de disminución de la absorbancia $\Delta \mathrm{A}$ sobre la curva de calibración correspondiente (fig. 2.6). 

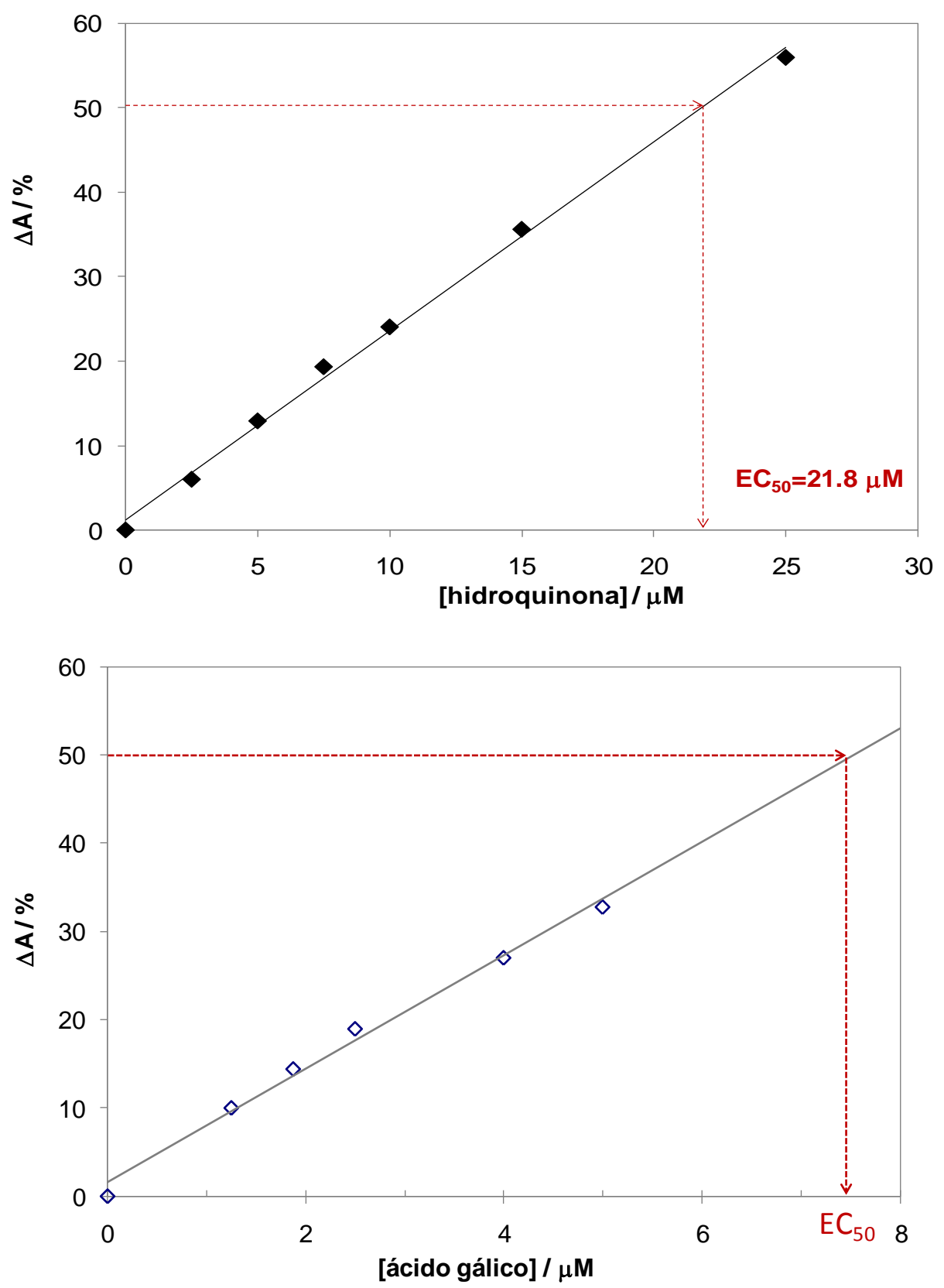

Fig. 2.6 Curva de calibración del sistema a)DPPH-hidroquinona b) DPPH-ácido gálico. La relación entre la absorbancia y la concentración se utiliza para determinar el $\mathrm{EC}_{50}$.

La tabla 2.3 muestra los valores de $\mathrm{EC}_{50}$ obtenidos para hidroquinona y ácido gálico, siendo este último el que presenta el valor menor, es importante la interpretación correcta de este número pues según la definición de $\mathrm{EC}_{50}$, este 
compuesto es el que reacciona con el DPPH de manera más eficiente pues en una concentración de solamente $7.49 \mu \mathrm{M}$ logra disminuir en $50 \%$ la absorbancia inicial del DPPH $100 \mu \mathrm{M}$. De la misma manera se puede observar que la reactividad de las moléculas aumenta conforme su estructura contiene mayor número de $\mathrm{OH}$ fenólicos y existe menor rigidez.

Tabla 2.3 $\mathrm{EC}_{50}$ de algunos compuestos fenólicos y sus estructuras.

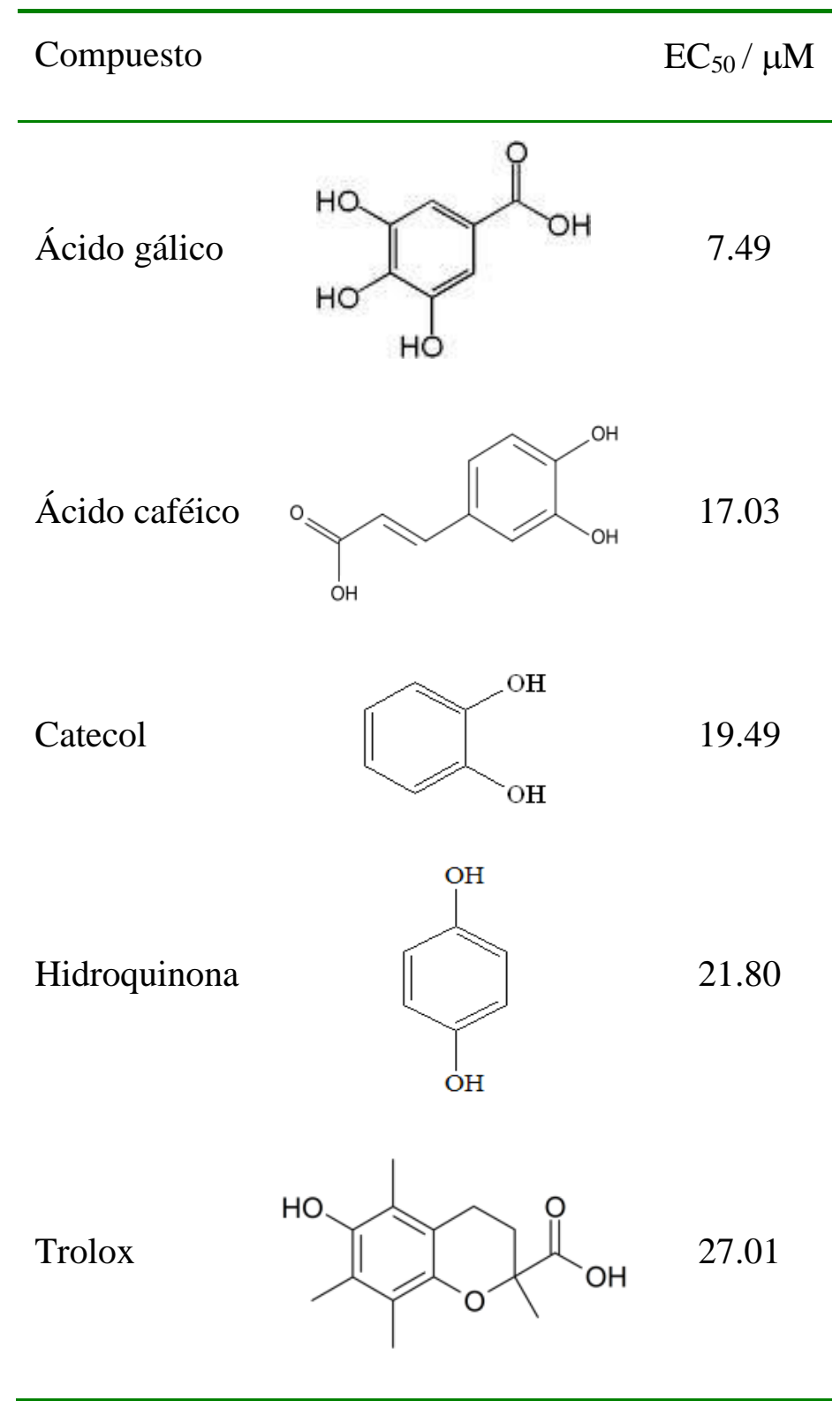


El método para la determinación de capacidad antioxidante evaluado espectrofotométricamente nos demuestra que es importante que para tener esta actividad cualquier molécula, debe contener en su estructura $\mathrm{OH}$ fenólicos, que pueda tener cierta flexibilidad y formar puentes de hidrógeno. Considerando que el DPPH también presenta características de oxidación reducción, se decidió analizar este comportamiento utilizando métodos electroquímicos.

\subsubsection{DPPH método electroquímico}

El método electroquímico utilizado para el estudio del DPPH se basa en la oxidación electroquímica del radical sobre el electrodo de pasta de carbono (EPC). Los parámetros usados en la voltamperometría diferencial de pulso (VPD) fueron seleccionados en ensayos previos. Se observó que aplicando las siguientes condiciones la intensidad y forma en los picos es óptima: $E_{\text {inicial }}=0$ $\mathrm{mV}, \mathrm{E}_{\text {final }}=1000 \mathrm{mV}$, velocidad $=50 \mathrm{mV} / \mathrm{s}$, amplitud $=10 \mathrm{mV}$, duración del pulso $=50 \mathrm{mseg}$, periodo del pulso $=200 \mathrm{mseg}$, sensibilidad $=10^{-4} \mathrm{~A} / \mathrm{V}$.

La figura 2.7 muestra los voltamperogramas de diferentes concentraciones de DPPH usando $\mathrm{KCl} 0.03 \mathrm{M}$ en metanol como electrolito soporte. El barrido de potencial se realizó entre 0 y $1.0 \mathrm{~V}$ donde aparecen dos procesos de oxidación en (I) 0.22 y (II) $0.77 \mathrm{~V}$. El primero de estos procesos se utiliza para seguir la concentración del DPPH que permanece en la celda después de la adición del trolox. 


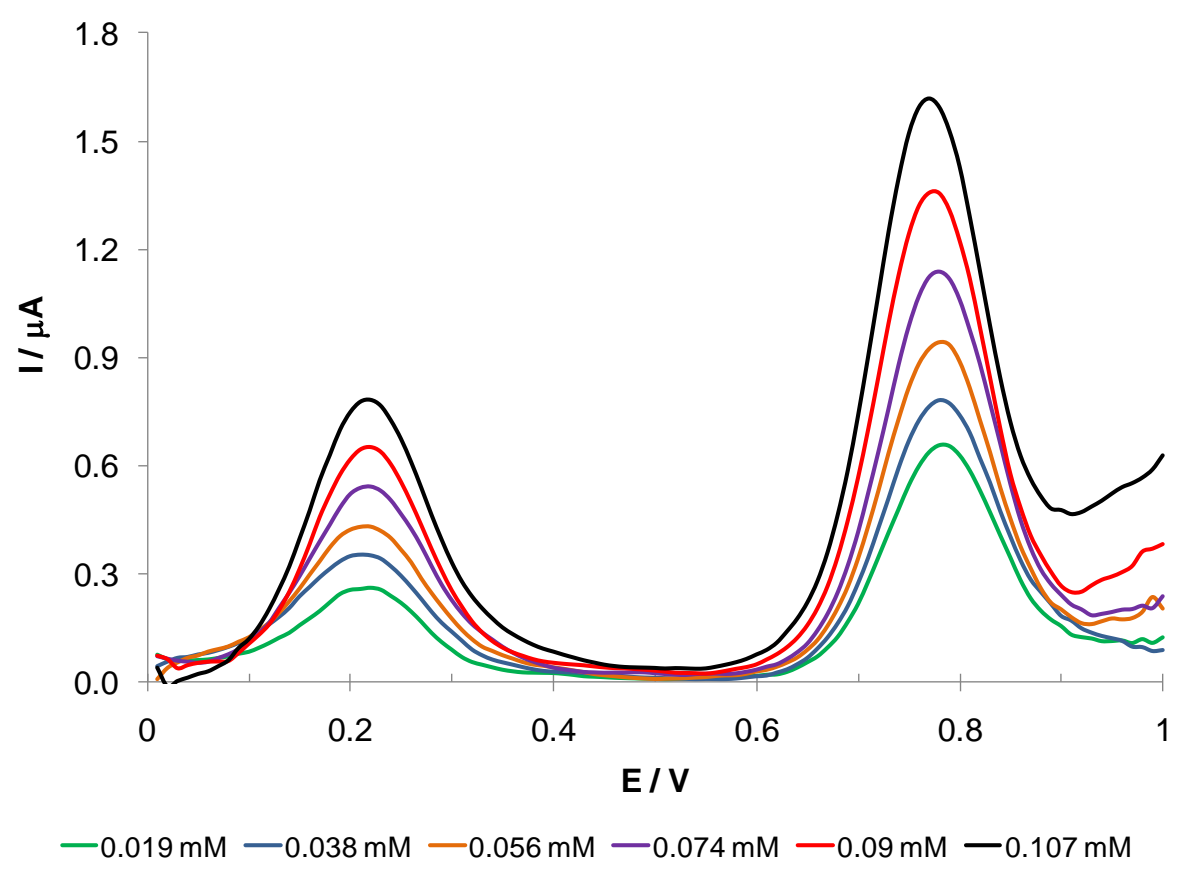

Fig. 2.7 VPD de DPPH medido a $50 \mathrm{mV}^{*} \mathrm{~s}^{-1}$ y amplitud de pulso de $10 \mathrm{mV}$ usando $\mathrm{KCl} 0.03$ $\mathrm{M}$ en metanol como electrolito soporte

Una forma de ilustrar el efecto de un compuesto antioxidante (AOx) sobre el radical libre es graficando el cambio en la intensidad de corriente de pico $\Delta \mathrm{I}_{\mathrm{p}}$ en función de la concentración del AOx en la celda.

Si $\mathrm{I}_{\mathrm{DPPH}}$.representa la corriente de pico del sistema cuando sólo el radical está presente y $\mathrm{I}_{\mathrm{AOx}}$ es la corriente de pico después de la adición del AOx entonces $\Delta \mathrm{I}_{\mathrm{p}}$ se calcula de acuerdo a la ecuación

$$
\Delta I_{\mathrm{p}}=\frac{I_{D P P H}-I_{A O x}}{I_{D P P H}}
$$

De esta forma la actividad antioxidante relativa de un compuesto " $x$ " expresada en equivalentes trolox (TEAC) está dada por la ecuación 


$$
\operatorname{TEAC}(\mathrm{x})=\frac{\Delta \mathrm{I}_{\mathrm{p}}(\mathrm{x})}{\Delta \mathrm{I}_{\mathrm{p}}(\operatorname{trolox})}
$$

La figura 2.8 muestra la relación entre la intensidad de corriente de oxidación del DPPH y la concentración de trolox en la celda. Al aumentar la concentración del trolox, la cantidad del radical que permanece en la celda baja y en consecuencia la intensidad en la corriente de oxidación es cada vez menor.

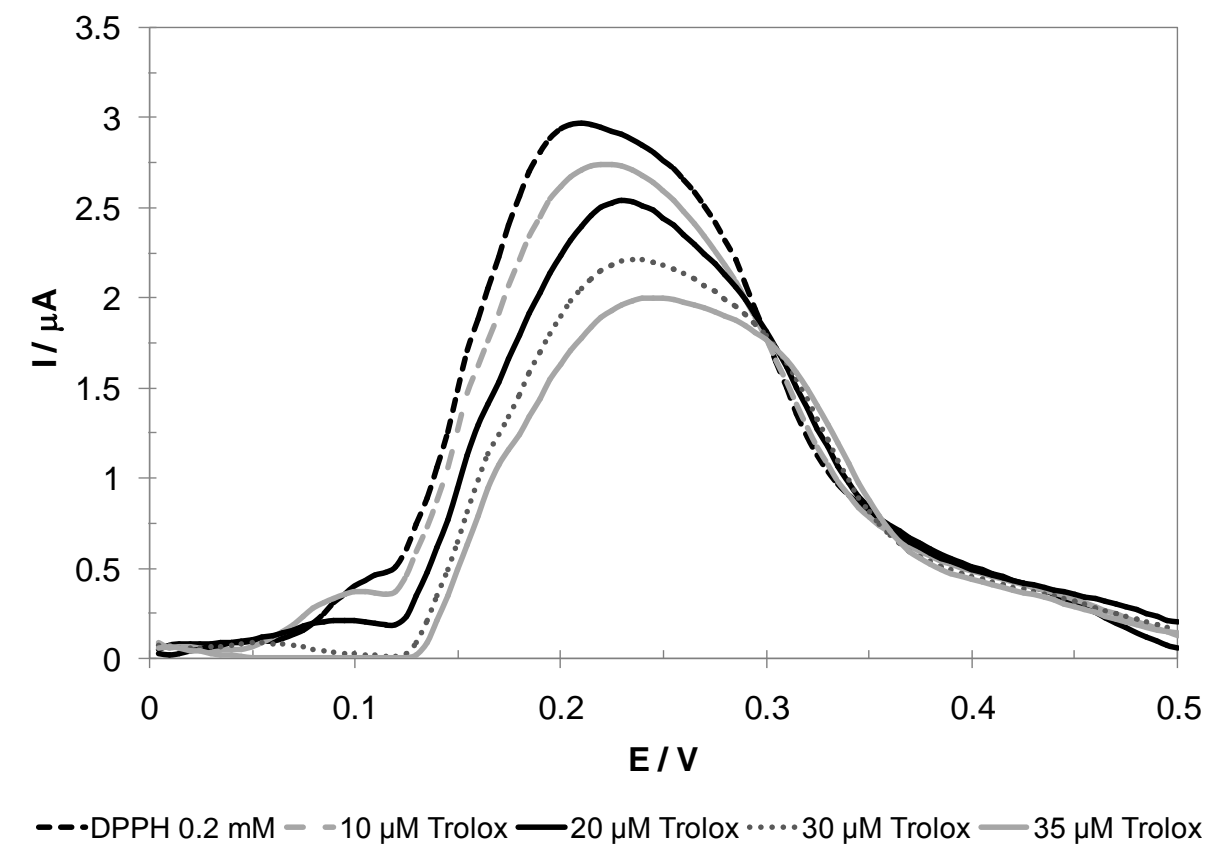

Figura 2.8. Oxidación de DPPH en $\mathrm{KCl} 0.03 \mathrm{M}$ en metanol. La $\mathrm{I}_{\mathrm{p}}$ disminuye después de las adiciones sucesivas de $50 \mu \mathrm{L}$ de trolox $1.0 \mathrm{mM}$.

Para establecer la capacidad antioxidante de compuestos polifenólicos se sigue la misma metodología. Inicialmente se determina la corriente de oxidación de DPPH $0.2 \mathrm{mM}$ disuelto en el electrolito soporte y posteriormente se realizan adiciones sucesivas de $50 \mu \mathrm{L}$ de una solución patrón $1.0 \mathrm{mM}$ del polifenol. $\mathrm{La}$ disminución en la corriente se asocia a la cantidad del radical consumido mientras que el nuevo máximo en la corriente indica la concentración residual 
del DPPH.(fig. 2.9). Tomando como referente el estándar trolox, se puede expresar la capacidad antioxidante de otros compuestos.

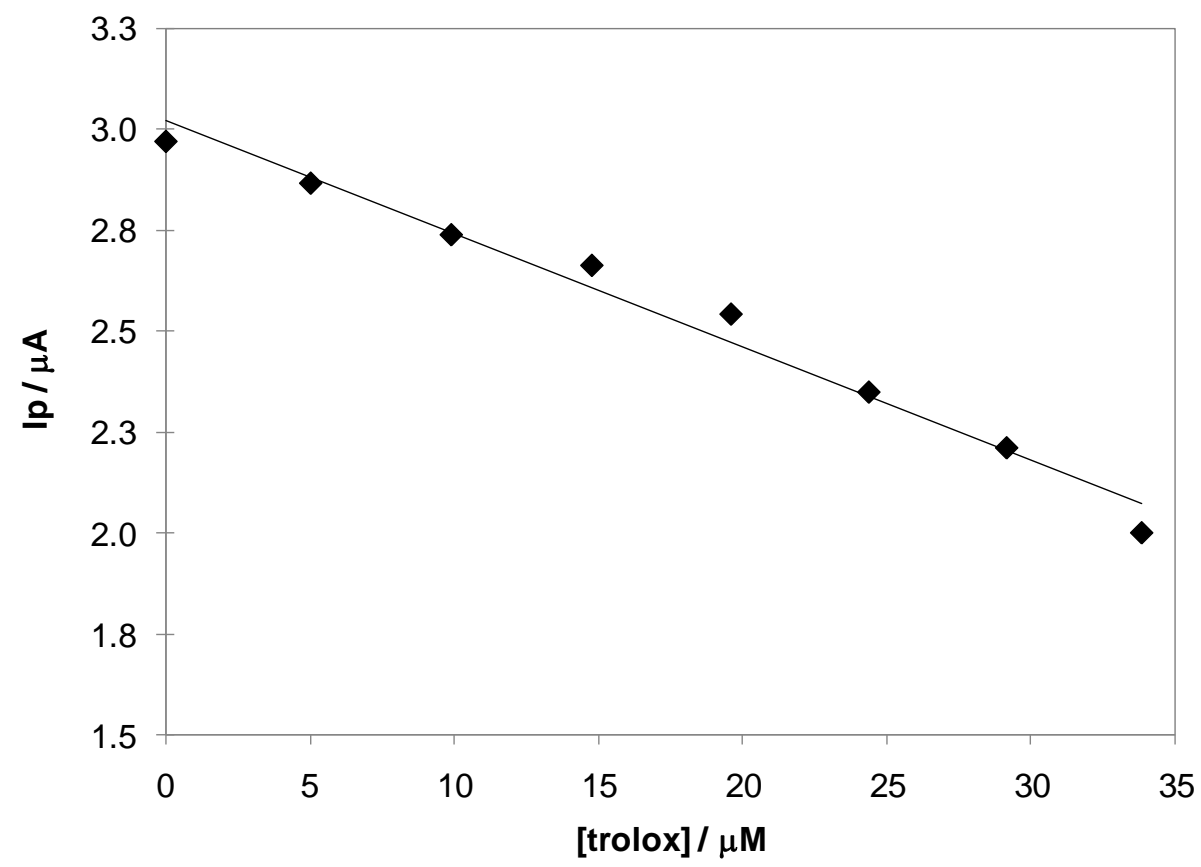

Fig. 2.9 Disminución de la intensidad de corriente del pico de oxidación $\mathrm{I}_{\mathrm{p}}$ del DPPH en 220 $\mathrm{mV}$ como función de la concentración total de trolox en la celda.

La figura 2.10 muestra las curvas de calibración de los sistemas trolox-DPPH y epicatequina-DPPH. Al aumentar la concentración del AOx en la celda, la concentración del DPPH disminuye y en consecuencia su corriente de oxidación también disminuye lo que provoca un aumento en $\Delta \mathrm{I}_{\mathrm{p}}$. La curva de calibración para el sistema trolox-DPPH es:

$$
\Delta \mathrm{I}_{\mathrm{p}}=731.44 \mu \mathrm{A} \mathrm{mM} \mathrm{m}^{-1} *\left[\text { trolox }_{\mathrm{T}}+0.0482 \quad \text { con } \mathrm{R}^{2}=0.9962\right.
$$

mientras que para la epicatequina se obtiene:

$$
\Delta \mathrm{I}_{\mathrm{p} .}=2047.40 \mu \mathrm{A} \mathrm{mM}^{-1} * \text { [epicatequina] }-0.5444 \text { con } \mathrm{R}^{2}=0.9960
$$




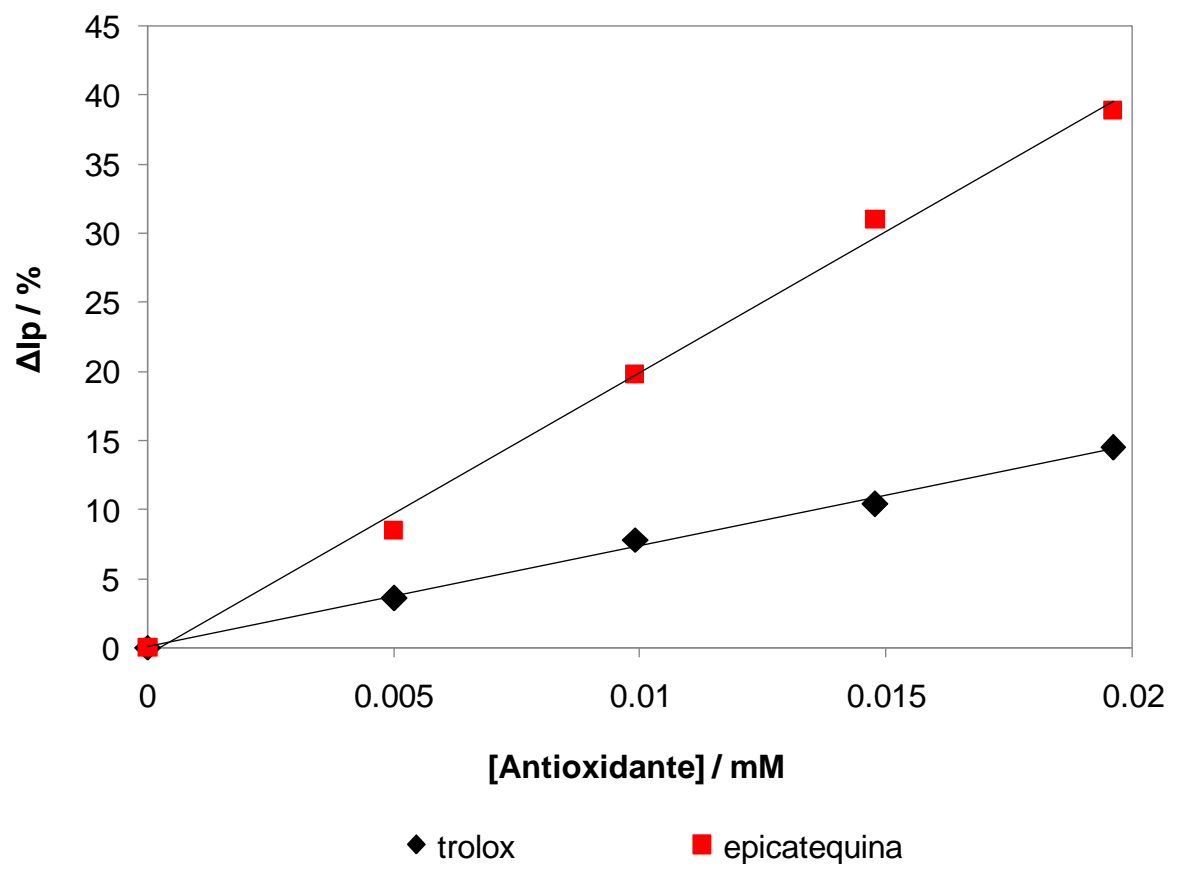

Figura 2.10. Curvas de calibración expresadas en valores relativos. $\Delta \mathrm{I}_{\mathrm{p}}$ aumenta al aumentar la concentración del compuesto antioxidante.

Considerando los resultados obtenidos por el método electroquímico se puede observar que el comportamiento de los cálculos de capacidad antioxidante es análogo al método espectrofotométrico.

\subsubsection{Análisis de CAox de muestras reales}

Usando como referencia el sistema trolox-DPPH, se determinó la CAox de extractos de uvas de las especies carignan y sirah. Los resultados se compararon a los obtenidos por el método espectrofotométrico (tabla 2.4). Inicialmente se agregan $4.0 \mathrm{~mL}$ del electrolito soporte en la celda electroquímica y se obtiene un voltamperograma con el fin de observar si existe alguna respuesta. Posteriormente se agrega $1.0 \mathrm{~mL}$ de la solución de DPPH $1.0 \mathrm{mM}$, se obtiene el voltamperograma y se determina la intensidad del pico de oxidacion. Después se agregan $50 \mu \mathrm{L}$ del extracto de uvas y se obtiene un nuevo voltamperograma. Se 
determina la diferencia entre la intensidad de corriente del pico para la solución del radical antes y después de adicionar el extracto. Esta diferencia es asociada a la acción sobre el DPPH de los compuestos antioxidantes contenidos en los extractos de uvas. Cada medición es realizada por triplicado y la actividad antioxidante se determina con la ecuación (9) expresando el resultado en unidades de equivalentes de trolox [17, 21,39].

Tabla 2.4 TEAC de extractos de uvas obtenidos por los métodos electroquímico (VPD) y espectrofotométrico (UV).

\begin{tabular}{lccccc}
\hline Muestra & $\Delta \mathrm{I}_{\text {muestra }}$ & $\Delta \mathrm{I}_{\mathrm{o}}$ & $\Delta \mathrm{I}_{\text {trolox }}$ & $\begin{array}{c}\text { TEAC } \mathrm{VPD} \\
/ \mu \mathrm{M}\end{array}$ & $\begin{array}{c}\text { TEAC } \mathrm{UV} \\
/ \mu \mathrm{M}\end{array}$ \\
\hline carignan & 1.73 & 0.09 & 0.92 & 19.56 & 17.61 \\
syrah & 1.93 & 0.09 & 0.92 & 21.83 & 22.68 \\
\hline
\end{tabular}

Los resultados obtenidos muestran valores similares por ambos métodos, lo que nos permite concluir que pueden utilizarse para la determinación de TEAC indistintamente, considerando las propiedades de los compuestos que se quieran estudiar.

\subsubsection{Análisis por el método Folin-Ciocalteu (FCR)}

La tabla 2.5 muestra los resultados obtenidos por FCR estableciendo el contenido fenólico equivalente (CFE) de catecol e hidroquinona expresado en equivalentes de ácido caféico por gramo de especie química. 
Tabla 2.5 EPC de estándares fenólicos.

EPC-FCR

mol ac. caféico / mol std.

Catecol 0.96

Hidroquinona

0.85

Los resultados indican que el catecol es más reactivo que la hidroquinona aunque su actividad antioxidante es menor que el estándar de referencia. Este comportamiento puede atribuirse a la estabilidad de la estructura resultante de la donación de un electrón pues es bien sabido que las propiedades antioxidantes de los compuestos fenólicos están relacionadas con la deslocalización en el anillo aromático del electrón desapareado lo cual estabiliza el radical libre [21, 26, 39] según la reacción

$$
\mathrm{M}(\mathrm{n})+\mathrm{e}^{-}(\mathrm{de} \mathrm{AH}) \rightarrow \mathrm{AH} \cdot+\mathrm{M}(\mathrm{n}-1)
$$

La figura 2.11 muestra los resultados obtenidos en los métodos DPPH y FCR en extractos de cuatro distintas cosechas de uvas de la variedad conocida como grenache noir. Los resultados expresados en términos de ácido caféico como estándar muestran valores superiores en el método FCR 


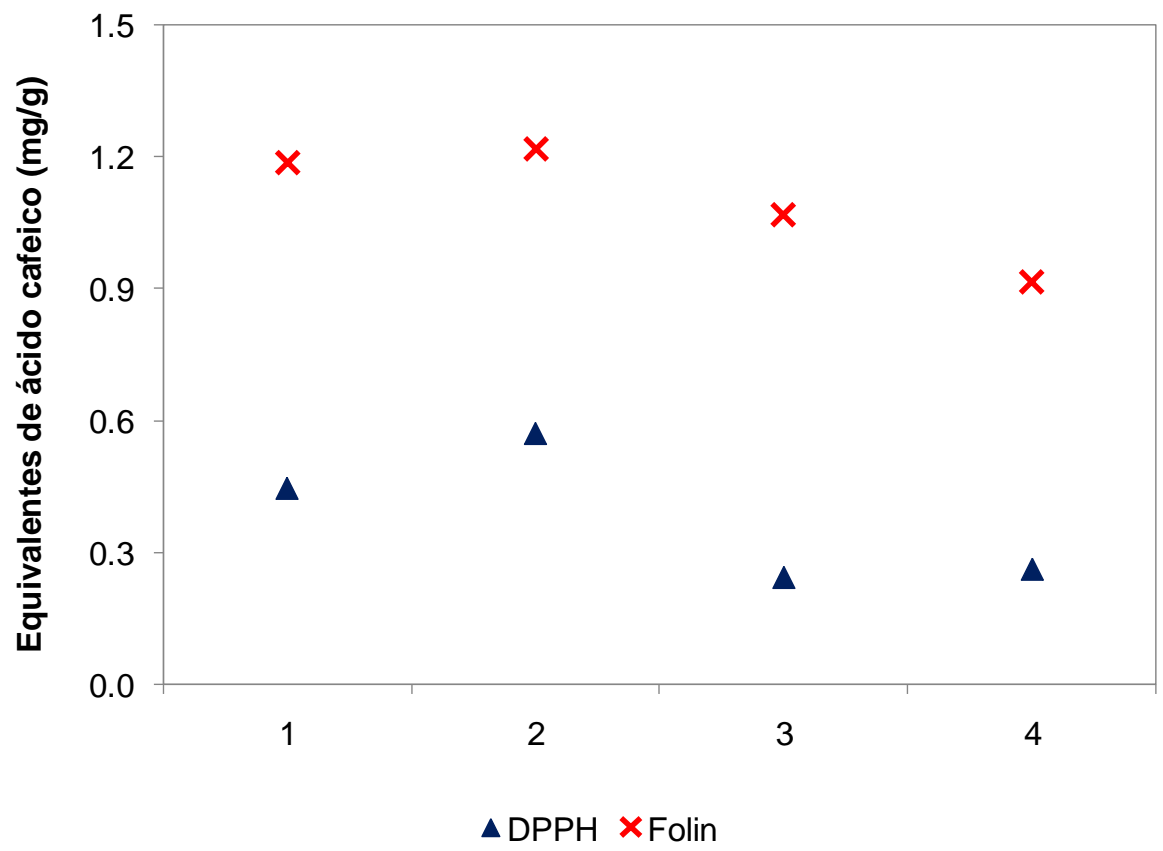

Fig. 2.11 Comparación de CFE de cuatro distintas cosechas de uvas Grenache noir determinadas por los métodos de FCR y DPPH.

En la tabla 2.6 se reportan el análisis de las infusiones herbales. En todos los casos se obtienen valores muy grandes por el método FC dado que las infusiones herbales contienen una gran cantidad compuestos no fenólicos que forman los complejos coloridos y elevan la absorbancia de la mezcla de reacción

Tabla 2.6 CFE de infusiones herbales obtenido por el método espectrofotométrico FCR.

\begin{tabular}{lc}
\hline & \multicolumn{1}{c}{ CFE } \\
& $\mu$ mol ac. caféico / g té \\
\hline Albahaca & 132.8 \\
Árnica & 111.1 \\
Hierbabuena & 158.2 \\
Jamaica & 163.4 \\
\hline
\end{tabular}


En algunos casos es posible eliminar estas especies interferentes o discriminar su contribución en el resultado final. Sin embargo, es evidente la presencia de compuestos fenólicos, mismos que pueden cuantificarse de manera selectiva por el método amperométrico.

Existen algunos métodos para la determinación analítica de las diferentes fracciones de compuestos contenidos en plantas y vegetales. En espectrofotometría UV se ha usado el polímero insoluble polivinilpirrolidona (PVP) para separar polifenoles pues al reaccionar con $\mathrm{OH}$ aromáticos, se forma un complejo insoluble. La figura 2.12 muestra el descenso en la absorbancia cuando el ácido caféico es tratado con PVP $10.0 \mathrm{mg} / \mathrm{mL}$, de igual forma las infusiones analizadas son previamente tratadas con PVP antes de formar la mezcla de reacción según el método FCR.

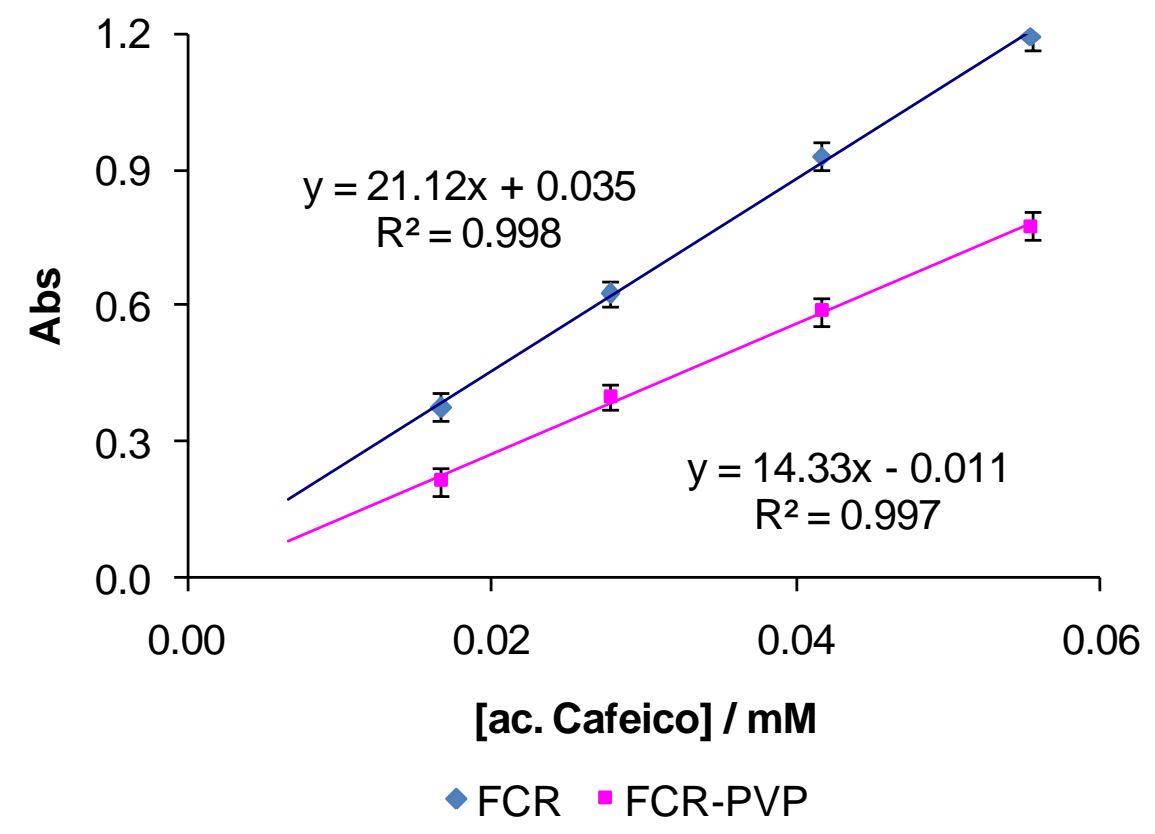

Fig. 2.12. Método FCR. Curva de calibración para ácido caféico. El descenso en la absorbancia es debido a la presencia del polímero PVP $10 \mathrm{mg} / \mathrm{mL}$. 
La tabla 2.7 muestra el contenido fenólico equivalente (CFE) en infusiones herbales obtenido por FCR y FCR modificado con PVP. Los valores son menores cuando se emplea el polímero debido a que los compuestos que cuentan con grupos $\mathrm{OH}$ aromáticos han sido precipitados de tal forma que puede discriminarse la contribución de los compuestos no fenólicos presentes Los resultados son expresados en equivalente de ácido caféico por gramo de hierba.

Tabla 2.7 Contenido fenólico equivalente CFE obtenido por el métodos FCR y FCR modificado usando PVP.

\begin{tabular}{lcc}
\hline & CFE & CFE \\
& FCR & FCR-PVP \\
& $\mu$ mol / g té & $\mu$ mol / g té \\
\hline Albahaca & 132.8 & 45.2 \\
Árnica & 111.1 & 41.2 \\
Hierbabuena & 158.2 & 54.0 \\
Jamaica & 163.4 & 63.1 \\
\hline
\end{tabular}

\subsection{Conclusiones}

El radical DPPH muestra cierta estabilidad a la exposición a la luz durante el tiempo de experimentación. El espectro UV-vis muestra un máximo de absorción cercano a $514 \mathrm{~nm}$ el cual no se ve afectado por el solvente (etanol o metanol). Debido a la toxicidad y volatilidad del metanol, la medición de la actividad antioxidante puede realizarse empleando etanol como solvente aunque 
la razón más importante radica en las perspectivas de esta investigación pues se pretende en un futuro aplicar ambos métodos sobre extractos herbales etanólicos.

Al comparar la actividad antioxidante de los extractos de uvas obtenida por dos métodos distintos, se observan resultados similares. Es posible optimizar otras condiciones de experimentación tales como el pH o el solvente.

Es posible determinar la actividad antioxidante por una gran variedad de métodos. Sin embargo, el empleo del radical DPPH en los métodos amperométrico y espectrofotométrico poseen ventajas en simplicidad, reproducibilidad y rapidez. 


\section{CAPÍTULO 3}

\section{Biosensores con Tirosinasa}

\subsection{Introducción}

Los polifenoles son importantes para la salud humana pues constituyen la principal clase de antioxidantes naturales presentes en alimentos y bebidas de origen natural. Los métodos más usados para la determinación cualitativa y cuantitativa de compuestos fenólicos incluyen colorimetría, HPLC, electroforesis capilar y espectrofotometría. Estos métodos implican complejos pre tratamientos de la muestra y son inapropiados para análisis in situ. Por otra parte, se han publicados numerosos trabajos sobre sensores que permiten la detección de fenoles simples incorporando materiales biológicos como elemento de reconocimiento [40-42]. Estos sensores con frecuencia emplean transductores electroquímicos en combinación con enzimas del grupo oxido-reductasas pues las especies consumidas o producidas durante el proceso redox suelen ser fácilmente leídos por el transductor amperométrico.

La tirosinasa y lacasa han sido ampliamente utilizadas como elemento de reconocimiento e inmovilizadas en distintas formas, materiales y tipos de electrodos para construir biosensores amperométricos [43].

La principal desventaja al emplear la tirosinasa es que ésta no muestra actividad para la oxidación de $p$ - y $m$-benzenodiol (figura 3.1) mientras que la enzima lacasa cataliza la oxidación de los tres isómeros $o$-, $m$-, y $p$-benzenodiol a las correspondientes $o-, m$-, y $p$-quinonas y por lo tanto puede ser empleada para la detección de estos bencenodioles con un considerable aumento en la intensidad de la respuesta amperométrica [44-45]. 


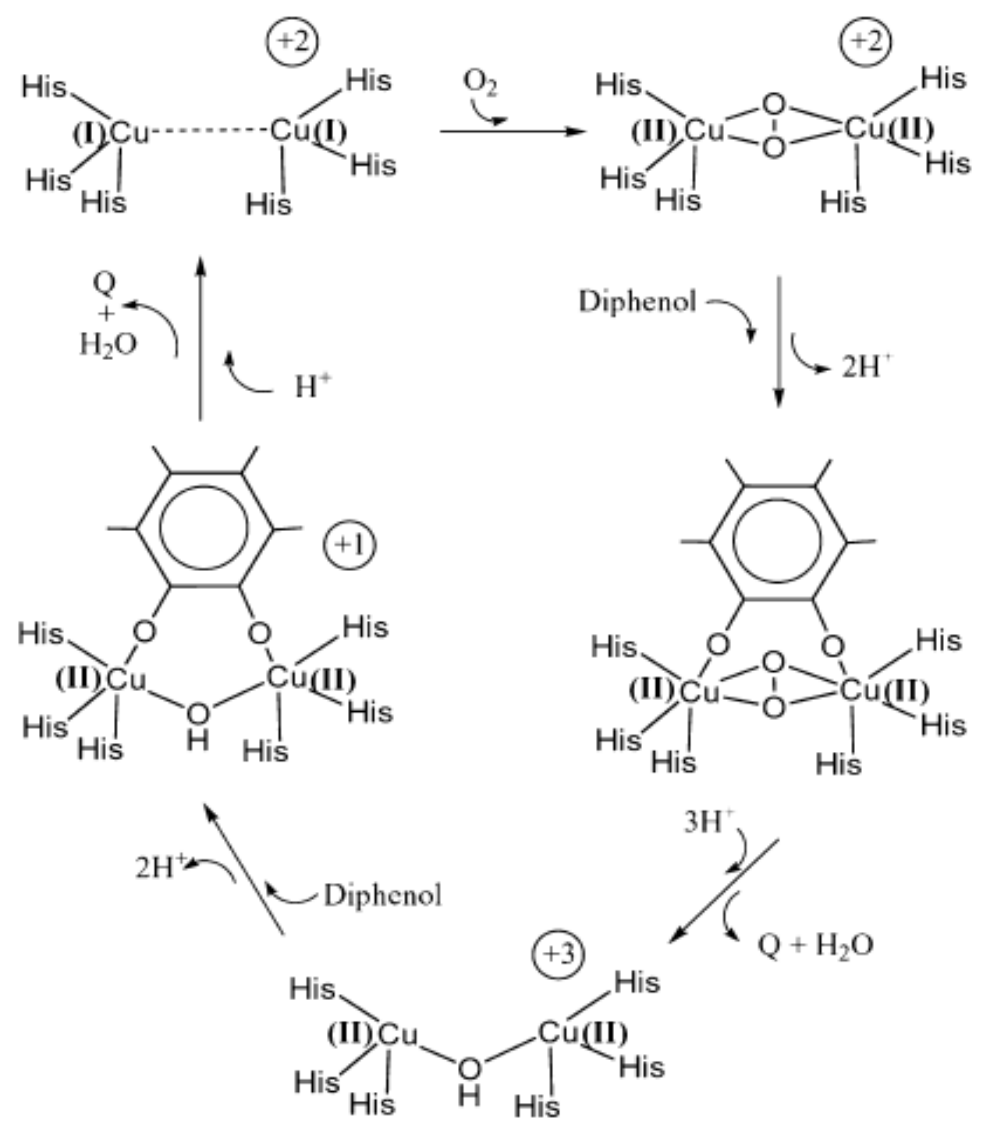

Figura 3.1 El ciclo de la difenolasa. En el esquema Q representa o-quinona. [22]

La estabilidad de las enzimas resulta un factor limitante para el tiempo de vida de un biosensor enzimático; en este sentido se utilizan distintas técnicas para inmovilizar la enzima manteniendo su actividad la cual es normalmente controlada por el $\mathrm{pH}$, la fuerza iónica, la temperatura y la presencia de cofactores. De tal forma que una etapa clave en la construcción de un biosensor es la inmovilización del elemento de reconocimiento sobre una membrana o matriz, que a su vez se fija a la superficie del transductor. Entre las técnicas empleadas las más comunes son la adsorción física, el atrapamiento, el entrecruzamiento o reticulado (cross-linking) y la formación de enlaces covalentes [47]. 
El reticulado o cross-linking, consiste en un entrecruzamiento intermolecular que enlaza las enzimas a soportes sólidos, como se muestra en la figura 3.2, se forma una red entre las enzimas y la especie química que se utiliza como entrelazante.

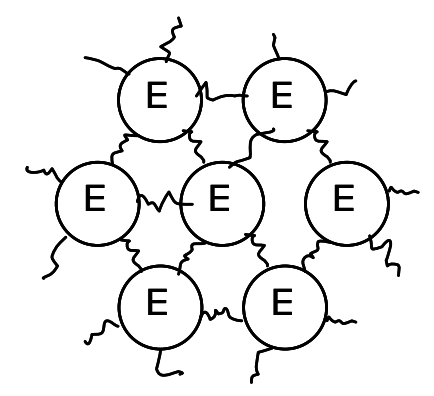

Figura 3.2. Reticulado (Cross-linking) [48]

El glutaraldehído es usado frecuentemente para formar este reticulado pues reacciona con los grupos amino en la lisina de una enzima y permite la difusión de los componentes involucrados en la reacción enzimática, su estructura es mostrada en la figura 3.3.

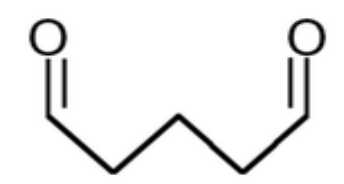

Fig. 3.3 Estructura del Glutaraldehído

En otra técnica de inmovilización la enzima es "atrapada" dentro de un polímero sobre el electrodo de trabajo (fig. 3.4). En este método a diferencia del reticulado, no existe interacción entre la enzima y el material de soporte 


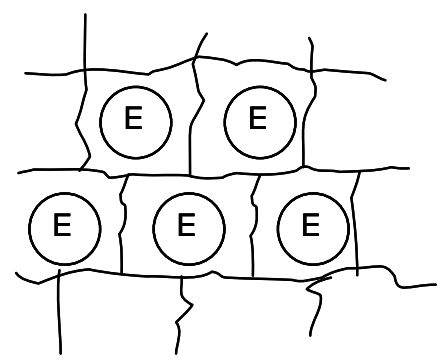

Fig. 3.4. Representación del atrapamiento de una enzima en una matriz polímerica [48]

El PVA-AWP (fig. 3.5) es una resina fotosensible soluble en agua que forma un polímero cuando se irradia con luz en el intervalo $300400 \mathrm{~nm}$.

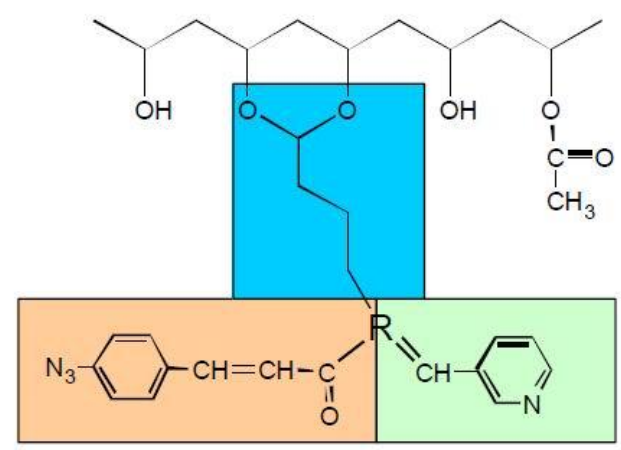

Fig. 3.5. Estructura del PVA-AWP

Dado que el sustrato debe alcanzar el sitio activo de la enzima y el producto de la reacción debe alcanzar la superficie del electrodo, el sistema de inmovilización debe ser capaz de permitir la difusión de estas especies pero también debe retener la enzima manteniendo intacta su actividad [49-50].

Enzimas del grupo PPO como la tirosinasa y lacasa han sido ampliamente utilizadas en biosensores para determinar compuestos fenólicos basados en mediciones amperométricas donde se monitorean las especies formadas en la reacción enzimática. 
La tirosinasa cuenta con dos núcleos de cobre en su estructura y con dos sitios activos uno de los cuales tiene afinidad por compuestos aromáticos (sitio de sustrato) y mientras que el otro muestra afinidad por agentes metal-enlazantes (sitio de oxígeno). Esta fenol-oxidasa cataliza dos reacciones: la orto hidroxilación del fenol para producir catecol y la oxidación de catecol a oquinona. El proceso se completa cuando la enzima es llevada nuevamente a su forma oxidada utilizando oxígeno molecular que a su vez se reduce a agua [51].

Las moléculas de o-quinona producidas en la oxidación enzimática pueden ser reducidas electroquímicamente a catecol sobre la superficie del electrodo a un potencial apropiado [48]. Esta reducción es empleada para monitorear la reacción. El proceso general está representado en figura 3.6.

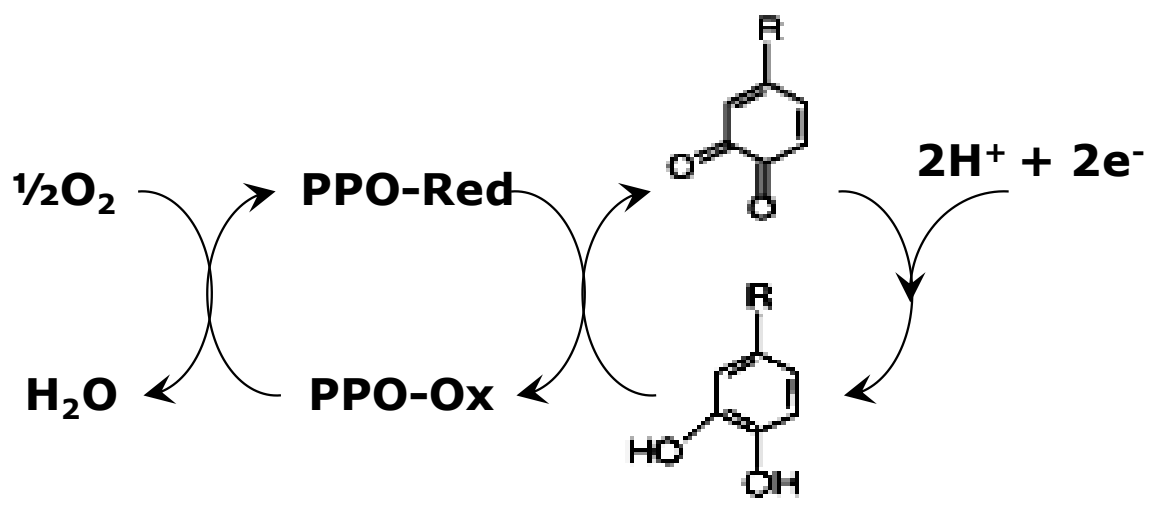

Fig. 3.6. Secuencia de reacciones en el biosensor modificado con una enzima PPO (TM o LTV) empleado en la detección de fenoles simples.

Existen varios sustratos para la tirosinasa con diferentes afinidades para el sitio activo. El más común es el catecol aunque también son empleados L-DOPA, dopamina, epinefrina y ácido 3,4-dihidroxifenilacetico [49]. 


\subsection{Experimental}

\subsubsection{Reactivos y Soluciones}

Todos los reactivos usados fueron de grado analítico adquiridos de SigmaAldrich excepto el etanol adquirido de Carlo Erba reagents. El polímero PVAAWP fue adquirido de Toyo Gosei Co., Japon. La enzima tirosinasa (Tyrosinase from mushrooms, Sigma, EC 1.14.18.1, 3900 unit/mg sólido) fue adquirida de Sigma. Las solución enzimática usada en la preparación de la mezcla con el polímero es TM $5.0 \mathrm{mg} / \mathrm{mL}$. $\mathrm{KH}_{2} \mathrm{PO}_{4}$ y $\mathrm{Na}_{2} \mathrm{HPO}_{4}$ fueron usados para preparar el amortiguador $0.1 \mathrm{M}$ de fosfatos $\mathrm{pH} 6.5 \mathrm{y} \mathrm{pH}$ 7.0. Soluciones $10^{-1} \mathrm{M}$ de catecol y ácido caféico en etanol se preparan el mismo día de su uso y se mantienen protegidas de la luz. Soluciones etanólicas $10^{-2}, 10^{-3}$ y $10^{-4} \mathrm{M}$ se preparan por dilución.

\subsubsection{Preparación de muestras}

Los extractos de uvas se preparan el mismo día de su uso. Las muestras (cosechadas en 2006 y 2007) son licuadas y posteriormente centrifugadas. Con la fase líquida se prepara una dilución al $20 \%$ v/v en etanol.

\subsubsection{Manufactura de electrodos y preparación de biosensores.}

Los SPE utilizados constan de tres pistas impresas con tinta de carbono sobre placas de PVC (DEK Printing Machines Ltd., England). Sobre el extremo de una de las pistas adicionalmente se imprime una capa con tinta de $\mathrm{Ag} / \mathrm{AgCl}$ para ser usada como electrodo de pseudoreferencia. El disco central corresponde al electrodo de trabajo con un diámetro de $5 \mathrm{~mm}$ mientras que la tercera pista constituye el electrodo auxiliar (fig. 3.7). 


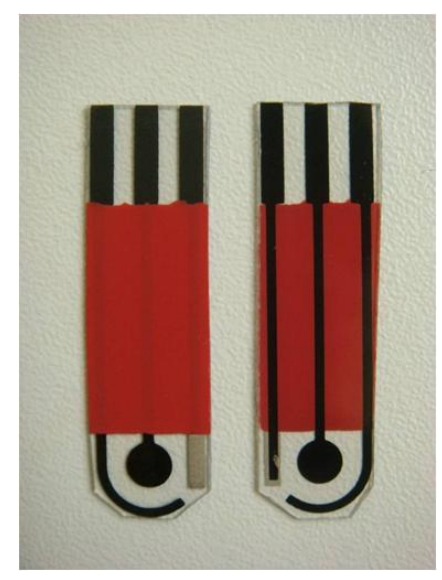

Fig. 3.7. Electrodos impresos con tinta de carbono. El electrodo de pseudo-referencia usado es $\mathrm{Ag} / \mathrm{AgCl}$

\subsubsection{Inmovilización por reticulado}

Los TM-SPE se preparan depositando directamente sobre la superficie del electrodo de trabajo $3.0 \mu \mathrm{L}$ de una solución de tirosinasa disuelta en BSA 0.1 M. La adición de esta proteína conduce a una actividad enzimática mayor y gran estabilidad [10]. Conocida la actividad enzimática es posible establecer el número de unidades a depositar sobre el sensor.

Después de depositar la solución TM en BSA $0.1 \mathrm{M}$, se permite la evaporación del solvente manteniendo el electrodo a $4{ }^{\circ} \mathrm{C}$ durante $4-6$ horas. Una vez secos, se procede a depositar el glutaraldehído (GLU) con el fin de construir el reticulado e inmovilizar a la enzima. Esta etapa se realizó en dos formas distintas. En la primera de ellas se depositan directamente sobre la enzima $15 \mu \mathrm{L}$ de una solución al $2.5 \%$ de GLU y se permite la reacción durante un minuto. Después de este lapso se retira la solución de GLU y el electrodo se lava cuidadosamente con $2 \mathrm{~mL}$ de amortiguador de fosfatos $\mathrm{pH}$ 7.0. Bajo este mismo procedimiento se prepararon biosensores usando una solución de GLU al 5.0\% en lugar de la solución al $2.5 \%$ utilizada inicialmente. 
Adicionalmente se evalúa otra variante para depositar el GLU sobre la enzima y formar el reticulado. La propuesta consiste en usar sólo vapores de la solución de GLU; esto se realiza por un espacio de 2 minutos durante los cuales se permite la evaporación del GLU en un matraz cerrado de tal forma que el electrodo esta en contacto con los vapores de la solución reticulante. Después de este lapso la membrana se lava con amortiguador de fosfatos $\mathrm{pH} 7.0$ y nuevamente se colocan en refrigeración hasta que están perfectamente secos. En este punto debe apreciarse una película delgada sobre la superficie del electrodo de trabajo.

\subsubsection{Inmovilización por atrapamiento}

En este método, la enzima se deposita sobre el electrodo de trabajo en una mezcla formada por una solución de tirosinasa $5 \mathrm{mg} \mathrm{mL}^{-1}$ y PVA-AWP en una proporción 50-50 en volumen. Una vez mezclados los componentes se debe agitar hasta que la mezcla es homogénea, entonces se depositan $3.0 \mu \mathrm{L}$ sobre el electrodo de trabajo. Los SPE se colocan bajo una lámpara de luz UV (8W) por un intervalo de 3 horas con el fin de permitir la polimerización. Después de este tiempo se almacenan a $4^{\circ} \mathrm{C}$ al vacío hasta su uso [2]. Siguiendo este procedimiento cada biosensor contiene $0.2 \mathrm{U}$ de la enzima.

\subsubsection{Instrumentación y procedimiento experimental}

\subsubsection{Voltamperometría cíclica}

Mediante voltamperometría cíclica $\left(20 \mathrm{mV} \mathrm{s}^{-1}\right)$ se realizó el estudio de los procesos redox de catecol $500 \mu \mathrm{M}$ (1,2-dihidroxibenceno) utilizando un SPE en el cual la superficie del electrodo de trabajo ha sido modificada con PVA-AWP pero sin incluir a la enzima. Este estudio permitirá establecer el potencial de trabajo óptimo a las condiciones experimentales seleccionadas 


\subsubsection{Mediciones Amperométricas}

La detección amperométrica de o-quinona es realizada con el método de adiciones estándar y seguida en un amperímetro BAS amperometric detector $L C-4 C$ conectado a una PC. La recopilación de datos se hace mediante el software especializado DAISY LAB 6.0. Basados en el estudio de CV se determinó realizar las mediciones aplicando un potencial de $-0.3 \mathrm{~V}$ medido contra la pseudoreferencia de $\mathrm{Ag} / \mathrm{AgCl}$ impresa en el electrodo la cual difiere en $266 \mathrm{mV}$ con el electrodo comercial $\mathrm{Ag} / \mathrm{AgCl} 3 \mathrm{M}$. Con el biosensor inmerso en una celda termo regulada y bajo agitación que contiene $10 \mathrm{~mL}$ de buffer $0.1 \mathrm{M}$ de fosfatos $\mathrm{pH} 7.0$ a $25^{\circ} \mathrm{C}$. Una vez aplicado el potencial indicado es necesario esperar hasta que la corriente sea estable. Cuando se alcanza esta línea de base se procede a inyectar consecutivamente pequeños volúmenes de la solución del sustrato (catecol) y se mide el cambio en la corriente después de cada inyección. Una curva de calibración se construye graficando la concentración total del sustrato en la celda en función del cambio total registrado en la corriente. La parte lineal de la curva de calibración indica el rango de respuesta mientras que la pendiente corresponde a la sensibilidad del sensor expresada en unidades de $\mathrm{mA} \mathrm{M} \mathbf{M}^{-1}$.

Adicionalmente se evalúa la estabilidad operacional del sensor realizando múltiples inyecciones de la solución del sustrato y registrando la respuesta en la corriente. Este análisis muestra la estabilidad de la enzima en el material de soporte, además de ser un indicador de la eficiencia del atrapamiento. Es importante recalcar que el material de soporte debe proveer a la enzima un ambiente adecuado para mantenerla inmóvil sin alterar su estabilidad y al mismo tiempo debe permitir la difusión a las moléculas de catecol y o-quinona. 


\subsection{Resultados y Discusión}

\subsubsection{Determinación del potencial de trabajo}

Para obtener el potencial de trabajo en los SPE, se hicieron estudios directamente en el electrodo SPE sin modificar la superficie del electrodo de trabajo (ET). El barrido de potencial inició en condiciones de corriente nula hacia valores positivos. La figura 3.8 muestra 4 voltamperogramas obtenidos en $0.1 \mathrm{M}$ amortiguador de acetatos $\mathrm{pH} 4.7$ para distintas concentraciones de catecol. Como se puede notar aparece un proceso de oxidación en $0.38 \mathrm{~V}$ con un incremento en la corriente del pico proporcional a la concentración, al invertir el barrido de potencial hacia valores negativos, se observa un pico de reducción alrededor de $0.2 \mathrm{~V}$. Basado en este resultado se eligió un valor de $-0.3 \mathrm{~V}$ para realizar las determinaciones amperométricas con el SPE ya modificado con la PPO.

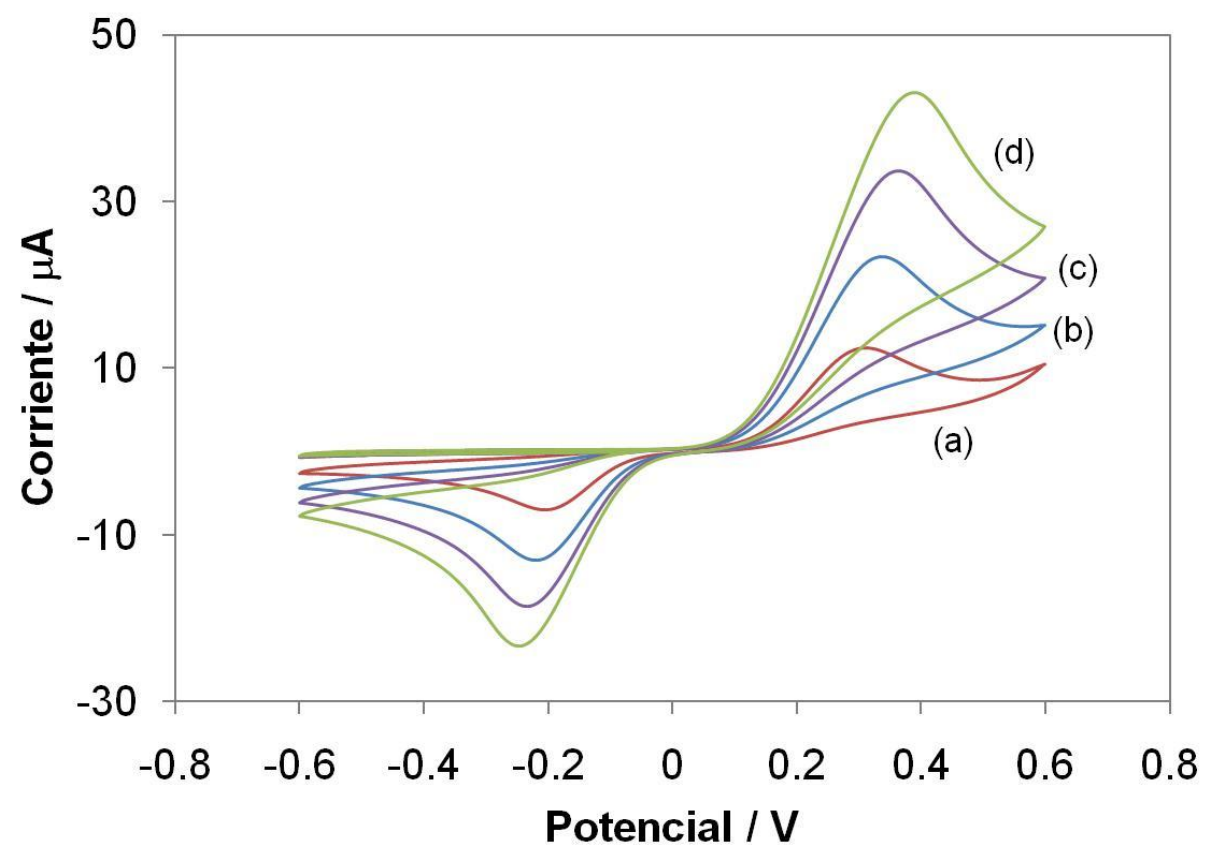

Fig. 3.8 CVs correspondientes al sistema SPE / $0.1 \mathrm{M}$ amortiguador de acetatos $\mathrm{pH} 4.7$ con catecol (a) $250 \mu \mathrm{M}$, (b) $500 \mu \mathrm{M}$, (c) $750 \mu \mathrm{M}$ y (d) $1 \mathrm{mM}$ medido a $0.1 \mathrm{~V} \mathrm{~s}^{-1}$. 


\subsubsection{Respuesta Amperométrica del biosensor TM-SPE}

\subsubsection{Cross-linking con glutaraldehído (GLU)}

En la figura 3.9 se muestran los resultados obtenidos para electrodos construidos con vapores y con solución de $2.5 \%$ y $5.0 \%$ de GLU. En todos los casos cada electrodo TM-SPE-GLU contiene 0.2 unidades enzimáticas.

En la tabla 3.1 se comparan los resultados de sensibilidad y rango de linealidad. Los electrodos que fueron construidos inmovilizando la enzima mediante vapores de GLU muestran mayor sensibilidad y rango de respuesta.

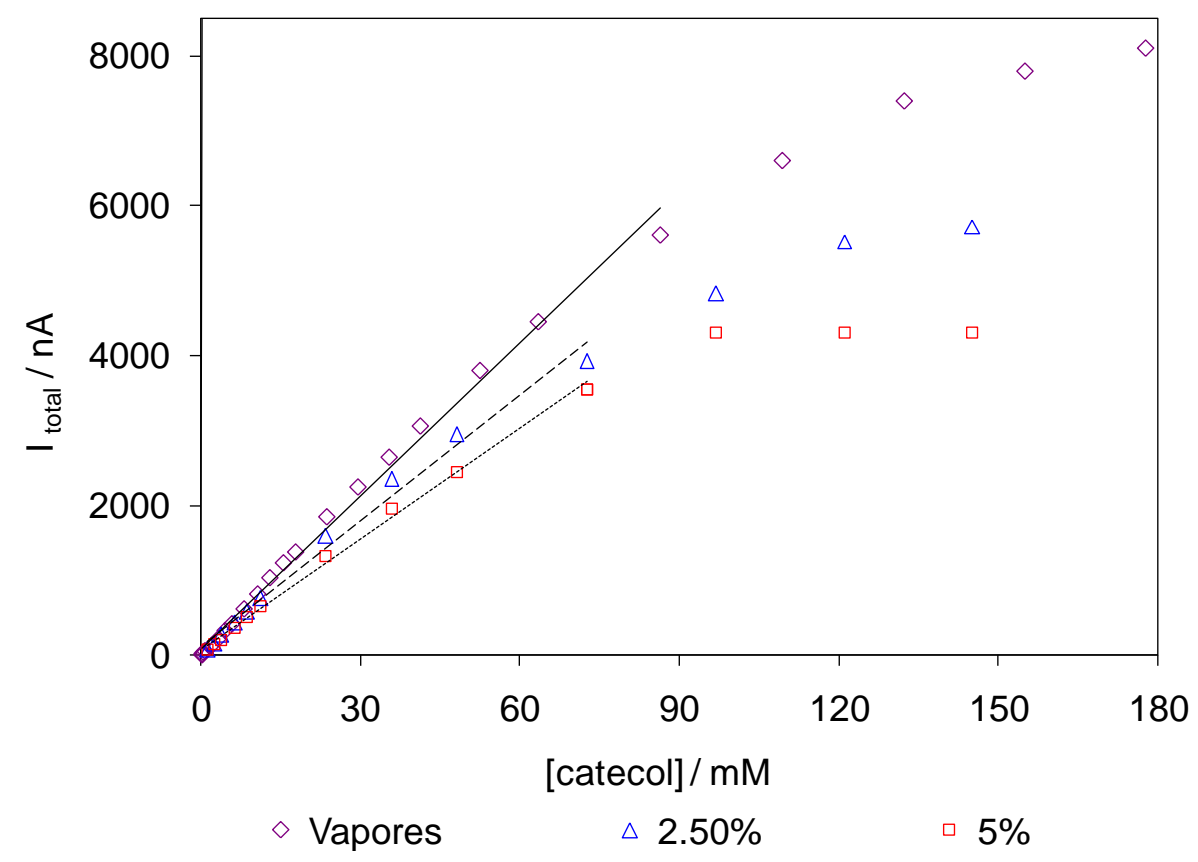

Fig. 3.9. Efecto del agente reticulante sobre la sensibilidad del biosensor en amortiguador de fosfatos $0.1 \mathrm{M} \mathrm{pH}$ 7.0. Los biosensores evaluados contienen 0.2 unidades de TM.

Una característica del reticulado es que debe permitir la difusión de las especies por lo que la enzima parece más expuesta usando solo vapores en comparación 
con la aplicación directa de una solución. Por otra parte, el sensor construido con la solución al $5.0 \%$ tiene la menor sensibilidad; nuevamente se asume que su reticulado es ligeramente más denso e inaccesible a la difusión. En general se concluye que la sensibilidad disminuye a mayor concentración de la solución de GLU usada.

Tabla 3.1 Comparación de las características en distintos SPE.

\begin{tabular}{|c|c|c|c|}
\hline & $\begin{array}{l}\text { Sensibilidad } \\
\qquad \mathrm{mA} \mathrm{M}^{-1}\end{array}$ & $\begin{array}{l}\text { Intervalo de linealidad } \\
\qquad \mu \mathrm{M}\end{array}$ & $\mathrm{R}^{2}$ \\
\hline Vapor & 68 & $0.06-35$ & 0.993 \\
\hline $2.5 \%$ & 56 & $1.24-35$ & 0.988 \\
\hline $5.0 \%$ & 49.3 & $1.24-35$ & 0.996 \\
\hline
\end{tabular}

\subsection{Composición de la matriz de soporte}

Buscando optimizar el desempeño analítico del biosensor, se evaluaron diferentes cantidades de TM sobre el electrodo de trabajo. En la figura 3.10 se muestran las curvas de calibración obtenidas al utilizar 3 cantidades de TM diferentes. 


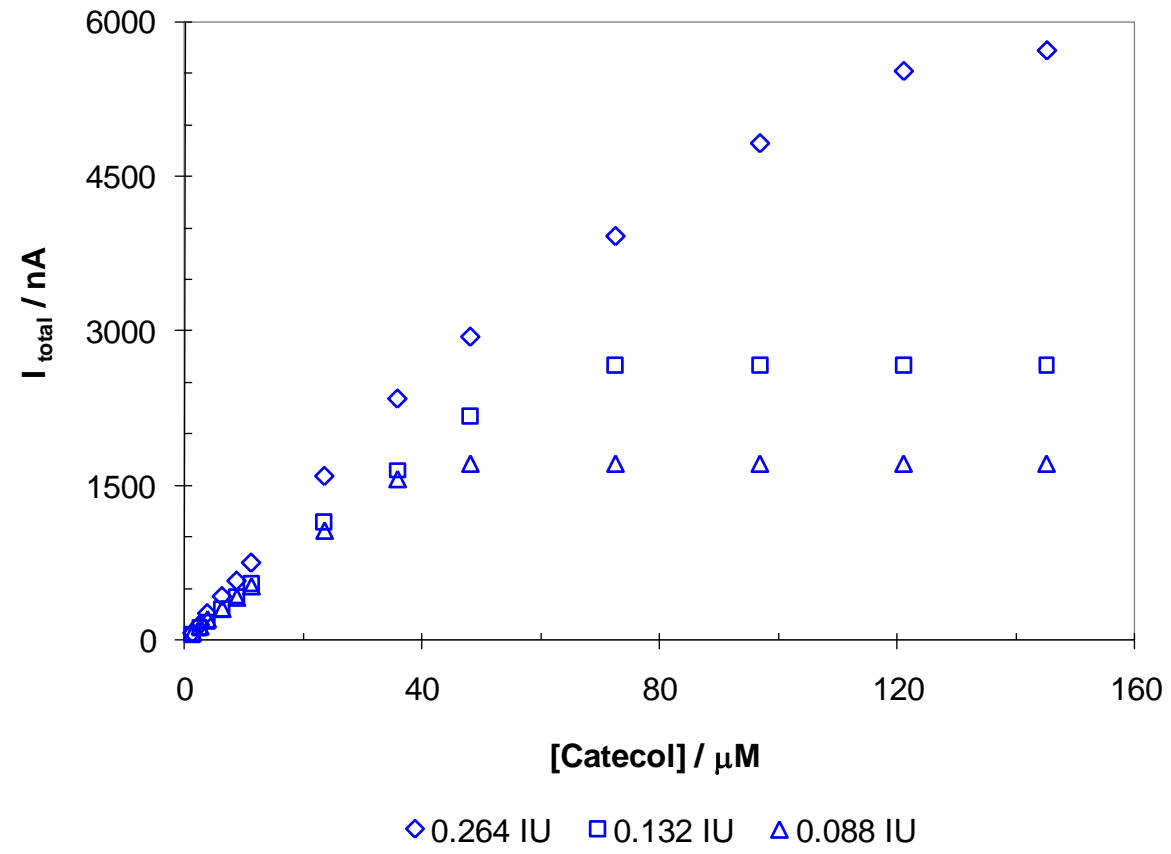

Fig. 3.10 TM-SPE (GLU 2.5\%) en amortiguador de fosfatos $0.1 \mathrm{M} \mathrm{pH}$ 7.0. Se evalúan diferentes cantidades de enzima en el sensor usando catecol como sustrato.

Las curvas de calibración de la figura 3.10 muestran la dependencia entre la cantidad de enzima en el electrodo de trabajo y la concentración de saturación. El biosensor que contiene 0.264 IU de TM exhibe mayor sensibilidad y un intervalo de respuesta lineal más amplio

\subsubsection{Atrapamiento en PVA-AWP}

Teniendo como objetivo evaluar sensores que empleen métodos de manufactura más prácticos, se construyen electrodos usando atrapamiento en polímero. La figura 3.11 muestra que el desempeño analítico de los TM-SPE construidos con PVA-AWP es superior en términos de sensibilidad e intervalo de linealidad además exhiben mayor reproducibilidad lo que se atribuye a que la mezcla enzimática que se deposita sobre el ET puede prepararse con mayor precisión en comparación con el depósito de GLU en el método de reticulado. 


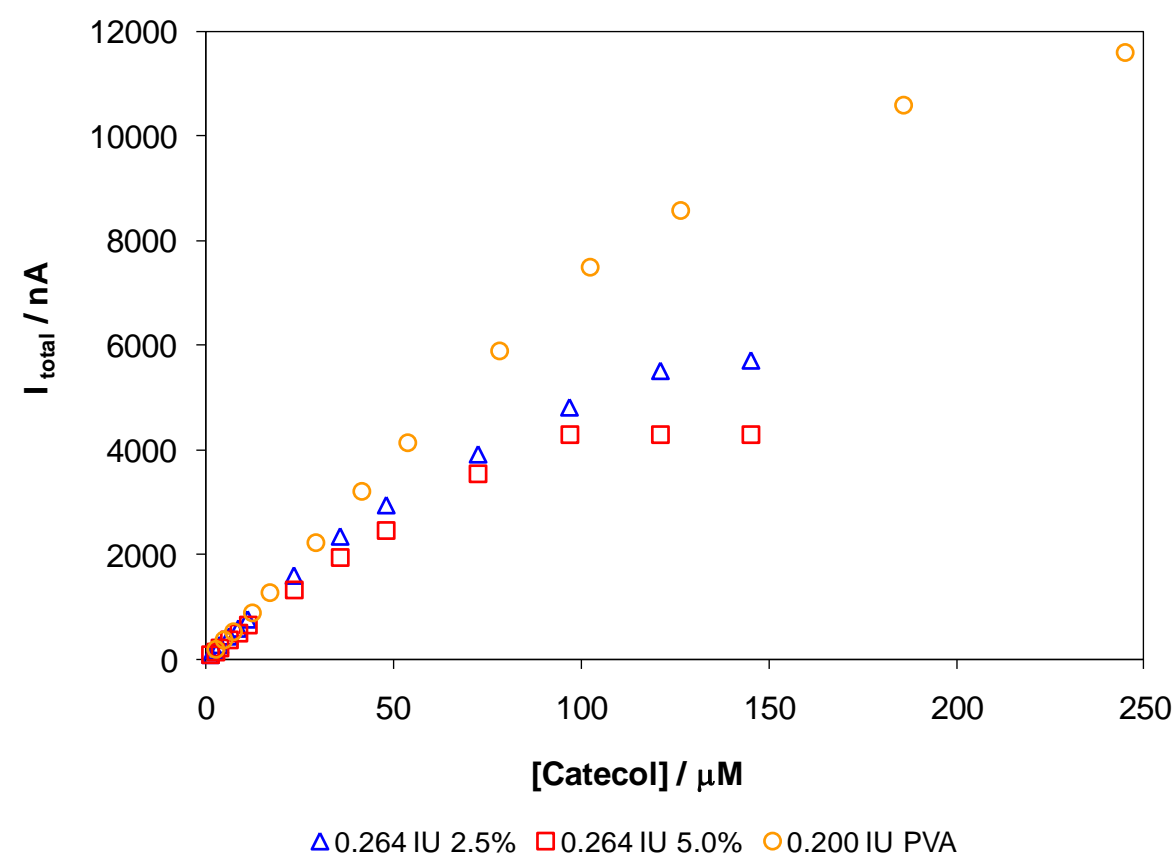

Fig. 3.11 Comparación de los métodos de inmovilización evaluando los TM-SPE ante catecol en solución amortiguada de fosfatos $\mathrm{pH} 7.0,25^{\circ} \mathrm{C}$ y $-0.3 \mathrm{~V}$.

Es importante mencionar que se requiere acondicionar el sensor TM-SPE-PVA antes de su uso; esto se realiza colocando el sensor en amortiguador de fosfatos pH 7.0 por un lapso de 2-3 hrs.

Al comparar el desempeño de ambos métodos de inmovilización evaluados bajo las mismas condiciones de operación, sus curvas de calibración muestran un intervalo de respuesta lineal más amplio y mayor sensibilidad, esto a pesar de contener solamente 0.2 unidades enzimáticas mientras que los biosensores TMSPE-GLU contienen 0.264 IU (fig. 3.11)

\subsubsection{Estabilidad del Biosensor TM-SPE}

El estudio de estabilidad que se presenta en la figura 3.12, muestra un marcado descenso en la respuesta inicial medida en adiciones consecutivas con el biosensor construido con vapores; por otra parte, a pesar de tener sensibilidad e 
intervalo de respuesta inferiores, el sensor construido utilizando la solución $2.5 \%$ de GLU mantiene por más tiempo la estabilidad de la respuesta en un mayor número de inyecciones.

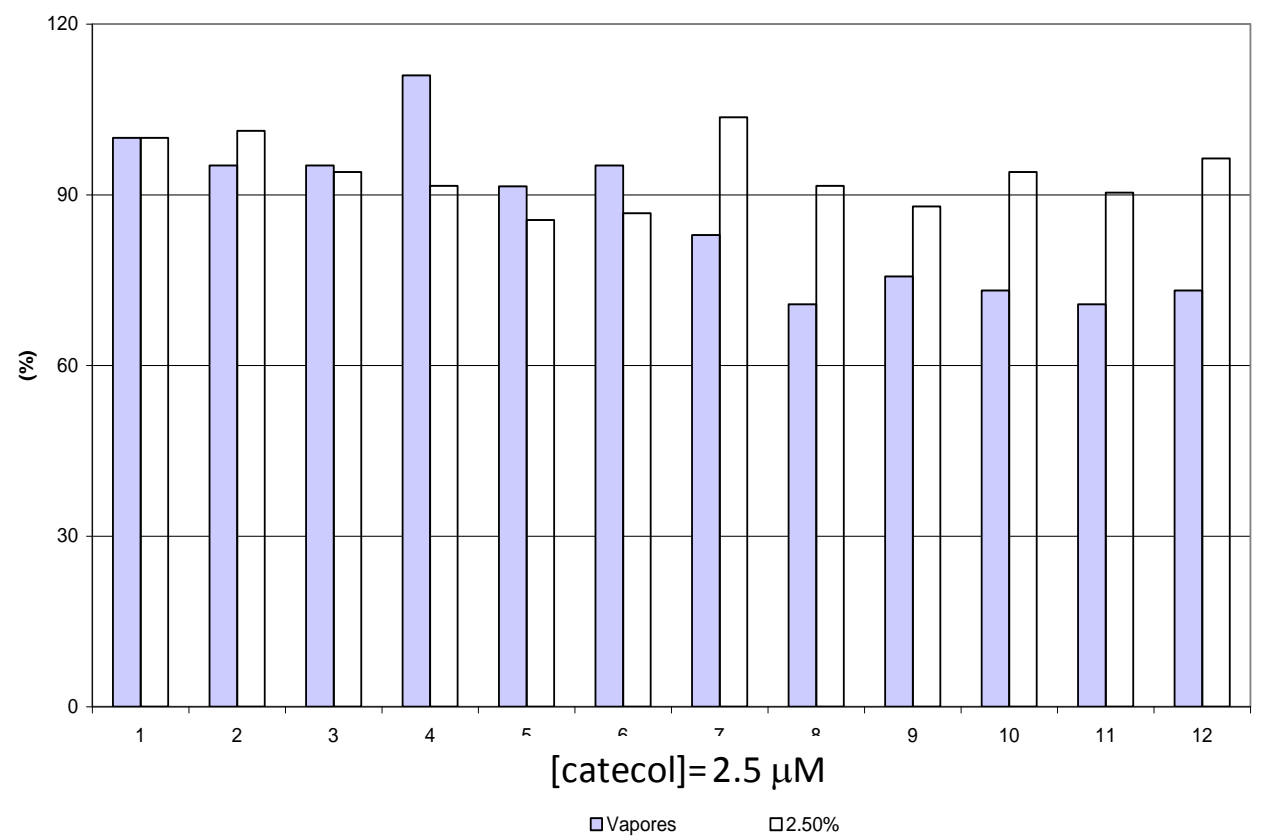

Fig. 3.12 Estabilidad del TM-SPE construido por entrecruzamiento usando vapores o solución de GLU al 2.5\%. El eje vertical muestra el porcentaje de la respuesta inicial mientras que el eje horizontal indica el número de mediciones realizadas (12 en total). La concentración de catecol en la celda es $2.5 \mu \mathrm{M}$.

Otra ventaja de este último electrodo es que el proceso de su construcción es más reproducible en comparación con el uso de vapores. En este último la cantidad depositada del GLU es controlada por su concentración en solución y por el tiempo de contacto entre el sensor y los vapores. Para los electrodos donde se depositan volúmenes fijos de concentración conocida, adicionalmente se permite la reacción por lapsos de tiempo fijos que van de uno hasta dos minutos. Basados en estas características se decidió tomar como base el electrodo construido usando solución al $2.5 \%$. 
De igual forma se comparan los resultados del estudio de estabilidad para ambos métodos de inmovilización. Los resultados muestran que la respuesta de los biosensores construidos por atrapamiento se mantiene estable por más tiempo mientras que para el cross-linking la sensibilidad va disminuyendo más rápidamente (fig. 3.13).

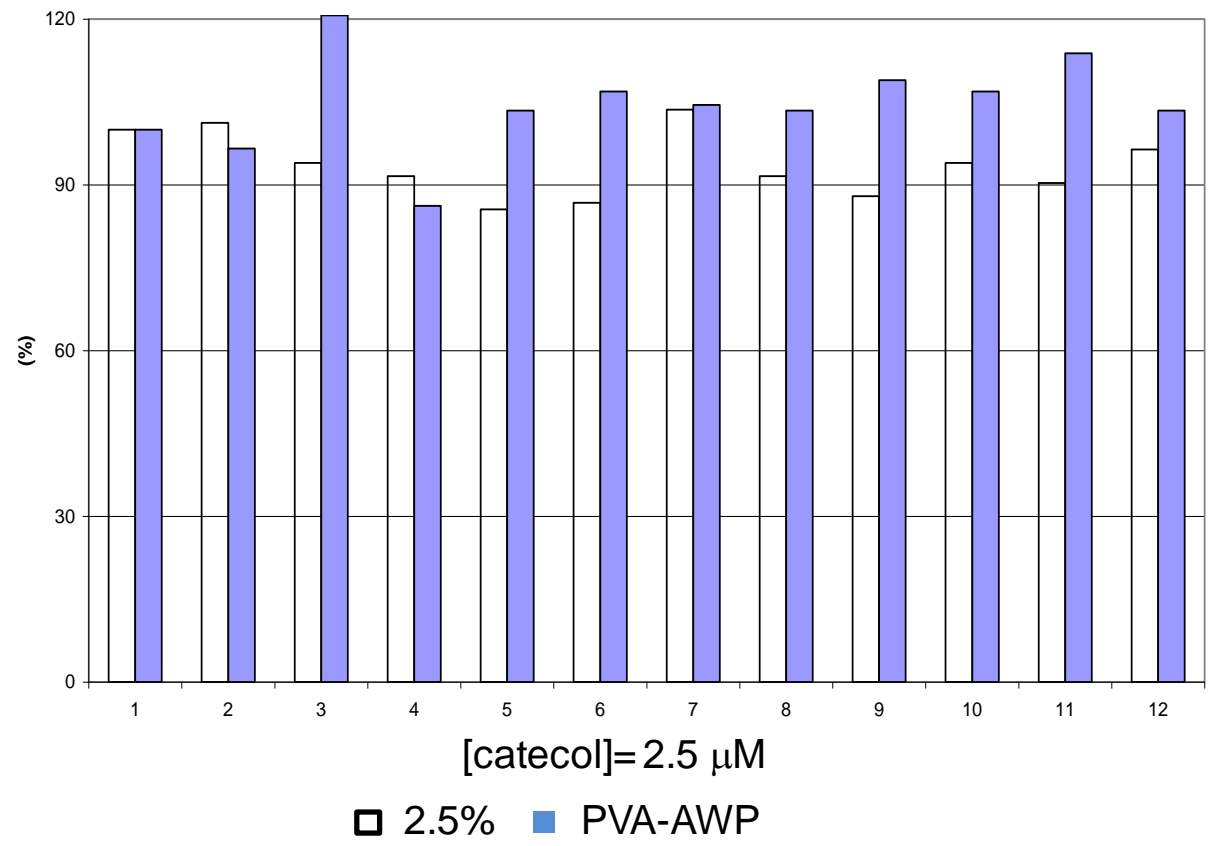

Fig. 3.13 Estudio de estabilidad de biosensores con matriz de soporte de PVA-AWP o GLU al $2.5 \%$. El eje vertical muestra el porcentaje de la respuesta inicial mientras que el eje horizontal indica el número de mediciones realizadas (12 en total). La concentración de catecol en la celda es $2.5 \mu \mathrm{M}$

El TM-SPE empleado para la determinación de la actividad antioxidante en extractos de uvas contiene 40 unidades enzimáticas. Esta cantidad fue elegida pues su intervalo de respuesta permite el uso de alícuotas del mismo volumen al usado al evaluar compuestos estándar. Las características analíticas del TM-SPE usado en el análisis de muestras reales se muestran en la tabla 3.2. 
Tabla 3.2 Características analíticas del biosensor TM-SPE

\begin{tabular}{cccccc}
\hline Sensor & Sensibilidad & $\begin{array}{c}\text { Intervalo de } \\
\text { linealidad }\end{array}$ & $\begin{array}{c}\text { Límite de } \\
\text { detección }\end{array}$ & $\mathrm{R}^{2}$ & Sustrato \\
& $10^{-3} \mathrm{~A} / \mathrm{M}$ & $10^{-6} \mathrm{M}$ & $10^{-6} \mathrm{M}$ & & \\
\hline TM-SPE & 38.1 & $0.1-200$ & 0.125 & 0.9997 & catecol \\
\hline
\end{tabular}

\section{CAPÍTULO 4}

\section{Biosensores con LTV}

\subsection{Introducción}

En las últimas tres décadas, la literatura clínica y de nutrición ha publicado numerosos estudios sobre radicales libres. Estos son moléculas altamente inestables generadas in vivo durante procesos metabólicos y que pueden ser neutralizados por ciertos compuestos conocidos como antioxidantes, los cuales se producen de manera natural en el cuerpo humano. Sin embargo, la contaminación, la exposición a la luz solar, el humo de tabaco o simplemente un mal funcionamiento de la producción natural de estos compuestos, son algunos de los factores que puede conducir a un exceso de radicales libres dentro del organismo humano lo cual induce un daño oxidativo en la células y promueve numerosas enfermedades degenerativas y envejecimiento. Por esta razón los antioxidantes juegan un papel muy importante previniendo la formación y evitando la acción de los oxidantes celulares [55-58]

En este sentido incontables compuestos comúnmente presentes en la dieta humana han sido intensamente señalados por sus propiedades antioxidantes, entre los más mencionados están las vitaminas C y E [59-61]. 
Los polifenoles forman un extenso grupo de compuestos encontrados en frutas, legumbres, cereales y plantas medicinales y presentan propiedades antioxidantes [62]. Por esta razón resulta de gran interés para investigadores de la salud y de la industria alimenticia, evaluar la capacidad de alimentos de origen natural en relación a los compuestos antioxidantes que contienen. Existe evidencia de que el contenido cambia de fruta a fruta, de cosecha a cosecha o de región a región. Sin embargo, hasta hoy en día los agricultores no reportan ninguna información respecto del contenido en compuestos antioxidantes, ni en los frutos utilizados como materia prima, ni de los productos que de estos se fabrican [63]. Determinar la efectividad relativa de compuestos específicos actuando como antioxidantes no es una tarea sencilla debido a la complejidad de la composición química de los alimentos [64]. Separar cada familia de antioxidantes y estudiarlos de forma individual tampoco es viable, pero sin duda sería de mucho provecho contar con un método sencillo para una determinación rápida y confiable de la efectividad antioxidante. Sin embargo, la capacidad antioxidante de un alimento obtenida utilizando un solo método parece ser inadecuada debido a que existe evidencia que revela diferentes mecanismos de reacción [65].

Existen incontables publicaciones que detallan el desarrollo de diversos métodos para determinar la capacidad antioxidante de una gran variedad de alimentos de origen natural [66-78]. Estos ensayos son útiles para establecer una clasificación de la actividad de las substancias antioxidantes y de los alimentos que las contienen, lo cual puede ser un indicador de la efectividad antioxidante después de su consumo [79]. Bebidas como infusiones herbales y tés no cuentan con valor nutricional alguno pero constituyen una atractiva fuente de antioxidantes a la dieta humana. La capacidad antioxidante de infusiones herbales y tés a sido estudiada por diferentes metodologías tales como ORAC y FRAP entre otras [80-93]. 
Debido a su alta especificidad, se han desarrollado muchos biosensores enzimáticos amperometricos para la cuantificación de polifenoles [94-118]. Comúnmente se han utilizado enzimas del grupo de las fenoloxidasas (PPO), aunque en la mayoría de los casos los sensores están basados en el uso de la tirosinasa [99-102, 104-106, 112, 113]. Aunque la lacasa también es efectiva, ha sido menos usada para el mismo propósito[103-107]. Mientras la tirosinasa cataliza la oxidación de monofenoles y o-difenoles [119-121], la lacasa puede catalizar la oxidación de $o$-, $m$ - y $p$-difenol a $o$-, $m$ - y $p$-quinonas [122]. En general el desempeño de este tipo de biosensores depende de varios aspectos, uno de los más importantes es conservar la actividad de la enzima cuando es confinada dentro de la matriz polimérica que inmoviliza la enzima sobre la superficie del electrodo de trabajo.

\subsection{Experimental}

\subsubsection{Reactivos y Soluciones}

Soluciones $100 \mathrm{mM}$ de catecol, resorcinol, hidroquinona y ácido caféico en etanol se preparan el día de su uso y se mantienen protegidas de la luz. Soluciones $10 \mathrm{mM}, 1.0 \mathrm{mM}$ y $0.1 \mathrm{mM}$ se preparan por dilución. Amortiguador

de fosfatos $100 \mathrm{mM}$ pH 6.5 y pH 7.0. Amortiguador de Acetatos $100 \mathrm{mM} \mathrm{pH}$ 4.7. Lacasa $10 \mathrm{mg} / \mathrm{mL}$ (Laccase from Trametes versicolor, Sigma, EC 1.10.3.2, 120 unidades/mg sólido), PVA-AWP (Toyo Gosei Co., Ltd., Japan).

\subsubsection{Preparación de muestras}

Infusiones acuosas $6.0 \mathrm{mg} / \mathrm{mL}$ se preparan el día de su uso. Las infusiones son colocadas a $60^{\circ} \mathrm{C}$ durante 60 minutos. Las hierbas utilizadas fueron previamente desecadas durante 24 horas a $60^{\circ} \mathrm{C}$ 


\subsubsection{Manufactura de Electrodos y preparación de Biosensores}

Los SPE utilizados son fabricados según el procedimiento detallado en la sección 3.3.3.

Sobre el electrodo de trabajo se depositan $4.0 \mu \mathrm{L}$ de una mezcla $50 \% \mathrm{v} / \mathrm{v}$ formada por la solución enzimática $10 \mathrm{mg} / \mathrm{mL}$ y PVA-AWP. Posteriormente se exponen a la luz UV a $4^{\circ} \mathrm{C}$ con el fin de permitir la polimerización. Finalmente se almacenan a $4^{\circ} \mathrm{C}$ hasta su uso, siguiendo este procedimiento cada LTV-SPE contiene 2.4 unidades enzimáticas (figura 4.1)

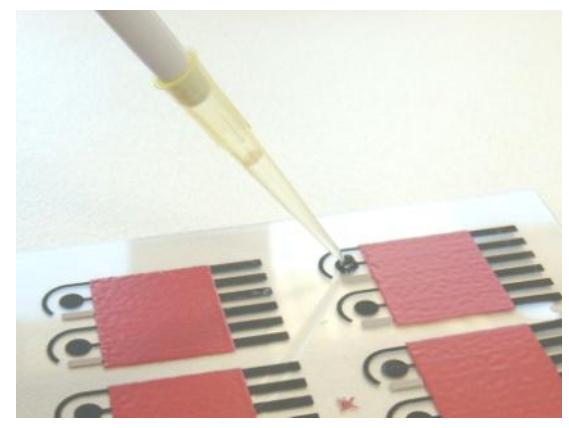

Fig. 4.1. Depósito de la mezcla enzimática sobre el electrodo de trabajo.

\subsubsection{Instrumentación y procedimiento experimental}

\subsubsection{Voltamperometría cíclica}

Mediante voltamperometría cíclica $\left(20 \mathrm{mV} \mathrm{s}^{-1}\right)$ se realizó el estudio de los procesos redox de hidroquinona $500 \mu \mathrm{M}$ (1,4-dihidroxibenceno) utilizando un SPE en el cual la superficie del electrodo de trabajo ha sido modificada con PVA-AWP pero sin incluir a la enzima. Este estudio permitirá establecer el potencial de trabajo óptimo a las condiciones experimentales seleccionadas 


\subsubsection{Mediciones Amperométricas}

Las mediciones amperométricas se realizan en una celda termo-regulada bajo agitación constante usando el método de adiciones estándar con un amperímetro BAS amperometric detector $L C-4 C$ conectado a una PC. La recopilación de datos se hace mediante el software especializado DAISY LAB 6.0.

\subsection{Resultados y Discusión}

\subsubsection{Determinación del potencial de reducción}

Dado que el método de cuantificación implica la reducción electroquímica de los productos de la reacción enzimática, el potencial de reducción aplicado es uno de los parámetros con mayor influencia sobre la respuesta analítica. De igual forma, la naturaleza del amortiguador empleado, el $\mathrm{pH}$ y la temperatura, son factores cuyo impacto debe ser considerado. La figura 4.2 muestra la $\mathrm{VC}$ obtenida para el sistema SPE / $500 \mu \mathrm{M}$ hidroquinona, amortiguador de acetatos $0.1 \mathrm{M}(\mathrm{pH} 4.7)$, a una velocidad de barrido de $0.1 \mathrm{~V} \mathrm{~s}^{-1}$. El barrido de potencial inició en condiciones de corriente nula $\mathrm{E}_{\mathrm{i}=0}=-0.12 \mathrm{~V}$ hacia valores negativos e invertido en $0.6 \mathrm{~V}$ incrementándose hasta $0.6 \mathrm{~V}$. Puede notarse claramente que cuando el potencial de electrodo se mueve hacia valores negativos desde $-0.12 \mathrm{~V}$ hasta -0.6 $\mathrm{V}$, no se registra ningún proceso de reducción. Esto indica que ni la hidroquinona ni algún otro componente del sistema exhiben procesos de reducción. Cuando el potencial se invierte a valores positivos, se observa un pico de oxidación en $0.27 \mathrm{~V}$ sólo cuando la hidroquinona está presente en la solución, de otra forma ninguna oxidación aparece (fig. 4.2) 


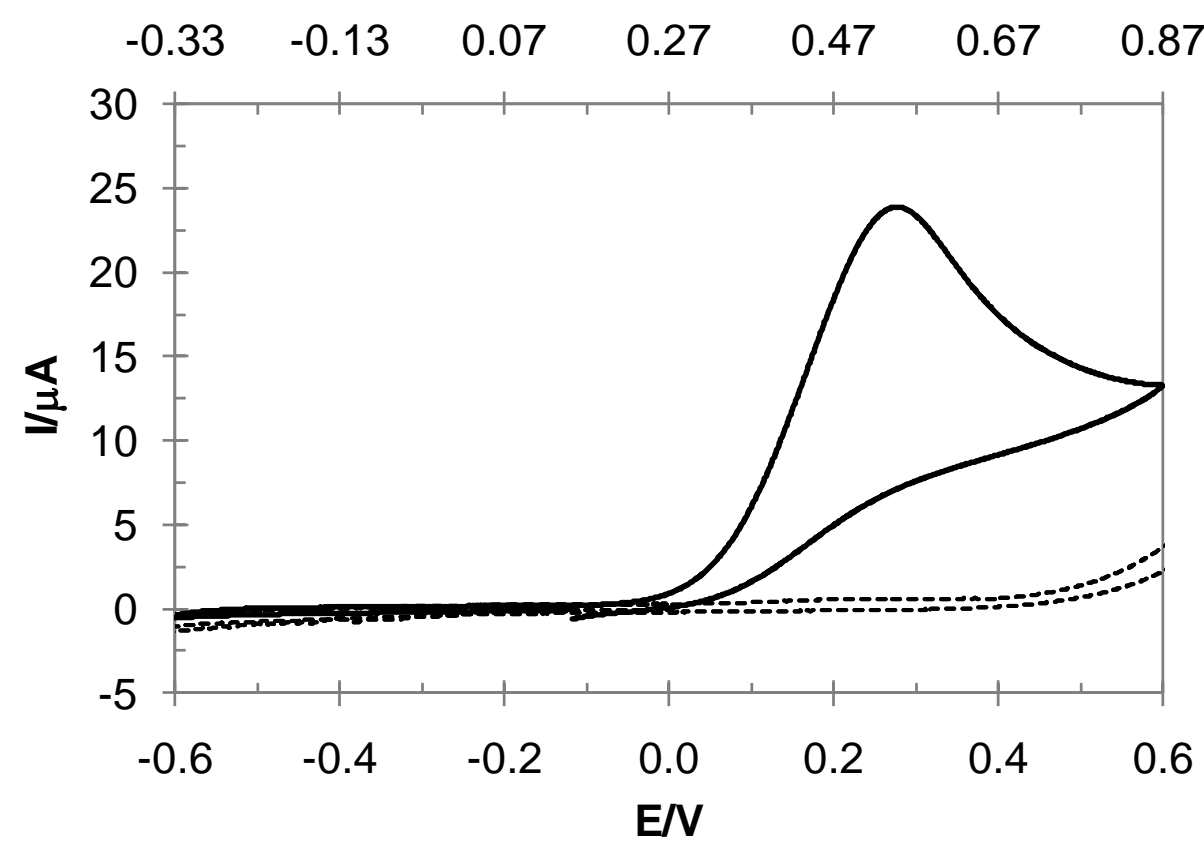

Fig. 4.2. VC del sistema SPE / $500 \mu \mathrm{M}$ hidroquinona, amortiguador de acetatos $0.1 \mathrm{M}(\mathrm{pH}$ 4.7) con $500 \mu \mathrm{M}$ de hidroquinona (linea continua) y sin hidroquinona (linea punteada) a $0.1 \mathrm{~V}$ $\mathrm{s}^{-1}$. En el eje horizontal secundario se reporta el potencial de celda referido al electrodo comercial Ag/AgCl/Cl-(ac) 3M.

La figura 4.3 muestra la VC obtenida para el sistema SPE / $500 \mu \mathrm{M}$ hidroquinona, amortiguador de acetatos $0.1 \mathrm{M}(\mathrm{pH} 4.7)$, a una velocidad de barrido de $0.1 \mathrm{~V} \mathrm{~s}^{-1}$. El barrido de potencial inició en condiciones de corriente nula hacia valores positivos invirtiéndose en $0.6 \mathrm{~V}$ y disminuyendo hasta $-0.6 \mathrm{~V}$. Un pico de oxidación se observa durante el barrido anódico en $0.27 \mathrm{~V}$ correspondiente a la oxidación de la hidroquinona a p-quinona. En potenciales catódicos aparece un pico en $-0.34 \mathrm{~V}$ correspondiente a la reducción de pquinona a hidroquinona. Con base en este resultado, se elige un intervalo de trabajo de -0.25 a $-0.35 \mathrm{~V}$ para realizar las determinaciones amperométricas dado que en estos potenciales los picos son de buena intensidad y libres de posibles interferencias de algunos otros procesos redox como la electro-reducción de oxígeno. 


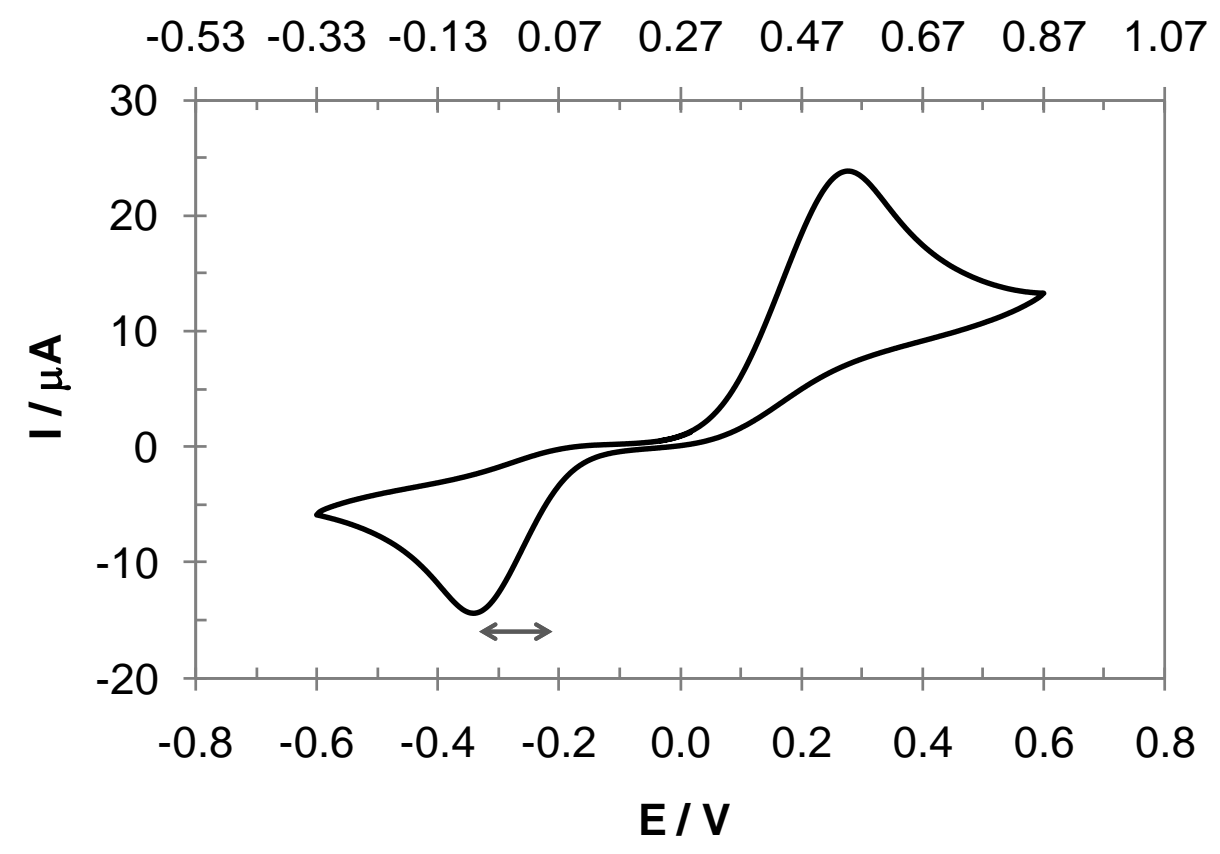

Figura 4.3. VC obtenida en el sistema SPE/ amortiguador de acetatos $0.1 \mathrm{M} \mathrm{pH} 4.7$, con 500 $\mu \mathrm{M}$ de hidroquinona a $0.1 \mathrm{~V} \mathrm{~s}^{-1}$. En el eje horizontal secundario se reporta el potencial de celda referido al electrodo comercial $\mathrm{Ag} / \mathrm{AgCl} / \mathrm{Cl}-(\mathrm{ac}) 3 \mathrm{M}$.

\subsubsection{Tiempo de respuesta del sensor}

Con el biosensor sumergido en la celda que contiene $10 \mathrm{~mL}$ de amortiguador 0.1 $\mathrm{M}$ de fosfatos $\mathrm{pH} 7.0$ bajo agitación constante a $30^{\circ} \mathrm{C}$, se aplica el potencial elegido (-0.3 V vs pseudo-referencia $\mathrm{Ag} / \mathrm{AgCl})$ y se monitorea la corriente de celda. Cuando esta es estable, se adiciona una alícuota de una solución de un compuesto estándar y se mide el cambio en la intensidad de corriente cuando esta es nuevamente estable.

En la figura 4.4 se puede apreciar que la respuesta del biosensor es inmediata pues en un tiempo inferior a 3 segundos la corriente se modifica y vuelve a un valor estable alrededor de 30 segundos después de la inyección; transcurrido de este tiempo la corriente cambia solamente a razón de $1 \mathrm{nA} / \mathrm{min}$. 


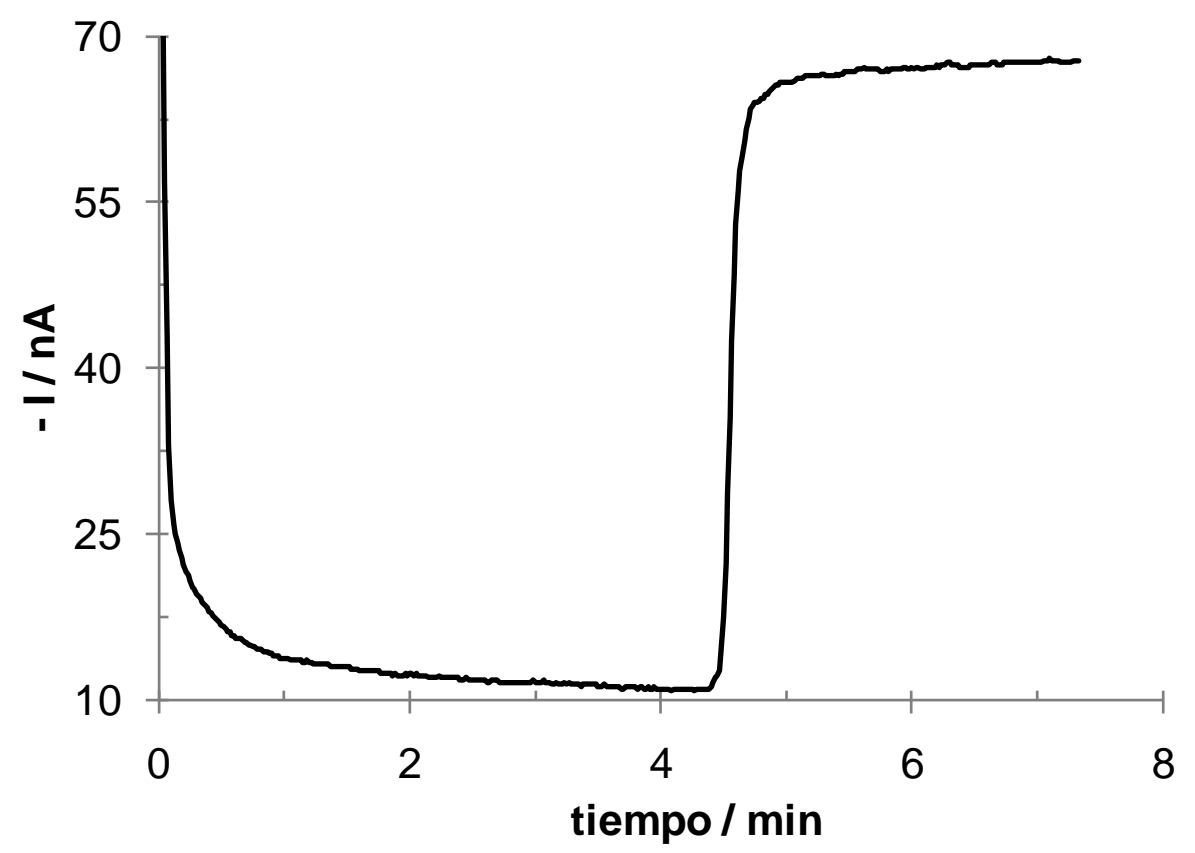

Figura 4.4. Respuesta del LTV-SPE ante la adición de una alicuota de una solucion de hidroquinona.

\subsubsection{Optimización del sensor}

Dado que el desempeño del LTV-SPE depende no solamente del potencial aplicado, debe considerarse también el efecto de algunas otras variables experimentales como la temperatura y el $\mathrm{pH}$. El objetivo es asegurar la respuesta amperométrica más alta posible evitando interferencias. Una curva de calibración es un gráfico de la corriente total versus la concentración molar del sustrato en la celda. La pendiente de esta gráfica es conocida como la sensibilidad del biosensor. La figura 4.5 muestra la curva de calibración de un LTV-SPE usando hidroquinona como sustrato en amortiguador de fosfatos 0.1 $\mathrm{M} \mathrm{pH} \mathrm{7.0,}-0.3 \mathrm{~V}$ y $30^{\circ} \mathrm{C}$. La gráfica muestra donde la corriente se incrementa linealmente cuando la concentración del sustrato también se incrementa. Esta característica analítica del biosensor se conoce como intervalo de linealidad. La dependencia lineal se ubica aproximadamente desde $25 \mu \mathrm{M}$ hasta $200 \mu \mathrm{M}$ de 
hidroquinona con una pendiente en este intervalo igual a $9.12 \pm 0.05 \mathrm{nA} \mu \mathrm{M}^{-1}$. Se observa un descenso en la sensibilidad en concentraciones superiores a 200 $\mu \mathrm{M}$, esto puede atribuirse a la cantidad de LTV en la matriz polimérica.

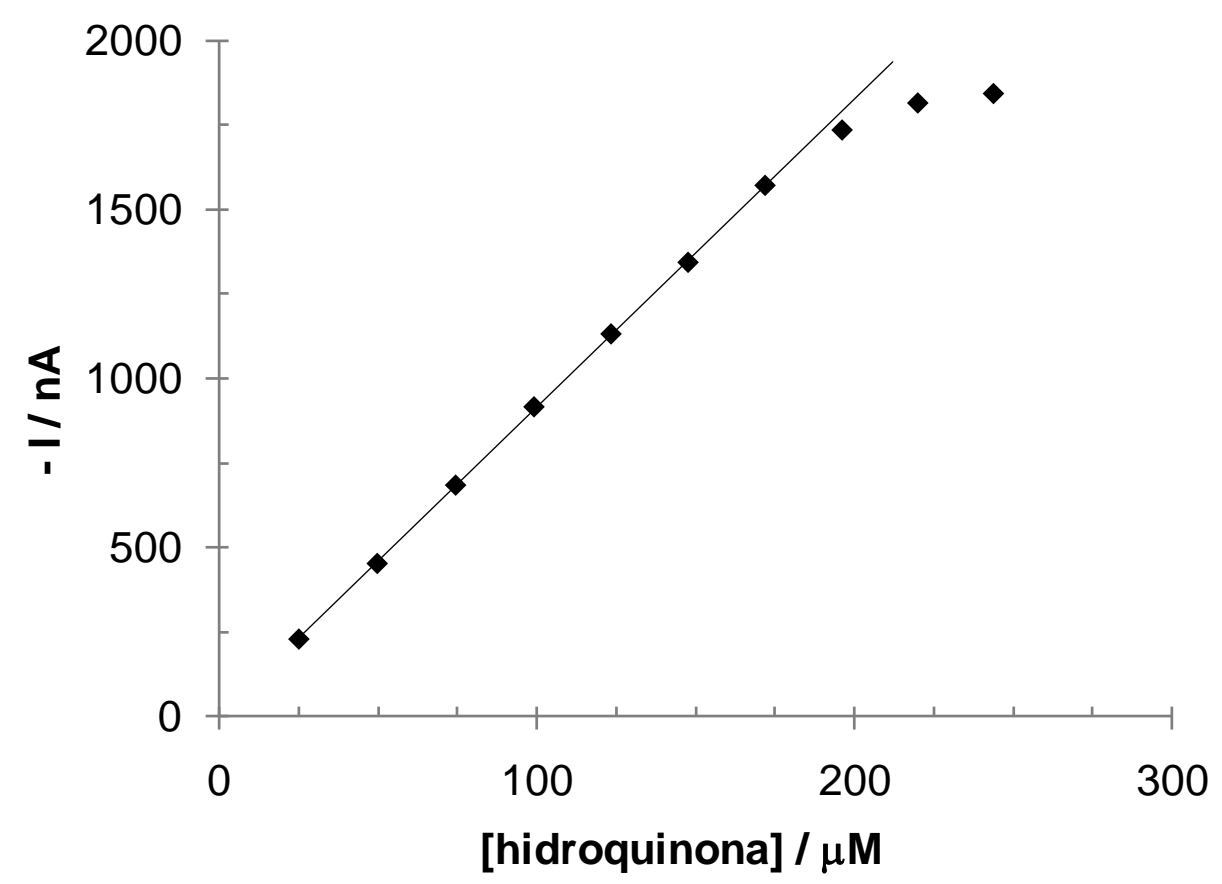

Fig. 4.5. Curva de calibración para el LTV-SPE con hidroquinona en amortiguador de acetatos $0.1 \mathrm{M} \mathrm{a}-0.30 \mathrm{~V}, \mathrm{pH} 7.0$ and $30^{\circ} \mathrm{C}$.

La optimización del biosensor se realiza comparando los valores de sensibilidad obtenidos en diferentes condiciones experimentales. Usando diferentes valores de temperatura, $\mathrm{pH}$ y potencial se realizan 8 experimentos diferentes cada uno correspondiente a una posible combinación de valores (dos por variable). Este análisis se realiza usando hidroquinona en concentraciones que van desde 25 hasta $125 \mu \mathrm{M}$ de acuerdo con la curva de calibración mostrada en la figura 4.5. 
Tabla 4.1. Variación de la sensibilidad de el LTV-SPE ante hidroquinona en amortiguador de acetatos $0.1 \mathrm{M}$ con diferentes factores como $\mathrm{pH}$, potencial aplicado y temperatura

\begin{tabular}{ccccc}
\hline $\begin{array}{c}\text { Temperatura } \\
{ }^{\circ} \mathrm{C}\end{array}$ & $\mathrm{pH} 4.7$ & $\mathrm{pH} 5.5$ & $\mathrm{pH} \mathrm{4.7}$ & $\mathrm{pH} 5.5$ \\
\hline 25 & $4.15 \pm 0.03$ & $2.21 \pm 0.04$ & $6.97 \pm 0.02$ & $4.52 \pm 0.05$ \\
& & & & \\
30 & $5.55 \pm 0.02$ & $3.28 \pm 0.11$ & $9.44 \pm 0.07$ & $6.61 \pm 0.14$ \\
\hline
\end{tabular}

Sensibilidad en $\mathrm{nA} \mu \mathrm{M}^{-1}$.

Como se puede ver en la tabla 4.1, la sensibilidad del biosensor varía considerablemente de acuerdo a las condiciones experimentales elegidas. Dado que hay una enzima involucrada, el valor de $\mathrm{pH}$ es definitivamente uno de los parámetros que provoca un gran efecto en el desempeño del sensor.

La figura 4.6 muestra la sensibilidad del LTV-SPE medida en cuatro distintos valores de $\mathrm{pH}$ a $-0.30 \mathrm{~V}$ y $30^{\circ} \mathrm{C}$. La sensibilidad más alta obtenida es $9.44 \mathrm{nA}$ $\mu \mathrm{M}^{-1}$ en amortiguador de acetatos $0.1 \mathrm{M}$ pH 4.7. De acuerdo a los resultados obtenidos estas condiciones son seleccionadas para el análisis de otros compuestos estándar e infusiones herbales. 


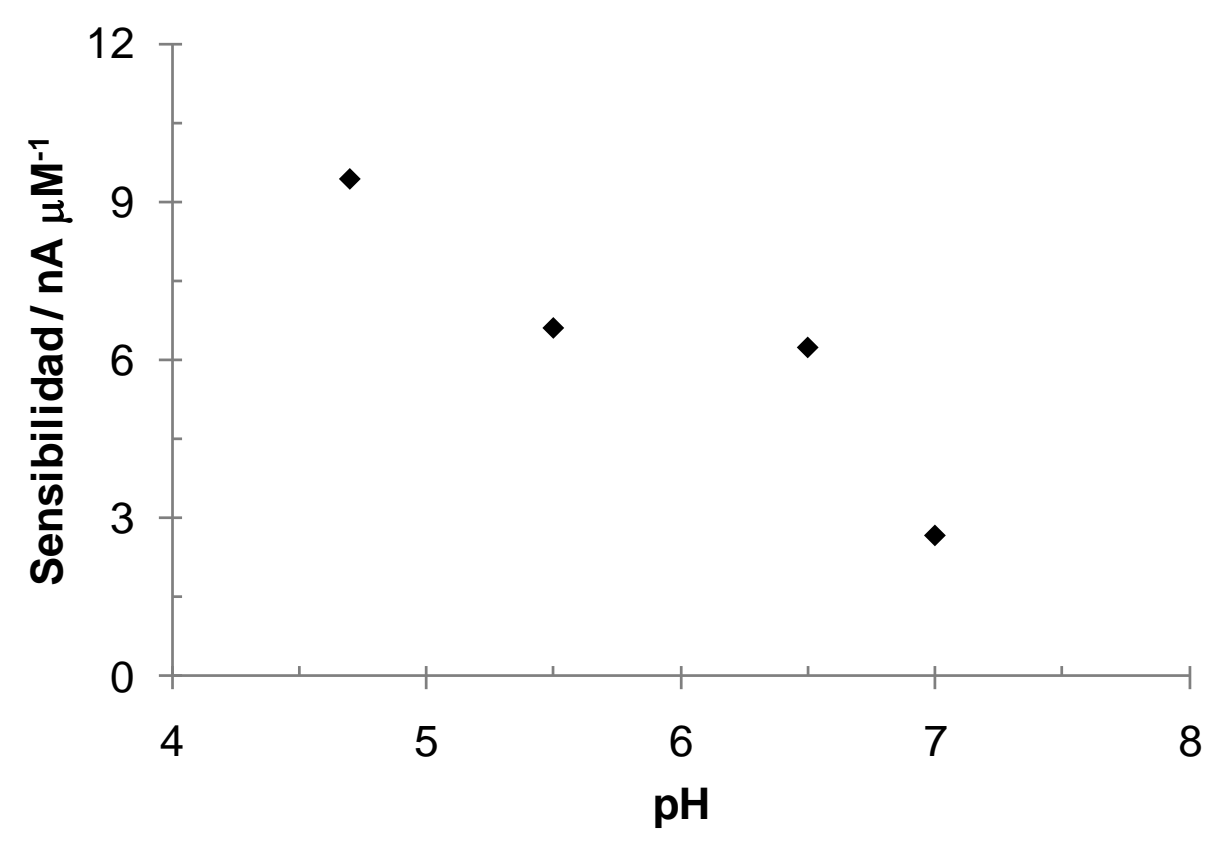

Figura 4.6. Dependencia de la sensibilidad del LTV-SPE con el $\mathrm{pH}$ a $-0.30 \mathrm{~V}$ vs $\mathrm{Ag} / \mathrm{AgCl}$ y $30^{\circ} \mathrm{C}$

\subsubsection{Respuesta del LTV-SPE ante diferentes polifenoles.}

Los tres isómeros o-, m- y p-difenol se analizaron utilizando las condiciones experimentales óptimas determinadas en la sección anterior (acetatos $0.1 \mathrm{M} \mathrm{pH}$ $4.7,30^{\circ} \mathrm{C}$ y $-0.30 \mathrm{~V}$ ) la figura 4.7 muestra las curvas de calibración en bajas concentraciones para hidroquinona y catecol. La figura 4.8 muestra la curva de calibración del resorcinol.

Como puede verse en la figura 4.7, existe una marcada diferencia en la sensibilidad del sensor ante distintos sustratos. El valor más alto obtenido corresponde a catecol $18.83 \pm 0.76 \mathrm{nA} \mu \mathrm{M}^{-1}$ mientras que el más bajo corresponde al resorcinol con $0.110 \pm 0.002 \mathrm{nA} \mu \mathrm{M}^{-1}$. 


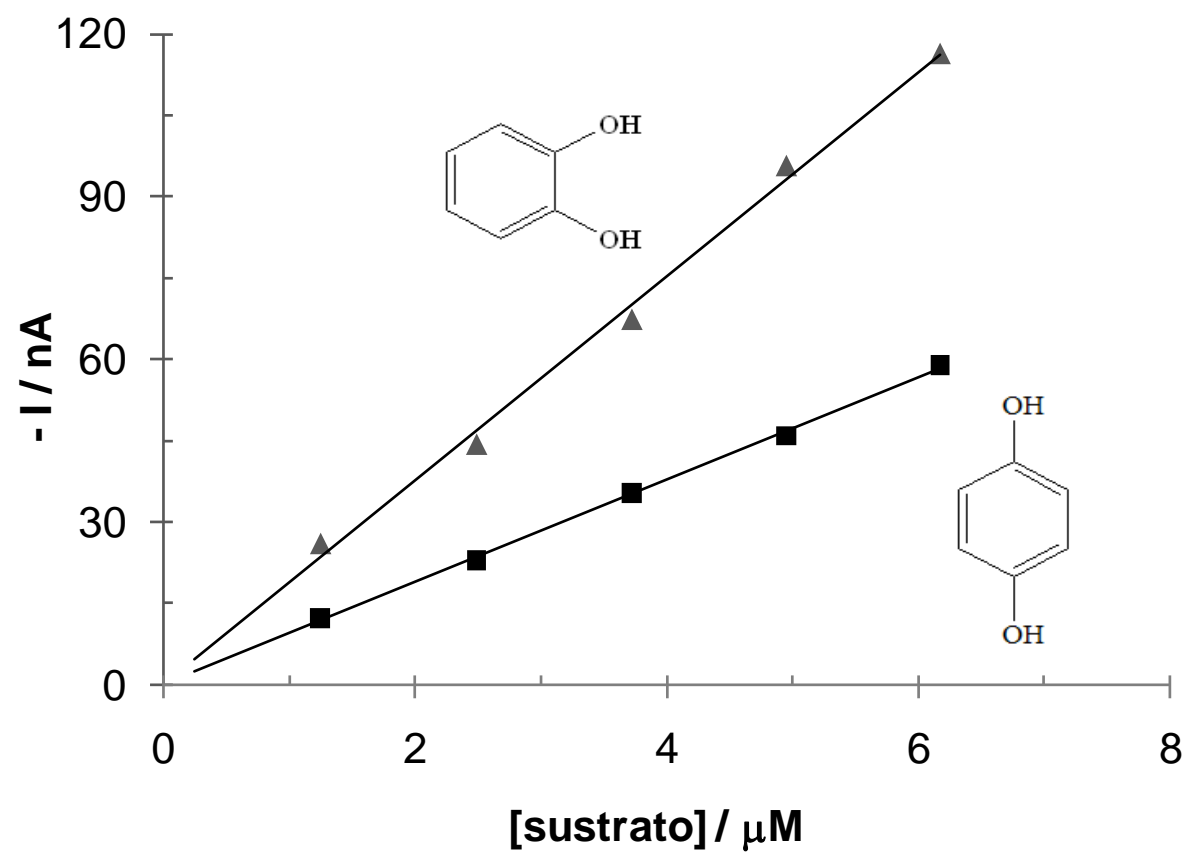

Figura 4.7. Respuesta del LTV-SPE ante diferentes sustratos en $\mathrm{pH} 4.7,-0.30 \mathrm{~V}$ y $30^{\circ} \mathrm{C}$.

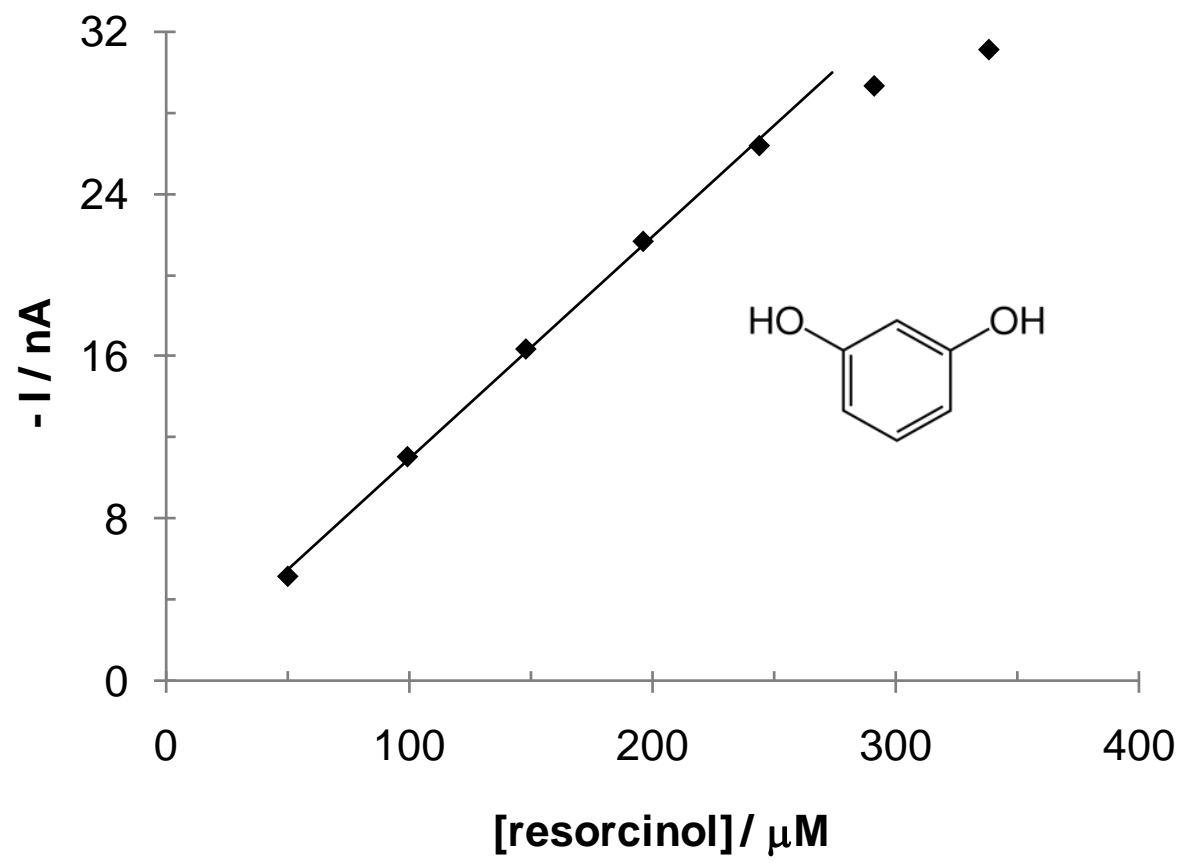

Figura 4.8. Respuesta del LTV-SPE ante resorcinol en $\mathrm{pH} 4.7,-0.30 \mathrm{~V}$ y $30^{\circ} \mathrm{C}$. 
En la tabla 4.2 se reportan los parámetros analíticos obtenidos de las curvas de calibración de las figuras 4.7 y 4.8 así como también se reportan los resultados obtenidos para ácido caféico. Con base en estos resultados es claro que el LTVSPE responde a diferentes difenoles. Para analizar posibles interferencias durante el análisis de muestras reales, se analizó una mezcla equimolar de catecol e hidroquinona. En este caso se obtuvo una sensibilidad de $11 \mathrm{nA} \mu \mathrm{M}^{-1}$ lo cual significa que el LTV-SPE puede usarse en el análisis de mezclas de difenoles.

Tabla 4.2 Parámetros analíticos correspondientes a las curvas de calibración de distintos compuestos fenólicos

\begin{tabular}{lcccc}
\hline & $\begin{array}{c}\text { Sensibilidad / } \\
\mathrm{nA} \mu \mathrm{M}^{-1}\end{array}$ & $\mathrm{R}^{2}$ & $\begin{array}{c}\text { Límite de } \\
\text { detección } / \mu \mathrm{M}\end{array}$ & $\begin{array}{c}\text { Intervalo de } \\
\text { linealidad } / \mu \mathrm{M}\end{array}$ \\
\hline Ácido caféico & $24.91 \pm 0.42$ & 0.9991 & 0.524 & $0.5-130$ \\
catecol & $18.83 \pm 0.76$ & 0.9951 & 0.558 & $0.5-175$ \\
hidroquinona & $9.44 \pm 0.19$ & 0.9988 & 1.071 & $1.1-130$ \\
resorcinol & $0.110 \pm 0.002$ & 0.9989 & 35.432 & $50-250$ \\
\hline
\end{tabular}

\subsubsection{Aplicación del LTV-SPE en análisis de muestras reales}

Para propósitos prácticos el LTV-SPE fue usado para determinar el CFE en infusiones herbales. El análisis de diferentes hierbas se realizó por adición directa de pequeñas alícuotas a la celda electroquímica con $10 \mathrm{ml}$ de amortiguador de acetatos en las condiciones experimentales óptimas de $\mathrm{pH}$, temperatura y potencial aplicado. La figura 4.9a muestra la respuesta corrientetiempo para adiciones sucesivas de una infusión de árnica $6.0 \mathrm{mg} \mathrm{ml}^{-1}$. Como 
puede observarse el tiempo de respuesta es considerablemente corto. En la curva cada escalón corresponde a una inyección de $50 \mu \mathrm{L}$. La corriente total se representa como una función de la concentración de hierba en la celda para obtener la sensibilidad del biosensor como $0.81 \pm 0.02 \mathrm{nA} / \mathrm{mgL}^{-1}$ (figura $4.9 \mathrm{~b}$ )
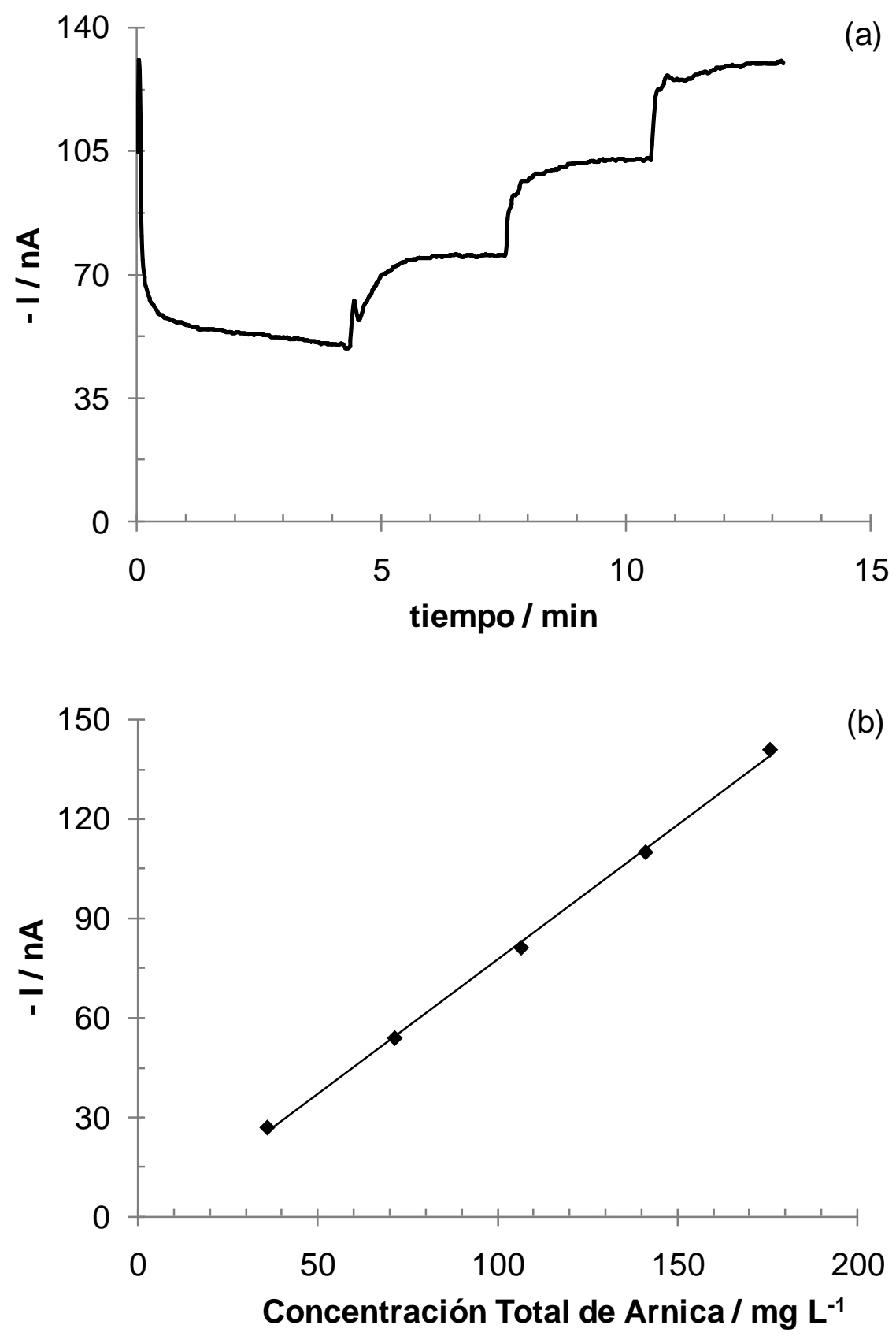

Figure 4.9. (a)Curva corriente-tiempo para adiciones sucesivas de infusión de arnica $6.0 \mathrm{mg}$ $\mathrm{ml}^{-1}$ a la celda electroquímica. (b) Concentración total de árnica en la celda versus la corriente total. La pendiente de esta línea recta corresponde a la sensibilidad del biosensor. 
La tabla 4.3 muestra los valores de sensibilidad y $\mathrm{R}^{2}$ para algunas infusiones herbales. Según los resultados obtenidos, la actividad de la lacasa para grupos $\mathrm{OH}$ en posiciones meta es muy baja en comparación con las posiciones orto y para, lo cual indica un mayor contenido en compuestos similares en estructura al catecol e hidroquinona.

Tabla 4.3 CFE de infusiones herbales determinados por el método amperometrico propuesto en este trabajo ( $\left.\mathrm{CFE}_{\mathrm{LTV}-\mathrm{SPE}}\right)$ y el método espectrofotometrico ( $\left.\mathrm{CFE}_{\mathrm{FCR}}\right)$.

\begin{tabular}{lcc}
\hline Hierba & $\begin{array}{c}\text { CFE } \text { LTV-SPE } \\
\text { mg ac. } \\
\text { Caféico/ litro } \\
\text { de té }\end{array}$ & $\begin{array}{c}\text { CFE FCR } \\
\text { mg ac. } \\
\text { Caco/ litro } \\
\text { de té }\end{array}$ \\
\hline Árnica & 47.0 & 120.1 \\
Albahaca & 5.8 & 205.7 \\
Naranjo & 4.0 & 142.5 \\
Hinojo & 25.3 & 162.8 \\
Hierbabuena & 37.6 & 171.0 \\
Jamaica & 35.4 & 188.4 \\
Palo azul & 109.2 & 297.5 \\
\hline
\end{tabular}

El CFE fue también determinado para cuatro diferentes tipos de uvas de cuatro variedades, los resultados se muestran en la figuras 4.10 


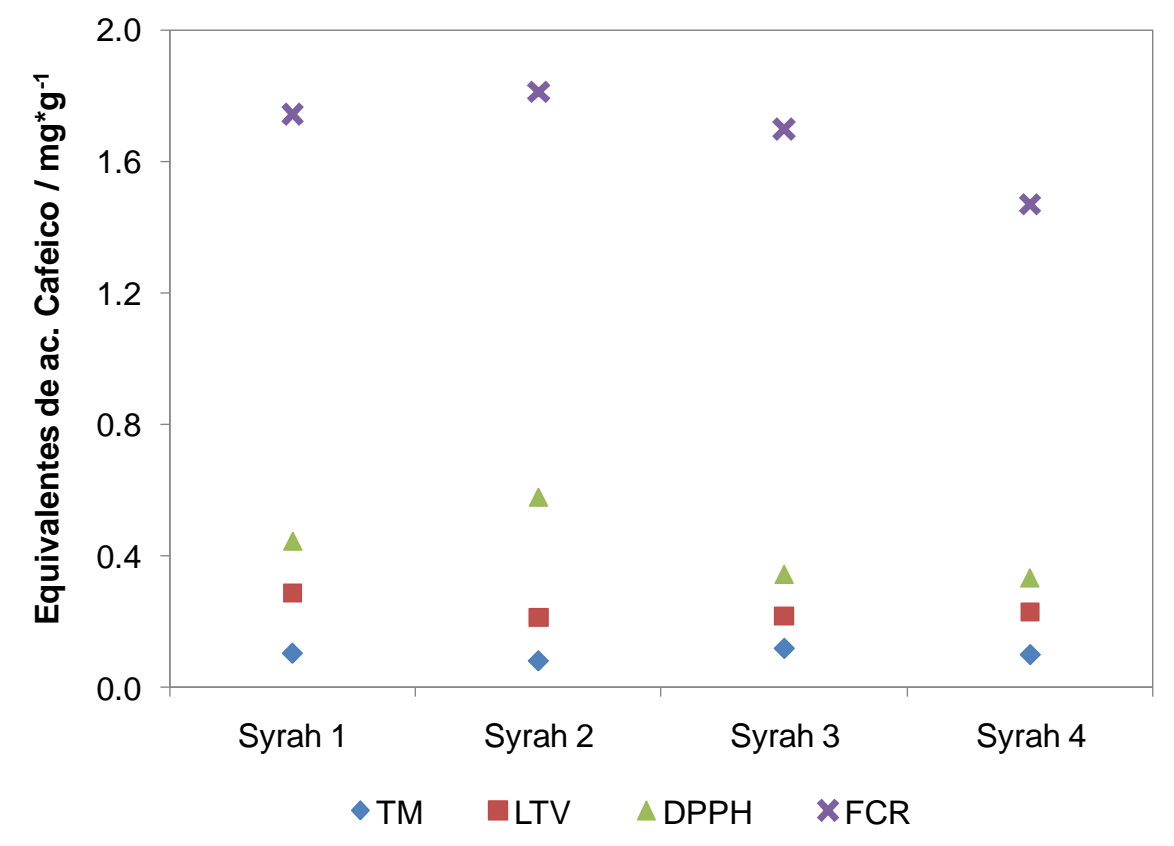

Figura 4.10. CFE para uvas Syrah cosechadas en diferente fecha. En la figura se muestra los resultados obtenidos por cuatro métodos distintos.

La figura 4.10 muestra el CFE obtenido mediante los métodos espectrofotométricos del DPPH y Folin-Ciocalteu (FCR) asi como el método amperométrico usando los biosensores TM-SPE y LTV-SPE. El estándar de referencia usado en los cuatro experimentos es el ácido caféico. Los resultados muestran un contenido fenólico muy elevado en el método Folin-Ciocalteu

\subsubsection{Estabilidad del Biosensor LTV-SPE}

Tanto la estabilidad operacional (fig. 4.11) como la estabilidad a almacenamiento (fig. 4.12) correspondientes al LTV-SPE fueron estudiadas. Los resultados indican que después de transcurrido un año en almacenamiento libre de humedad a $4^{\circ} \mathrm{C}$ el electrodo mantiene más del $60 \%$ de su respuesta original. 


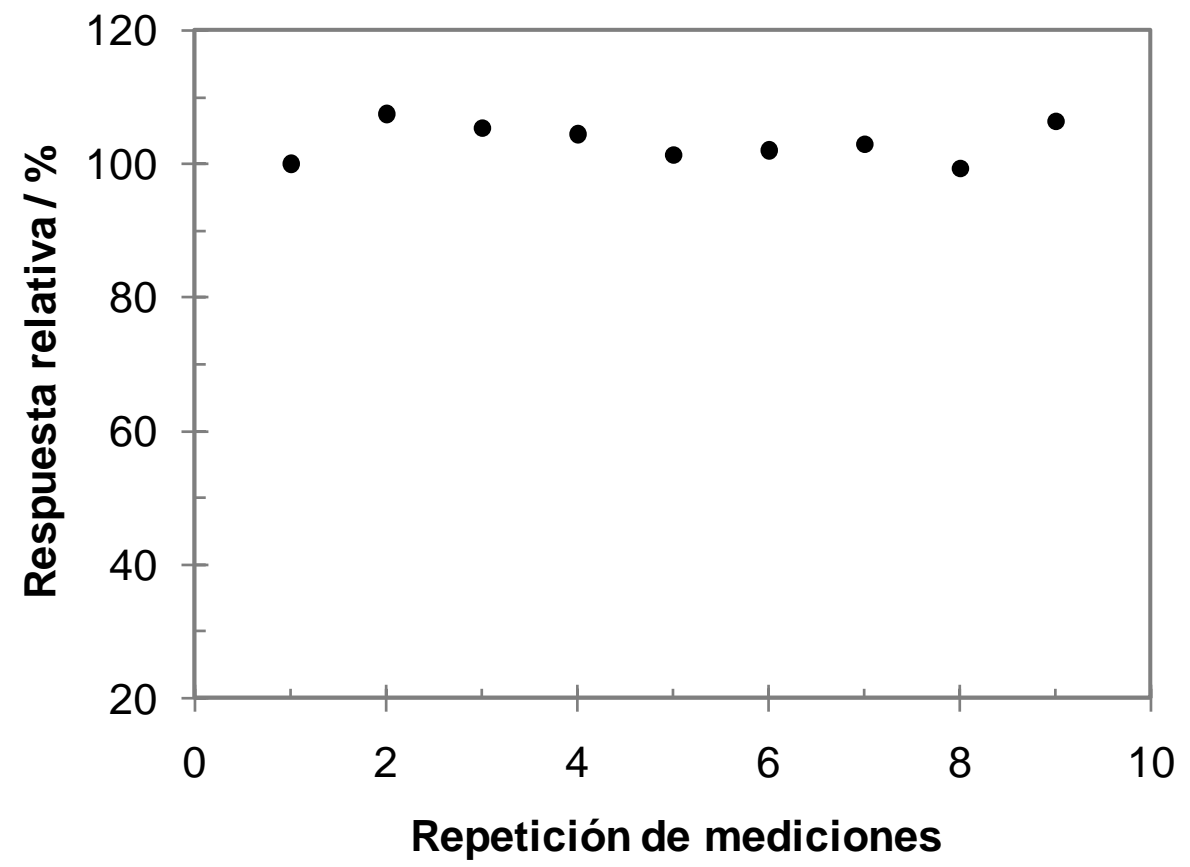

Fig. 4.11 Respuesta amperométrica usando un mismo LTV-SPE frente a catecol $50 \mathrm{mM}$ en solución amortiguada de acetatos $\mathrm{pH} 4.7$ y $30^{\circ} \mathrm{C}$ aplicando un potencial de $-0.3 \mathrm{~V}$. RSD = 2.73 .

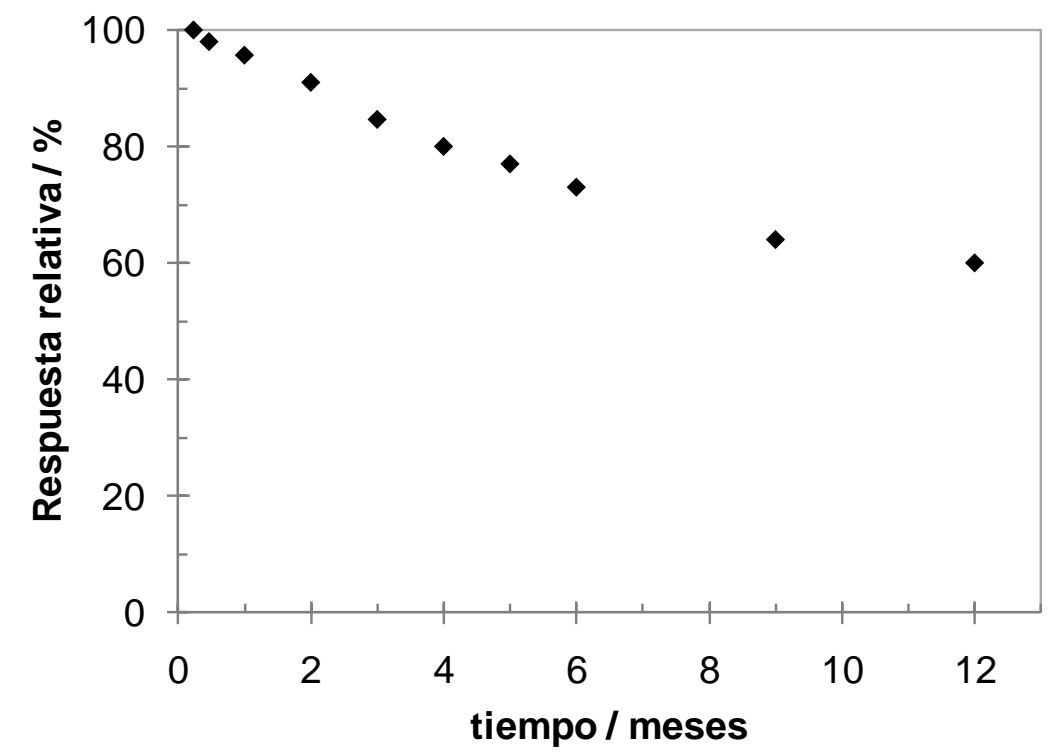

Fig. 4.12 Estabilidad de la respuesta amperométrica en función del tiempo de almacenamiento a $4^{\circ} \mathrm{C}$. 
Se puede concluir que el biosensor propuesto exhibe propiedades analíticas superiores para la cuantificación de los difenoles más comunes y puede compararse con otros dispositivos publicados en la literatura. Adicionalmente, el biosensor propuesto posee un tiempo de vida considerablemente amplio, es desechable, no requiere un electrodo de referencia externa y por su tamaño es apropiado para análisis in situ. 


\section{Conclusiones}

La evaluación de dos formas distintas al construir sensores bajo el sistema crosslinking revela marcadas diferencias en su desempeño, principalmente en lo que a sensibilidad y estabilidad se refiere. Adicionalmente resulta más reproducible la construcción de los sensores donde se deposita directamente la solución de glutaraldehído. Es posible evaluar otras variantes como mezclar soluciones de Glutaraldehído y tirosinasa ó permitir la total evaporación sobre el electrodo de trabajo.

Al comparar el desempeño de dos métodos de inmovilización, el atrapamiento en PVA-AWP muestra mejor desempeño en todas las características del sensor; el rango de linealidad es más amplio, su sensibilidad mayor aunque su estabilidad similar al cross-linking ya que su funcionamiento resulta sólo ligeramente menos afectado al uso y al transcurso del tiempo. Aunque la mayor sensibilidad se obtiene en sensores que emplean cross-linking fabricados con vapores, el reticulado parece no retener adecuadamente las moléculas de tirosinasa y su sensibilidad decae rápidamente incluso sin uso.

Los biosensores LTV-SPE y TM-SPE construidos por inmovilización muestran buen desempeño analítico en la cuantificación de difenoles. Se desarrolló un biosensor con LTV para la determinación del contenido fenólico equivalente. Los resultados muestran que la inmovilización de esta enzima usando PVAAWP resulta eficiente. El proceso de inmovilización sugerido provee una matriz de soporte capaz de retener la enzima y al mismo tiempo permite la difusión de las especies involucradas en la oxidación enzimática y la reducción electroquímica de los productos.

Las condiciones experimentales tienen una influencia determinante en el desempeño del biosensor y en su sensibilidad. Los biosensores desarrollados 
usando LTV muestran una excelente estabilidad y buen desempeño en términos del tiempo de respuesta, sensibilidad, estabilidad operacional y sencillez en su manufactura de tal forma que pueden ser usados para determinación del contenido fenólico sin realizar tratamiento previo en las muestras.

En conclusión, la facilidad del método de fabricación y preparación mínima de las muestras se combinan en estos bioelectrodos para un análisis rápido y confiable del contenido fenólico en infusiones herbales. 


\section{Perspectivas}

Como perspectivas de este trabajo de investigación, se considera analizar las infusiones herbales usando otros métodos de análisis como cromatografía o electroforesis capilar, esto con el fin de determinar cuantitativamente el contenido de polifenoles segregando cada una de las familias presentes y lograr establecer una correlación con los resultados obtenidos con los biosensores propuestos. Esto permitirá establecer específicamente la eficiencia y estabilidad de cada familia en cuanto a sus propiedades antioxidantes se refiere, pues como ya se ha comentado, cada estructura tiene una reactividad distinta en condiciones experimentales específicas.

Por otra parte, se pretende también ampliar el estudio del método espectrofotométrico de Folin-Ciucalteu modificado usando el polímero PVP lo cual permitiría la separación de las diferentes contribuciones de cada familia de compuestos presentes en las muestras, de tal forma que se logre establecer el contenido fenólico real eliminando la contribución de las especies interferentes no fenólicos que reaccionan con el reactivo de Folin-Ciocalteu. Una vez establecido el contenido real de compuestos fenólicos, este se podría relacionar con los resultados obtenidos en el método amperométrico pues como se demuestra en este trabajo de investigación, únicamente los isómeros orto y para (cuantificados con el biosensor LTV-SPE) contribuyen significativamente a la respuesta amperométrica del biosensor.

Adicionalmente se pretende evaluar otros polímeros como matriz de soporte, esto con el fin de encontrar un polímero de uso común que logre superar las propiedades que presenta el PVA-AWP cuya principal desventaja es su costo e inestabilidad pues debe almacenarse fuera del contacto con la luz y a $4-7^{\circ} \mathrm{C}$. 


\section{Referencias}

[1] G. Wolf, The discovery of the antioxidant function of vitamin E: the contribution of Henry A. Mattill, J Nutr 135 (2005) 363-366.

[2] B. Halliwell, Annu. Rev. Nutr. (1996) 16:33-50.[3] T. Finkel, N.J. Holbrook. Nature (2000) 408 (6809): 239-47.

[4] I. Rudolf, J Am Coll Nutr, 20 (2001) 464S-472S

[5] B. Tepe, M. Sokmen, H. Askin Akpulat, A. Sokmen, Food Chemistry 92 (2005) 89-92.

[6] W. Mullen, S. C. Marks, and A. Crozier, J. Agric. Food Chem. 55 (2007) 3148-3157.

[7] E. Gómez-Plaza, A. Miñano, J. M. López-Roca. Food Chemistry 97 (2006) 87-94.

[8] Fang Fang, Jing-Ming Li, Qiu-Hong Pan, Wei-Dong Huang. Food Chemistry 101 (2007) 428-433.

[9] Changjiang Guo, Guohua Cao, Emin Sofic and Ronald L. Prior. J. Agric. Food Chem., 45 (1997)1787-1796.

[10] S. Buratti, S. Benedetti, M.S. Cosio. Talanta 71 (2007) 1387-1392.[11] A. Prakash, Medallion laboratories, Antioxidant activity, Vol 19 No. 2 (2001)

[12] D. Villaño, M. Soledad Fernández-Pachón, A. M. Troncoso, M. C. GarcíaParrilla., Analytica Chimica Acta 538 (2005) 391-398.

[13] J. Kulys, I. Bratkovskaja. Talanta 72 (2007) 526-531.

[14] A. M. Alonso, C. Dominguez, D. A. Guillen and C. G. Barroso. J. Agric. Food Chem. 50 (2002) 3112-3115-

[15] P. Molineux, J. Sci. Tech., 26, 2, (2004).

[16] E. Kuskoki, A. Asuero, M. García-Parrilla, Ciencia y tecnología de alimentos, Vol 24, 4, 2004.

[17] C. Sánchez-Moreno, J. A. Larrauri and F. Saura-Calixto. J. Sci. Food Agric., 76 (1998) 270-276.

[18] Brand-Williams W, Cuvelier M E, Berset C 1995. LebensmWiss Technol., 28 (1) 25-30. 
[19] C. Samaniego-Sánchez, A.M. Troncoso-González, M.C. García-Parrilla, J.J. Quesada-Granados, H. López García de la Serrana, M.C. López Martínez. Analytica Chimica Acta 593 (2007) 103-107.

[20] J. Wang and P. Sporns, J. Agri. Food chem., 1999 (47) 2009-2015.

[21] K. Robards, M. Antolovich; Analyst; 122, (1997) 11R - 34R.

[22] J. J. Mabry, K. R. Markham, M. B. Tomas; Springer-Verlag, New York 1970.

[23] J. B. Harborne, J. J. Mabry, H. Mabry; “The flavonoids". Chapman; London 1975.

[24] J.J. Dalluge, B.C. Nelson; J. Chromatogr. A; 881 (2000) 411-424.

[25] H. Sakakibara, Y. Honda, S. Nakagawa, H. Ashida, K. Kanasawa; J. Agric. Food Chem.; 51 (2003) 571-581.

[26] V. L. Singleton, J. A. Rossi. Colorimetry of total phenolics with phosphomolybdic regents, Am. J. Enol.Vitic., 16 (1965) 144-15

[27] E. M. Siegbahn, J. Biol. Inorg. Chem, 8 (2003) 567-576.

[28] J. Svitel and S. Miertus., Environ. Sci. Technol. 32 (1998) 828-832.

[29] M. Velasco-Garcia and T. Mottram. Biosensor technology addressing agricultural problems. Biosystems Engineering, 84 (2003) 1-12.

[30] P.D. Patel,. Trends in Analytical Chemistry, 21 (2002) 96-115.

[31] L.D. Mello and L.T. Kubota, Food Chemistry, 77 (2002) 237-256.

[32] R. H. Hall, Biosensor technologies for detecting microbiological foodborne hazards Microbes and Infection, 4 (2002) 425-432.

[33] F. Ortega, Biosensores y Biochips, Real Ac. Nac Farm. Madrid (2006) 4549

[34] V. González, E. García, O. Ruiz, Gago Cabezas L V. González Rumayor, Aplicaciones de biosensores en la industria agroalimentaria, Dirección General de Universidades e Investigación (2005)

[35] M. Gerard, A. Chaubey and B.D. Malhotra, , Biosensors and Bioelectronics, 17 (2002) 345-359. 
[36] D. Huang, B. Ou and R. L. Prior. J. Agric. Food Chem. 2005, 53, 18411856

[37] S. Milardovic, D. Ivekovic, Bioelectrochemistry. 68 (2006) 175-180

[38] B. Ozcelik, J.H. Lee. Journal of food science. 68 (2003) 487-490.

[39] L. M. Magalhaes, M. A. Segundo, S. Reis, J. L.F.C. Lima, Analytica chimica acta 613 (2008) 1-19

[40] S.A.S.S. Gomes, J.M.F. Nogueira, M.J.F Rebelo., 20 (2004) 1211-1216.

[41] Seung Cheol Chang, Keith Rawson, Calum J. McNeil, Biosensors and Bioelectronics, 17 (2002) 1015-1023.

[42] M Gamella, S. Campuzano, A Reviejo and J.M. Pingarron, J. Agric. Food Chem.

[43] V. Carralero Sanz, Ma. Luz Mena, A. González-Cortés, P. Yáñez-Sedeño, J. M. Pingarrón, Anal. Chim. Acta 528 (2005) 1-8.

[44] J.N. Rodríguez-López, M. Bañon-Arnao, F. Martinez-Ortiz, J. Tudela, R. Varon, F. García-Canovas. Biochim. Biophys. Acta 1160 (1992) 221-228

[45] A. Sánchez-Ferrer, J. N. Rodríguez-López, F. García-Canovas, F. GarcíaCarmona, Biochim. Biophys. Acta 1247(1995. ) 1-11

[46] M. Velasco Garcia and T. Mottram. Biosensor technology addressing agricultural problems. Biosystems Engineering, 84 (2003) 1-12.

[47] L.D. Mello and L.T. Kubota,. Food Chemistry, 77 (2002) 237-256.

[48] A. Turner, I. Karube and G Wilson. Biosensors, Fundamentals and applications. Oxford Science publications.

[49] J. Vidal, S. Esteban, J Gil and J Castillo., Talanta, 68 (2006) 791-799.

[50] J.P. Hervás-Pérez, M Sanchez-Paniagua López, E. López-Cabarcos and B. López-Ruiz. Biosensores and bioelectronics 22 (2006) 429-439.

[51] Z. Liu, B. Liu, Jilie Kong and Jiaqui Deng. Anal chem, 72 (2000) 4707.

[52] A.E.G. Cass, Biosensors a practical approach, The practical approach series Karp, G, 2002. $3^{\text {rd }}$ ed., Cell and Molecular biology, pp 100-103 
[53] N.H. Horowitz, M. Gling and G. Horn. 1970. Tyrosinase (Neurospora crassa) in methods in Enzymology, Vol. XVII (H Tabor and CW Tabor eds) p 615-620

[54] S.H. Pomerantz and J.P. Li , Tyrosinase (Hamters Melanoma) in methods in enzymology, Vol XII, p 620-626.

[55] L. A. Bazzano, J. He, L. G. Ogden, C. M. Loria, S. Vupputuri, L. Myers, Am. J. Clin. Nutr. 76 (2002) 93-99.

[56] F. Brighenti, S. Valtueña, N. Pellegrini, D. Ardigo, D. Del Rio, S. Salvatore, P. Piatti, M. Serafini, I. Zavaroni, Br. J Nutr., 93 (2005) 619-625.

[57] C. Pitsavos, D. B. Panagiotakos, N. Tzima, C. Chrysohoou, M. Economou, A. Zampelas, Am. J. Clin. Nutr, 82 (2005) 694-699.

[58] A. Trichopoulou, T. Costacou, C. Bamia, D. Trichopoulos, N. Engl. J. Med., 348 (2003) 2599-2608.

[59] B. Halliwell, Annu. Rev. Nutr., 16 (1996) 33-50.

[60] I. Rudolf, J Am Coll Nutr, 20 (2001) 464S-472S

[61] B. Prieto-Simón, M. Cortina, M. Campàs, C. Calas-Blanchard, Sens Actuators B Chem, 129 (2008) 459-466

[62] A. M. Alonso, C. Domínguez, D. A. Guillén, C. G. Barroso, J Agric Food Chem, 50 (2002) 3112-3115.

[63] L. Campanella, A. Bonanni, E. Finotti , M. Tomassetti, Biosens Bioelectron, 19 (2004) 641-651

[64] M. Gamella, S. Campuzano, A. J. Reviejo, J. M. Pingarrón. J. Agric. Food Chem. 54 (2006) 7960-7967.

[65] D. Huang, B. Ou, R. L. Prior, J. Agric. Food Chem. 53 (2005) 1841-1856.

[66] A.M. Aljadi, M.Y. Kammaruddin, Food Chem. 85 (2004) 513-518.

[67] S. Kumazawa, T. Hamasaka, T. Nakayama, Food Chem. 84 (2004) 329339.

[68] T. Nagai, M. Sakai, R. Inoue, H. Inoue, N. Suzuki, Food Chem. 75 (2001) 237-240.

[69] S. Buratti , S. Benedetti, M.S. Cosio, Talanta 71 (2007) 1387-1392. 
[70] M. Arnao, A. Cano, M. Acosta, Recent Res. Dev. Agric. \& Food Chem. 2 (1998) 893-905.

[71] A. Cano, J. Hernández-Ruiz, F. García-Cánovas, M. Acosta, M. Arnao, Phytochem. Anal. 9 (1998) 196-202.

[72] M.I. Gil, F.A. Tomás-Barberán, B. Hess-Pierce, D.M. Holcroft, A.A. Kader, J. Agric. Food Chem. 48 (2000) 4581-4589.

[73] R.L. Prior, G. Cao, Free Radic. Biol. Med. 27 (1999) 1173-1181.

[74] G. Cao, R.M. Russell, N. Lischner, R.L. Prior, J. Nutr. 128 (1998) 23832390.

[75] G. Cao, S.L. Booth, A. Sadowski, R.L. Prior, Am. J. Clin. Nutr. 68 (1998) 1081-1087.

[76] R.L. Prior, H. Hoang, L. Gu, X. Wu, M. Bacchiocca, L. Howard, M. Hamps-Woodill, D. Huang, B. Ou, R. Jacob, J. Agric. Food Chem. 51 (2003) 3273-3279.

[77] M.S. Fernández-Pachón, D. Villano, M.C. García-Parrilla, A.M. Troncoso, Anal. Chim. Acta 513 (2004) 113-118.

[78] D. Villano, M.S. Fernández-Pachón, A.M. Troncoso, M.C. García-Parrilla, Anal. Chim. Acta 538 (2005) 391-398.

[79] D. Villano, M.S. Fernández-Pachón, M.L. Moyá, A.M. Troncoso, M.C. García-Parrilla, Talanta 71 (2007) 230-235.

[80] C.R. Caldwell, Anal. Biochem. 293 (2001) 232-238.

[81] A.M. Campos, E. Lissi, Boletín Sociedad Chilena de Química, 40 (1995) 375-381.

[82] G. Cao, E. Sofic, L.R. Prior, J. Agric. Food Chem. 44 (1996) 3426-3431.

[83] C.W. Chen, J.F. Chiou, C.H. Tsai, C.W. Shu, M.H. Lin, T. Z. Liu, J. Agric. Food Chem, 54 (2006) 9297-9302.

[84] I. Jimenez, A. Garrido, R. Bannach, M. Gotteland, H. Speisky, Phytother. Re. 14 (2000) 339-343.

[85] G. Maulik, N. Maulik, V. Bhandari, V.E. Kagan, S. Pakrashi, D.K. Das, Free Radic. Res. 27 (1997) 221-228. 
[86] P.O'Brien, C. Carrasco-Pozo, H. Speisky, Chem. Biol. Interact. 159 (2006) $1-17$.

[87] A.R. Rechner, E. Wagner, L. Van Buren, F. Van De Put, S. Wiseman, C.A. Rice-Evans; Free Radic. Res. 36 (2002) 1127-1135.

[88] V. Roginsky, T. Barsukova, J. Med. Food, 4 (2001) 219-229.

[89] V. Roginsky, E. Lissi, Food Chem. 92 (2005) 235-254.

[90] G. Schmeda-Hirschmann, J. Rodriguez, C. Theoduloz, S.L. Astudillo, G. Feresin, A. Tapia, Free Rad. Res. 37 (2003) 447-452.

[91] K. Wojcikowski, L. Stevenson, D. Leach, H. Wohlmuth, G. Gobe, J. Altern. Complement. Med. 13 (2007) 103-109.

[92] T. Yokozawa, E.J. Cho, Y. Hara, K. Kitani, J. Agric. Food Chem. 48 (2000) 5068-5073.

[93] E. Alarcón, A.M. Campos, A.M. Edwards, E. Lissi, C. López-Alarcón, Food Chem. 107 (2008) 1114-1119.

[94] J.J. Roy, T.E. Abraham, K.S. Abhijith, P.V. Sujith Kumar, M.S. Thakur, Biosens. Bioelectron. 21 (2005) 206-211.

[95] R.S. Freire, N. Durán, L.T. Kubota, Talanta 54 (2001) 681-686.

[96] L. Campanella, A. Bonanni, E. Finotti, M. Tomassetti, Biosens. Bioelectron. 19 (2004) 641-651.

[97] D. Odaci, S. Timur, N. Pazarlioglu, M.R. Montereali, W. Vastarella, R. Pilloton, A. Telefoncu, Talanta 71 (2007) 312-317.

[98] O.D. Leite, K.O. Lupetti, O. Fatibello-Filho, I. C. Vieira, A. de M. Barbosa, Talanta 59 (2003) 889-896.

[99] J. Wang, F. Lu, S.A. Kane, Y.K. Choi, M.R. Smyth, K. Rogers, Electroanalysis 9 (1997) 1102-1109.

[100] M. Hedenmo, A. Narváez, E. Domínguez, I. Katakis, J. Electroanal. Chem. 425 (1997) 1-11.

[101] S. Liu, J. Yu, H. Ju, J. Electroanal. Chem. 540 (2003) 61-67.

[102] A.I. Yaropolov, A.N. Kharybin, J. Emnéus, G.Marko-Varga, L. Gorton, Anal. Chim. Acta 308 (1995) 137-144. 
[103] A. Jaroz-Wilkolazka, T. Ruzgas, L. Gorton, Talanta 66 (2005) 1219-1224.

[104] C. Nistor, J. Emnéus, L. Gorton, A. Ciacu, Anal. Chim. Acta 387 (1999) 309-326.

[105] N. Peña, A.J. Reviejo, J.M. Pingarrón, Talanta 55 (2001) 179-187.

[106] B. Serra, S. Jiménez, M.L. Mena, A.J. Reviejo, J.M. Pingarrón, Biosens. Bioelectron. 17 (2002) 217-226.

[107] F. Vianello, A. Cambria, S. Ragusa, M. T. Cambria, L. Zennaro, A. Rigo,. Biosens. Bioelectron. 20 (2004) 315-321.

[108] S. Campuzano, B. Serra, M. Pedrero, J.M. Villena, J.M. Pingarrón, Anal. Chim. Acta 494 (2003) 187-197.

[109] R.S. Freire;N. Durán, L.T. Kubota, Anal. Chim. Acta 463 (2002) 229-238.

[110] D. Quan; Y. Kim, K.B. Yoon, W.Shin, Bull. Korean Chem. Soc. 3 (2002) 385-390.

[111] D. Quan, W. Shin, Electroanalysis 16 (2004) 1576-1582.

[112] S. Timur, 1. Pazarliog, N. Pilloton, R. Telefoncu, Sens. Actuators B Chem. 97 (2004) 132-136.

[113] R.S. Freire, N. Durán, J. Wang, L.T. Kubota, Anal. Lett. 35 (2002) 29-38.

[114] R.S. Freire, S. Thongngamdee, N. Durán, J. Wang, L.T. Kubota, Analyst 127 (2002) 258-261.

[115] O. Adeyoju, E.J. Iwuoha, M.R. Smyth, D. Leech, Analyst 121(1996) 18851889.

[116] Rajesh, K. Kaneto, Current Appl. Phys. 5 (2005) 178-183.

[117] Z. Liu, J. Deng, D. Li, Anal. Chim. Acta, 407 (2000) 87-96.

[118] B. Wang, J. Zhang, S. Dong, Biosens. Bioelectron. 15 (2000) 397-402.

[119] A. Karioti, A. Protopappa, N. Megoulas, H. Skalts, Bioorgan. Med. Chem. 15 (2007) 2708-2714

[120] V. Carralero Sanz, Ma. Luz Mena, A. González-Cortés, P. Yáñez-Sedeño, J. M. Pingarrón, Anal. Chim. Acta 528 (2005) 1-8.

[121] J.J. Roy, T.E. Abraham, J. Mol. Catal. B Enzym. 38 (2006) 31-36. 
[122] M. Gamella, S. Campuzano, A.J. Reviejo, J.M. Pingarrón, J. Agric. Food Chem. 54 (2006) 7960-7967

[123] V.L. Singleton, J.A. Rossi, Am. J. Enol. Vitic.16 (1965) 144-158.

[124] V.L. Singleton, R. Orthofer, R.M. Lamuela-Raventos, Methods Enzymol. 299 (1999) 152-178.

[125] R. Stevanato, S. Fabris, F. Momo, J. Agric. Food Chem., 52 (2004) 62876293.

[126] V. Carralero Sanz, Ma. Luz Mena, A. González-Cortés, P. Yáñez-Sedeño, J. M. Pingarrón, Anal. Chim. Acta 528 (2005) 1-8.

[127] S.C. Chang, K. Rawson, C. J. McNeil, Biosens. Bioelectron. 17 (2002) 1015-1023.

[128] M. ElKaoutit, I. Naranjo-Rodriguez, K.R. Temsamani, M. P. HernándezArtiga, D. Bellido-Milla, J. L. Hidalgo-Hidalgo de Cisneros.Food Chem. 110 (2008) 1019-1024.

[129] M. El Kaoutit, I. Naranjo-Rodriguez, K.R. Temsamani, J.L. HidalgoHidalgo de Cisneros, Biosens Bioelectron. 22 (2007) 2958-2966.

[130] M.R. Montereali, L. Della Seta, W. Vastarella, R. Pilloton, J. Mol. Catal. B-Enzym., (2009). doi: 10.1016/j.molcatb.2009.07.014. 